Relazioni industriali eni e modelli europei:

Francia e Germania

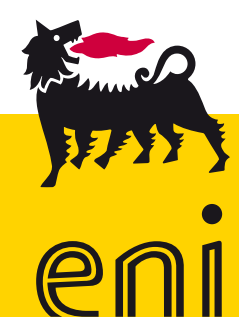





\section{Relazioni industriali eni e modelli europei: Francia e Germania}

\section{minn \\ อกi}

eni spa

Unità Legislazione

e Contenzioso del lavoro

Unità Pianificazione e Controllo,

Risorse Umane e Relazioni Industriali

Piazzale Enrico Mattei, 1 - 00144 Roma

\section{Crowe Horwath}

Studio Associato Servizi Professionali Integrati

Dipartimento Diritto del Lavoro

Prof. Tiziano Treu - Prof. Angelo Pandolfo 



\section{indice}

Premessa

a cura di T. Treu

Osservazioni sullo svolgimento della ricerca e sulla composizione del Rapporto. Mutamenti istituzionali nelle relazioni industriali europee

a cura di T. Treu e M. Faioli

Sezione prima

Parte generale - (A) Executive summary

Parte generale - (B) Analisi comparativa

1) Francia. Relazioni industriali e livelli di contrattazione.

Strategia di rafforzamento e sindacato "ubiquo"

a) Assetto sindacale e rappresentatività

b) Principio maggioritario per la validità del contratto collettivo

e preminenza del livello aziendale

c) Il principio di favor è sostituito dal principio specialia generalibus derogant. La regola che risolve il problema a monte?

d) Clausole di blocco e clausole di autorizzazione

e) Osservazioni conclusive. Sindacalismo "virtuale" e contrattazione collettiva "micro-corporativista"

2) Germania. Relazioni industriali e livelli di contrattazione.

Co-determinazione e vincolo al contratto collettivo

a) Contrattazione collettiva settoriale e "stepping out" del datore di lavoro

b) Consiglio di fabbrica e diritto di co-determinazione. Il potere di veto nella contrattazione aziendale di deroga. La regola del favor (Günstigkeitsprinzip)

c) Il decentramento regolato. Le clausole di apertura (Öffnungsklauseln) provengono "dall'interno del sistema"

d) Osservazioni conclusive. Il perché della tenuta sistemica del modello tedesco 


\section{Sezione seconda}

Contenuti specifici. Negoziare la flessibilità in azienda

1) Orario di lavoro 38

i) Case study: Polimeri Europa France 41

ii) Case study: Eni Germany 43

2) Reazione alla crisi di impresa - Programmi di Short-Time Work (STW) 44

i) Case study: Polimeri Europa France 44

3) Sistema partecipativo $\quad 47$

i) Partecipazione alla gestione 47

ii) Partecipazione finanziaria/retribuzione incentivante 50

4) Conflitto e clausole di tregua 52

5) Lotta all'assenteismo

Conclusioni

a cura di T. Treu

Decentramento contrattuale. Better not cheaper 56

Accordo Eni e contesto italiano 60

Assenteismo 66

Conflitto 67

Tendenze convergenti e indicazioni generali da sviluppare 70

Intervista a I. C. Gaglianò sul tema 72 a cura di D. Noviello e D. Calabrò

Le possibili aree di sperimentazione partecipata in Eni: l'arbitrato 
1. Eni e le possibili aree di sperimentazione partecipata.

La continuità rispetto al passato

2. L'arbitrato: uno strumento nelle mani di azienda e sindacato

3. I possibili spazi di applicazione dell'istituto nell'ambito dei diritti disponibili

4. Giudici e arbitri. Sentenza e Lodo. Diritto o equità 78

5. I tempi del giudizio e quelli dell'arbitrato 79

6. I costi e i vantaggi dell'arbitrato 79

7. Uno Sguardo Oltralpe a Francia e Germania 80

8. Tabella riepilogativa e considerazioni conclusive

Competitività e partecipazione: il modello di relazioni industriali Eni nell'accordo del 26 maggio 2011 


\title{
Premessa
}

\author{
a cura di Tiziano Treu
}

La globalizzazione prima e la crisi economica poi hanno esercitato forti pressioni su tutti i sistemi economici e sociali dei paesi sviluppati. Tale pressione ha investito direttamente le relazioni industriali che sono una parte importante dei nostri sistemi economici, e che sono particolarmente esposti alle sfide della competizione globale.

L'impatto è particolarmente sentito nei paesi europei perché l'Europa ha sempre ritenuto che gli istituti delle relazioni industriali, la contrattazione collettiva e la partecipazione siano una parte costitutiva centrale del proprio modello sociale. Tanto è vero che fin dal 1991 la Comunità ha sancito istituzionalmente il ruolo centrale della contrattazione e financo la sua priorità rispetto alla via legislativa come strumento di regolazione di rapporti di lavoro, capace di contemperare in modo equilibrato i diversi e spesso contrapposti interessi delle parti, imprese e lavoratori. Negli anni successivi I'Unione ha sancito per direttiva l'importanza della partecipazione dei lavoratori nell'impresa, come metodo integrativo della contrattazione.

Peraltro tutti i sistemi storici di relazioni industriali dei nostri paesi sono stati costruiti per funzionare in sistemi produttivi, quelli fordisti, relativamente standardizzati e in crescita, operanti all'interno di contesti nazionali relativamente protetti, sostenuti in varia misura dal potere pubblico e da una legislazione protettiva.

Tutti questi elementi di contesto sono rapidamente cambiati con I'intensificarsi della concorrenza globale, con il ridursi, il venir meno delle barriere protettive e con la conseguente perdita di controllo dei poteri statali rispetto alle scelte economiche, comprese quelle riguardanti i rapporti fra lavoro e impresa.

D'altra parte le innovazioni produttive e organizzative, in specie quelle rese possibili dalle tecnologie dell'informazione, hanno accentuato la diversificazione dei lavori rispetto al modello fordista e la capacità delle imprese di rispondere alle esigenze di flessibilità sollecitate dal mutare dei modelli di consumo e dalle stesse pressioni competitive. La pressione sui modelli nazionali di contrattazione collettiva è andata crescendo già prima dell'attuale crisi, in parallelo con l'aprirsi dei mercati, sotto la spinta di un "perceived imperative of flexibility" (Howell \& Givan, 2011) e ha messo in discussione la capacità delle relazioni industriali nazionali di funzionare nel nuovo contesto dell'economia flessibile e globalizzata. La criticità della sfida è accentuata dal fatto che oggi i margini di risorse pubbliche e private si sono ristretti a seguito della minore capacità delle nostre economie di produrre e di garantire miglioramenti continui ai trattamenti retributivi e di welfare dei lavoratori.

I segnali dei sistemi europei continentali sono particolarmente evidenti perché il loro tradizionale impianto centralizzato e le tecniche di regolazione tendenzialmente rigide in essi prevalenti si sono mostrati sempre meno capaci di adattarsi alle pressioni competitive e al cambiamento del contesto. Tanto è vero che si è diffusa l'opinione che proprio tali caratteri e la conseguente scarsa adattabilità delle relazioni industriali hanno contribuito nel tempo a ridurre la capacità di innovazione e la competitività dei paesi europei fino a prefigurare veri e propri rischi di eurosclerosi. 
A queste sfide i sistemi europei di relazioni industriali hanno reagito con modalità diverse in corrispondenza ai caratteri storici che li hanno conformati (Howell \& Givan, 2011; Turner, 2009; Ferner \& Hyman, 1992). Su queste tendenze nazionali, I'Unione Europea ha esercitato una influenza relativa, contrariamente a quanto alcuni auspicavano; per I'inadeguatezza delle competenze istituzionali e degli strumenti disponibili, ma anche per la mancanza di volontà dei governi europei di esercitare una azione comunitaria incisiva sulle relazioni fra imprese e mondo del lavoro.

Sono, dunque, queste vicende che vanno analizzate per individuare le possibili evoluzioni delle relazioni industriali, le tendenze alla convergenza fra i vari sistemi e, viceversa, le risposte diversificate dei vari paesi.

L'indagine qui presentata tiene conto di queste condizioni di contesto e si concentra in particolare su due sistemi di importanza centrale nella storia delle relazioni industriali continentali, quello tedesco e quello francese.

Si tratta di un fenomeno rilevato in generale nell'evoluzione delle vicende europee perché è dal confronto e dalla competizione fra diversi sistemi nazionali e persino fra le diverse pratiche aziendali che dipenderà l'evolversi delle relazioni industriali nei due possibili sensi della convergenza e divergenza (Visser, 2004).

Si tratta di due paesi decisivi per l'economia e per l'equilibrio dell'Europa. I loro sistemi di relazioni industriali presentano caratteri strutturali diversi che si radicano nella storia. Sono diversi i caratteri del sindacato, unitario quello tedesco e fortemente radicato, ideologicamente diviso e alquanto debole per organizzazione e numero di adesioni, quello francese. Sono diversi i rapporti fra le parti sociali, alquanto conflittuali in Francia, ispirati in Germania a cultura e pratiche partecipative, in particolare nelle imprese ove operano istituti di partecipazione forte, fino a una vera e propria cogestione.

Peraltro entrambi i sistemi presentano una struttura della contrattazione tradizionalmente basata su due livelli; nazionali e aziendali, fra loro correlati sia pure, come vedremo, in modo diverso e con spinte al decentramento. Hanno in comune quindi un sistema articolato che è proprio del modello europeo continentale e che lo differenzia dal sistema britannico e da quello degli USA, tradizionalmente privi (o quasi) di contrattazione nazionale provvisti di relazioni industriali essenzialmente decentrate a livello delle singole aziende.

Così pure in entrambi i paesi le relazioni industriali sono inserite in un sistema di legislazione protettiva del lavoro e di un welfare pubblico diffuso che le sostiene. Anche questi sono tratti emblematici del modello sociale europeo, che lo hanno a lungo ispirato, soprattutto quello tedesco. Essi ora sono esposti alle sfide della competizione globale che li costringe ad adeguare le loro strutture rigide agli imperativi della flessibilità. Anche per questo aspetto è diversa la situazione dei paesi anglosassoni le cui relazioni industriali hanno operato in ordinamenti giuridici privi dei vincoli e dei sostegni di una legislazione protettiva. 
La ricerca non ha considerato i paesi scandinavi del Nord Europa ove le relazioni industriali si sono sviluppate fino a raggiungere un alto grado di compattezza e stabilità, ma secondo logiche estranee da quelle del sistemi europei ${ }^{1}$ e tuttora resistenti a una omologazione con i paesi continentali. Entrambi i paesi considerati dall'indagine hanno reagito alle sfide della globalizzazione introducendo modifiche profonde nei loro sistemi economici e sociali, comprese le relazioni industriali. Anzi la riforma di queste è stata considerata essenziale per migliorare la capacità competitiva di quei paesi. Come vedremo, le modifiche introdotte in Francia e in Germania sono in parte differenti, ma hanno in comune il tratto fondamentale di aumentare il grado di adattabilità, o come si dice di "plasticità", delle loro istituzioni per metterle in grado di reagire positivamente agli shock esterni (Howell \& Givan, 2011).

Questa tendenza si è espressa in generale nella spinta verso un decentramento della struttura contrattuale con un allargamento degli spazi in cui può operare la contrattazione collettiva aziendale, anche oltre le regole fissate dai contratti nazionali. La tendenza è emblematizzata dalle c.d. clausole di deroga e si traduce nella possibilità delle relazioni sindacali aziendali di intervenire su aspetti critici per la competitività delle imprese con maggiore libertà e incisività del passato.

Proprio per questo le recenti condizioni dei due sistemi rendono la loro analisi particolarmente utile anche per la situazione italiana. Le riforme introdotte in quei sistemi hanno mostrato una buona capacità di mediazione rispetto alle pressioni economiche e di offrire soluzioni di coordinamento rispetto ai problemi del mercato. Queste prove di plasticità/adattabilità sono rilevanti non solo per l'importanza di quei sistemi, ma perché hanno saputo affrontare questioni controverse affrontate da anni anche nel sistema italiano e di recente oggetto di importanti accordi sia nazionali sia aziendali.

L'analisi generale dei sistemi francese e tedesco si è accompagnata con I'approfondimento delle dinamiche relative ad alcune grandi aziende di settori in cui opera Eni e appartenenti al gruppo. Le indicazioni provenienti dalla ricerca sono discusse alla stregua delle recenti evoluzioni delle relazioni industriali italiane, in particolare quelle che hanno portato all'accordo del 28 giugno 2011, un accordo che (per molti versi) risponde alle stesse sollecitazioni presenti negli ordinamenti esaminati. Più specificamente esse sono confrontate con le tendenze dei rapporti sindacali maturati nel Gruppo Eni, fino all'accordo siglato il 26 maggio 2011. Questo accordo è intervenuto dopo l'avvio della presente ricerca, ma trova riscontro e valorizzazione ulteriore alla luce dei risultati di questa. L'indagine è stata animata dalla convinzione che la riflessione comparata qui proposta è importante per capire meglio la portata dei grandi cambiamenti in corso nei rapporti fra mondo delle imprese e mondo del lavoro e per trarne indicazioni utili per innovare le relazioni industriali italiane.

Inoltre il gruppo di lavoro è convinto che la collocazione di Eni in settori strategici della nostra economia e la sua esperienza internazionale conferiscono ai rapporti sindacali sviluppati nel

1 Anche in Svezia le relazioni industriali hanno subito trasformazioni in direzione di un decentramento sia pure mediate dalle istituzioni del sistema (Howell \& Givan, 2011). 
gruppo un rilievo centrale nel panorama italiano, e che essi, come conferma l'ultimo accordo, possono contribuire in maniera rilevante all'innovazione dell'intero nostro sistema, interagendo attivamente con le evoluzioni registrate nello scenario delle relazioni industriali italiane.

\section{Osservazioni sullo svolgimento della ricerca e sulla composizione del Rapporto. Mutamenti istituzionali nelle relazioni industriali europee a cura di Tiziano Treu e Michele Faioli}

Le organizzazioni sindacali della Francia e della Germania rappresentano, se studiate anche con un approccio comparativo, un laboratorio importante per comprendere l'evoluzione delle relazioni industriali in Europa. Il presente Rapporto permette di individuare, nell'ambito di questa indagine comparativa, la reazione delle relazioni industriali nella crisi economico-finanziaria attuale e le ragioni che stanno alla base di un modello sindacale partecipativo, rinnovato o adeguato secondo strategie volte a favorire lo sviluppo.

Le organizzazioni francesi e tedesche hanno dimostrato, secondo livelli di intensità differenti, una propria capacità di (i) mediazione rispetto alle pressioni economiche, (ii) distribuzione del potere tra gli attori sociali, nonché (iii) definizione di soluzioni di coordinamento rispetto ai problemi del mercato nella dinamica globale/locale.

Quelle organizzazioni sono inserite in sistemi di relazioni industriali che hanno un elevato livello di flessibilità e adattabilità, tanto da apparire sistemi dotati di particolare "plasticità" (Howell \& Givan, 2011). Nella competizione globale questa plasticità è parsa anche come un segnale di debolezza del sistema sindacale a causa di una certa inclinazione di esso a essere soggetto a fenomeni di erosione (Ferner \& Hyman, 1992).

Lo studio del mutamento delle istituzioni sindacali francesi e tedesche rispetto alle forze del mercato globale/locale è realizzato in una prospettiva di confronto con l'assetto italiano, in cui si inserisce il Gruppo Eni e il relativo modello di relazioni industriali.

Del resto i sistemi contrattuali e sindacali, costruiti in ambiti nazionali, si confrontano con il contesto dei mercati globalizzati e gestiscono la relativa pressione la quale ricade, tanto più nell'attuale crisi finanziaria ed economica, direttamente su di essi.

Il presente Rapporto si compone di due sezioni. La prima sezione attiene alla descrizione del sistema di relazioni industriali che è venuto a svilupparsi in Francia e in Germania. La seconda sezione riguarda I'analisi della contrattazione collettiva e l'incidenza di essa su alcuni istituti o discipline del rapporto di lavoro nell'ambito dei due ordinamenti scelti. Tra queste discipline ci sono l'orario di lavoro, la flessibilità 
organizzativa, la lotta all'assenteismo, la partecipazione istituzionale e finanziaria, lo sciopero e le clausole di tregua, la reazione alla crisi di impresa.

Nella prima sezione del Rapporto si propone una comparazione tra sistema francese e sistema tedesco. Ciò permette di cogliere l'importanza del contratto collettivo, nella relativa dimensione nazionale e decentrata. Si vedrà che il decentramento contrattuale non è un fenomeno di destrutturazione delle relazioni sindacali, al contrario, se effettuato con determinati attori istituzionali ( $v$. in particolare il caso tede$\mathrm{sco})$, può rappresentare un percorso di maggiore praticità anche per l'efficacia dei contratti collettivi. La tendenza al decentramento contrattuale sta riguardando, con pressioni e misure diverse, tutti i sistemi nazionali dell'Europa, essendo frutto anche della globalizzazione delle economie e della crisi recente.

Osservando questo fenomeno si intravede una via per uscire dalla logica degli automatismi o quasi-automatismi ed entrare in una dinamica più efficace tra livelli di contrattazione (nazionale/aziendale o nazionale/territoriale).

Riflettere sul decentramento contrattuale permette di individuare le criticità di ciò che può essere definito "completezza" (o "onnicomprensività") del contratto collettivo nazionale.

Nell'esperienza tedesca ( $\mathrm{e}$ in parte anche in quella francese) possiamo osservare che (i) nel livello nazionale, sono poste discipline di tutela ridefinite sulla base di ciò che è considerato essenziale e (ii) nel livello decentrato, si notano, da una parte, discipline specifiche, e dall'altra, clausole di apertura controllate o progressive.

In questa prospettiva viene analizzato anche il fenomeno della dissociazione del datore di lavoro dall'organizzazione imprenditoriale di riferimento, finalizzato alla negoziazione di contratti collettivi aziendali/decentrati non rientranti nell'orbita del contratto collettivo nazionale. Questo caso è prevalentemente attribuibile al contesto tedesco.

Osservando le attuali condizioni sfavorevoli del contesto economico appare anche da questa ricerca che sono impraticabili strategie di rifiuto di ogni tipo di concessione.

Dal modello francese si intuisce quanto difficile sia attuare strategie sindacali di controllo degli accordi in deroga. Nel sistema tedesco si verifica una situazione ove i consigli di fabbrica sono relativamente autonomi dai sindacati nazionali e possono intraprendere iniziative derogatorie, anche al di là dei limiti del quadro nazionale.

Un decentramento senza regole si intravede, invece, nell'assetto tradizionale italiano "perché la giurisprudenza prevalente riconosce che gli accordi in deroga alla contrattazione nazionale, in quanto atti di autonomia collettiva, sono comunque validi, anche oltre i limiti stabiliti dall'accordo interconfederale del 2009 e dai successivi contratti collettivi nazionali $[\ldots]$ ", ed è per questa ragione che "I'accordo interconfederale del 2009 
ha [...] previsto una duplice forma di controllo centralizzato sugli accordi in deroga: la definizione preventiva dei casi e delle materie suscettibili di deroga, con limiti rigorosi e poi l'autorizzazione successiva all'attuazione della deroga da parte dei contraenti nazionali, su richiesta degli attori aziendali" (Treu, Le relazioni industriali nell'era della globalizzazione: gli accordi in deroga in Europa e la sfida ai sistemi contrattuali, 2011).

Nella seconda sezione si delineeranno i contenuti specifici di alcuni istituti gestiti, talvolta co-gestiti, mediante contrattazione collettiva decentrata.

È stata data particolare attenzione alla flessibilità del tempo di lavoro rispetto al quale si noterà nel sistema tedesco il potere di veto del consiglio di fabbrica e nel sistema francese la flessibilità introdotta in via di deroga. 


\section{Sezione prima}

\section{Parte generale - (A) Executive summary}

Per svolgere un'analisi utile per gli obiettivi della presente ricerca si definiscono, preliminarmente e in via schematica, gli elementi centrali che compongono i sistemi di relazioni industriali francese e tedesco.

Tali elementi saranno oggetto di trattazione specifica, con argomentazioni anche critiche, nella Parte generale - (B) Analisi comparativa e nella Sezione seconda (Contenuti specifici).

I dati numerici riportati sono tratti dalle statistiche elaborate dall'EIRO (www.eiro.eu) e/o dall'ETUI (www.etui.org).

\section{Francia Germania}

\section{Tasso di sindacalizzazione}

$8 \%$

(circa 1,8 milioni di aderenti, da intendersi come lavoratori attivi, non pensionati)

\section{Organizzazioni sindacali}

- CGT (700.000 lavoratori aderenti), CFDT, CGTFO, CFTC, CFE-CGC (considerate maggiormente rappresentative, con prerogative già riconosciute ex lege)

- FSU, UNSA, Solidaires

Dal 2008 è stato introdotto un nuovo meccanismo di misurazione della rappresentatività a livello nazionale, settoriale e aziendale.

Il meccanismo sarà definitivamente a regime dal 2013.

Con riferimento alle associazioni datoriali si può notare che MEDEF è l'organizzazione più grande e più importante ( 87 federazioni, 600 associazioni e 165 organizzazioni regionali).

Vi è anche la Confédération générale des petites et moyennes enterprises, CGPME, e la Union professionnelle artisanale, UPA. T.

Dal 2001 esiste anche il Conseil des entreprises, employeurs et groupements de l'économie sociale, CEGES, per il settore no profit.

\section{Tasso di sindacalizzazione}

$22 \%$

(circa 7,9 milioni di aderenti, il cui $20 \%$ è composto da lavoratori in pensione)

\section{Organizzazioni sindacali}

- DGB (6,19 milioni di lavoratori aderenti), CGB (280.000 lavoratori aderenti). Si tratta di due confederazioni che ricomprendono al proprio interno diverse organizzazioni verticali in relazione ai più importanti settori del sistema industriale.

- IG Metall - sindacato importante del settore metalmeccanico non collegato a DGB o a CGB.

- Ver.di - sindacato relativo ai settori del commercio, bancario, telecomunicazioni.

- IGBCE - sindacato relativo al settore chimico e dell'energia.

Per ciò che concerne le associazioni datoriali si può prendere in considerazione il seguente quadro:

- Bundesvereinigung der Deutschen Arbeitgeberverbände, BDA - si tratta di una confederazione "ombrello" che raccoglie una serie di associazioni datoriali (56 settoriali, 14 regionali). Non svolge direttamente la contrattazione collettiva. Coordina le iniziative.

- Bundesverband der Deutschen Industrie, BDI anche questa confederazione ripete il modello "ombrello", limitandosi a raccomandare misure comuni alle associazioni aderenti. 


\section{Contrattazione collettiva}

- La contrattazione collettiva si attua su tre livelli (nazionale, settoriale, aziendale).

- La negoziazione per la contrattazione collettiva aziendale è obbligatoriamente attuata su base annuale, su richiesta del sindacato. Le materie oggetto di tale negoziazione riguardano la retribuzione incentivante, la durata del lavoro, l'organizzazione dell'orario di lavoro, l'inserimento professionale dei lavoratori disabili. Se il contratto aziendale viene sottoscritto dalle parti, il datore di lavoro beneficia di uno sgravio sul costo del lavoro (10\% più altri incentivi fiscali).

- Nelle imprese o gruppi di imprese con più di 300 lavoratori triennalmente è prevista una negoziazione con finalità informative/consultive.

- Il contratto aziendale può derogare i livelli superiori in base al principio "specialia generalibus derogant". Vengono definite le aziendale (retribuzione, inquadramento professionale, previdenza complementare, formazione professionale).

- Sono stati introdotti meccanismi per rendere "valido" il contratto collettivo (il concetto di "validità" coincide approssimativamente con il

- Tali meccanismi sono modellati sul principio di maggioranza. La validità di un contratto collettivo di settore determina I'assoggettamento contrattuale di tutti i datori di lavoro le cui associazioni abbiamo sottoscritto e approvato il contratto collettivo. L'estensione degli effetti del contratto collettivo di settore può avvenire anche per mezzo di decreto governativo. Anche a livello aziendale il principio di maggioranza (dei lavoratori e/o l'erga omnes del contratto aziendale. materie escluse dalla competenza del contratto concetto "applicabilità"). dei rappresentanti sindacali) regola la validità e

\section{Contrattazione collettiva}

- La contrattazione collettiva si attua su più livelli. I contratti collettivi di settore sono negoziati a livello nazionale o di Land. Con questi contratti interagiscono i contratti collettivi di livello aziendale.

- Il contratto collettivo aziendale è negoziato con i consigli di fabbrica (Betriebsrat).

- Il Betriebsrat è composto da lavoratori eletti mediante procedure definite in via legislativa.

- Il contratto collettivo aziendale regola materie che (i) non sono di competenza del livello di contrattazione settoriale o (ii) rientrano nelle prerogative di informazione/consultazione definite dalla legge Betriebsverfassungsgesetz (art. 87 della normativa del 1952, riformata nel 2001 e nel 2004 - di seguito anche "BVG").

- Il consiglio di fabbrica esercita di fatto un potere di veto sulle materie di cui all'art. 87 citato, inducendo un processo di negoziazione che generalmente termina con la sottoscrizione di un contratto aziendale.

- Vige il principio di favor (Günstigkeitsprinzip), il quale consiste nella regola secondo cui il livello aziendale non può derogare in peius ciò che è definito a livello settoriale. Tuttavia il principio di favor è stato inteso dalla giurisprudenza in modo assai flessibile, determinando di volta in volta una valutazione del sacrificio a cui sottoporre i lavoratori per salvare l'occupazione.

- Legge e contratto collettivo settoriale non escludono il potere di negoziare a livello aziendale clausole di apertura - Öffnungsklauseln. Queste clausole sono utilizzate per far fronte a situazioni di crisi o a situazioni di altro genere considerate dal sindacato adatte alla modifica di regole nazionali.

- Vi è anche un meccanismo di possibile dissociazione delle imprese dall'organizzazione datoriale; consiste nella possibilità del datore di lavoro di appartenere all'organizzazione datoriale senza vincolo di assoggettamento al contratto collettivo settoriale (Ohne Tarifbindung Status - OT Status).

\section{Rappresentanza sindacale a livello aziendale}

- I modelli di rappresentanza sindacale a livello aziendale sono complessi.

- Vi è un sistema tendenzialmente duale (soggetti eletti/soggetti designati). In alcuni casi vi è un organismo unitario.

\section{Rappresentanza sindacale a livello aziendale}

- La rappresentanza sindacale in azienda si indentifica quasi completamente nel consiglio di

- Il sindacato locale/nazionale/settoriale è in collegamento con il consiglio di fabbrica. fabbrica. 


\section{Francia}

- La rappresentanza/rappresentatività in azienda si gioca su tre criteri del sindacato che intenda nominare un delegato o far parte del comitato: indipendenza, trasparenza finanziaria nella gestione e percentuale minima di lavoratori votanti per quel sindacato $(10 \%)$.

- Il numero dei delegati sindacali dipende dal numero dei dipendenti dell'azienda (v. tabella di seguito).

- Il numero dei componenti del consiglio aziendale dipende dal numero dei dipendenti dell'azienda ( $v$. tabella di seguito).

- Le funzioni del delegato e del comitato sono differenziate.

- Il diritto di informazione viene esercitato dal delegato e/o dal comitato.

- Il diritto di consultazione viene esercitato dal comitato.

- La legge definisce una serie di garanzie per l'azione sindacale in azienda (tutela in caso di licenziamento, permessi, aspettative, uso dei locali e sostegno economico).

\section{Partecipazione alla gestione aziendale}

- Esistono tre possibilità di presenza del lavoratore negli organi gestori (1. elezione in qualità dei rappresentanti/settore pubblico o para-pubblico; 2 . indicazione in rappresentanza dei lavoratori azionisti; 3. partecipazione alle sedute dell'organismo gestorio - rappresentanti sindacali/componenti del comitato in qualità di uditori con diritto di parola).

- La partecipazione è definita in via legislativa.

\section{Germania}

- Il consiglio di fabbrica esercita i poteri riconosciuti dalla legge anche a prescindere dal collegamento, diretto o indiretto, dei propri componenti con il sindacato locale/nazionale/ settoriale.

- I diritti/poteri di informazione e consultazione, il diritto di co-determinazione sono fissati dalla norma di legge (art. 87 BVG). Tra le materie di competenza del consiglio di fabbrica vi sono le seguenti: condotte dei lavoratori e codice disciplinare, orario di lavoro, riduzione orario di lavoro, tempo e luogo del pagamento della retribuzione, monitoraggio e vigilanza sui lavoratori, aspettative, congedi, coordinamento per sicurezza sul lavoro, impostazione di forme di previdenza/assistenza privata aziendale, gestione di appartamenti aziendali da locare, retribuzione (metodi), bonus o perfomance plan, organizzazione del lavoro, performance di gruppi di lavoratori, piani e gestione.

- La legge regola anche le garanzie dei componenti del consiglio di fabbrica (permessi, aspettative, etc.).

\section{Partecipazione alla gestione aziendale}

- Nell'organismo di vigilanza di aziende mediograndi (più di 500 lavoratori) vengono nominati rappresentanti dei lavoratori.

- Il numero dei rappresentanti varia in relazione al numero dei lavoratori dell'azienda. 


\section{Parte generale - (B) Analisi comparativa}

\section{Francia. Relazioni industriali e livelli di contrattazione. Strategia di rafforzamento e sindacato "ubiquo"}

Secondo il Rapport de la Commission pour la libération de la croissance français (2008) la crescita dell'economia francese sarà determinata anche da un sistema sindacale "rinforzato" 2. È questa una formula sintetica che evidenzia efficacemente i limiti e le potenzialità del sistema francese di relazioni industriali. È noto che si tratta di un sistema fortemente destrutturato a livello nazionale/locale, sottoposto a una formalizzazione legislativa sproporzionata e tendenzialmente debole nel sistema di rappresentanza in azienda. Il tasso di sindacalizzazione in Francia è tra i più bassi dei paesi OCSE. Si segnala il $5 \%$ di lavoratori nel settore privato e il $15 \%$ del settore pubblico. Il $90 \%$ dei lavoratori è coperto da contratto collettivo (dati EIRO). I giorni di sciopero in un anno possono raggiungere quantità non irrilevanti (122.91 giorni nelle annualità che corrono tra 2004 il 2007 su mille lavoratori - dati DARES/EIRO; la media europea è di circa 34 giorni). Gli incrementi salariali su base collettiva possono attestarsi su 3,2\% (contro la media europea del 5,53\%, periodo 2004-2007 - dati EIRO).

\section{a. Assetto sindacale e rappresentatività}

L'assetto sindacale attuale francese è venuto a costituirsi dopo la seconda guerra mondiale. Nella Costituzione francese non vi sono norme sulla rappresentanza e rappresentatività sindacale. Mediante legge ordinaria (art. L 131.1 e ss. del Code du travail) sono stati posti i criteri di legittimazione per i sindacati considerati rappresentativi. Si tratta di criteri presuntivi non dissimili da quelli tradizionalmente impiegati nel contesto italiano (Enrico, 2006) ${ }^{3}$. Gli altri sindacati devono, invece, provare la propria rappresentatività con indici indicati nel codice del lavoro (tra questi, il numero degli aderenti, l'autonomia, la contribuzione sindacale, l'esperienza e la storia, l'atteggiamento patriottico durante la resistenza). Le prerogative sindacali di quest'ultime organizzazioni sindacali possono essere esercitate a livello di settore e d'impresa, non a livello nazionale/intercategoriale (Enrico, 2006; Ray, 2004). Tuttavia questi criteri di rilevazione della rappresentatività delle organizzazioni sindacali francesi sono ritenuti non più coerenti con I'assetto giuridico-economico contemporaneo. Anche i due criteri indicati dalla giurisprudenza (efficacia dell'attività sindacale e capacità promozionale del sindacato) non hanno fornito risposte adeguate al problema della rappresentatività.

\footnotetext{
2 Nel capitolo «Moderniser le dialogue social» del Rapport de la Commission pour la libération de la croissance français (2008) si può leggere la seguente osservazione «l'améliorament de le croissance implique un dialogue social renforcé: des stratégie de consultation, de concertation et négociation efficaces et équilibrées donnent aux partenaires sociaux l'espace nécessaire pour établir le garanties essentielles à la sécurisation des parcours professionnels. La loi occupe aujourd'hui dans notre pays un espace trop important. Il nous faut désormais favoriser l'intervention des acteurs économiques et sociaux pour créer les conditions d'un nouvel équilibre loi/accord contractuel entre les organisations patronales et syndicales» (p. 105). 3 Con l'accordo interconfederale tra Confindustria, CIGL, CISL e Uil del 28 giugno 2011 questo assetto è stato mutato.
} 
I cinque sindacati (CGT, CFDT, FO, CFTC, CFE-CGC) che godono della présomption irréfragable de représentativité hanno prerogative significative nel contesto sindacale francese (a livello nazionale, oltre alla contrattazione, tali sindacati partecipano alla gestione della previdenza pubblica e privata, alla definizione degli assetti di formazione professionale, alla distribuzione dei finanziamenti pubblici/aiuti di stato, ecc.; a livello settoriale, essi sono gli unici a poter negoziare contratti collettivi; a livello aziendale, essi possono designare il delegato sindacale). Le differenze rispetto alle altre organizzazioni sindacali vengono in evidenza proprio nell'esercizio delle prerogative in materia di contrattazione e gestione previdenziale (Le Queux \& Sainsaulieu, 2010).

\section{La presunzione di rappresentatività trova origine in normative degli anni} '30-'50 contenenti procedure di estensione erga omnes dell'efficacia dei contratti collettivi mediante decreto. Il contratto collettivo siglato dai sindacati rappresentativi (secondo quella presunzione) veniva applicato erga omnes. Su il cd. "club des cinq" sono state successivamente proiettate una serie di norme che hanno disciplinato prerogative di vario genere.

Nel delineare l'asse del sistema sindacale francese ci si imbatte in una serie di questioni preliminari.

Il sistema francese di relazioni industriali si è notevolmente trasformato nel corso degli anni '90. Essendo stato assoggettato nel dopoguerra a una rigida regolazione, con livelli centralizzati di contrattazione e limitata autonomia delle parti a livello aziendale, il sistema francese si è orientato verso un decentramento contrattuale e istituzionale, creando un intenso network di istituzioni sindacali per la negoziazione, la consultazione e la rappresentanza a livello locale/aziendale che si è diffuso rapidamente su tutto il territorio (Amossé, 2006). Questa trasformazione si è determinata mediante (i) la creazione di istituzioni sindacali che operano a livello locale/aziendale nonché (ii) il mutamento di quelle esistenti con attribuzione di nuove funzioni. In questo processo è stato determinante l'intervento legislativo finalizzato a promuovere la creazione/trasformazione delle istituzioni sindacali e della relativa capacità di svolgere attività sindacale in azienda (Howell, 2009).

Il Rapporto Hadas-Lebel del 2006 e il Parere del Conseil économique et social del 2006 seguono la medesima traiettoria di critica rispetto al sistema francese di relazioni industriali, venutosi a costituire in questi ultimi due decenni, indicando alcuni principi per il rinnovamento:

- ferma restando la presunzione di rappresentatività, è necessaria una revisione periodica dell'elenco delle organizzazioni rappresentative;

- è necessario un aggiornamento dei criteri di rappresentatività;

- $\quad$ si deve ridefinire e specificare il campo delle prerogative sindacali;

- $\quad$ si deve semplificare il riconoscimento della rappresentatività. 
Nella Position Commune del $2008{ }^{4}$ si decise di incidere sulla revisione dei criteri di rappresentatività, con un richiamo del sistema di riscontro elettorale. Si insistette anche per la trasparenza finanziaria delle organizzazioni sindacali. In questo concetto di trasparenza rientra un metodo indiretto di controllo della rappresentatività perché viene a costituirsi un sistema di verifica delle rendicontazioni contabili, del numero degli iscritti e della contribuzione percepita dagli aderenti.

Tra i criteri di rappresentatività si deve segnalare la soglia minima percentuale di riscontro del sindacato presso i lavoratori. È un parametro necessario per la verifica della rappresentatività (Antonmattéi, 2006).

I livelli di soglia minima sono i seguenti (legge n. 2008-789 del 20.8.2008):

\section{livello aziendale}

- $10 \%$ dei voti espressi al primo turno delle ultime elezioni del comitato aziendale (o della delegazione sindacale unica del personale o, in mancanza, dei delegati del personale, qualunque sia il numero dei votanti).

\section{livello di branche/interconfederale}

- $8 \%$ in occazione delle medesime elezioni - la soglia, però, si aggiunge a ulteriori parametri (requisiti generali, diffusione territoriale equilibrata, rappresentatività in alcuni settori).

Il sistema di misurazione del consenso ha come baricentro le elezioni aziendali. I riflessi di queste elezioni ricadono sul livello di branche/interconfederale ("contratto collettivo di categoria" o "contratto collettivo nazionale").

È un meccanismo ascendente (dal basso verso l'alto) che determina uno schema secondo cui il lavoratore, esprimendo il voto per il proprio rappresentante sindacale in azienda, permette a un certo sindacato di superare/raggiungere la soglia minima di rappresentatività a livello aziendale e a livello di branche/intercategoriale.

Le opinioni su questo meccanismo sono almeno due. Alcuni segnalano che il monopolio delle grandi cinque confederazioni non è stato di fatto scalfito, data la permanenza dei requisiti generali di rappresentatività e della presunzione di rappresentatività (Neron, 2009). Altri, invece, insistono per la dinamicità del sistema di democrazia industriale francese, proteso a una maggiore concorrenzialità tra soggetti sindacali (Borenfreund, 2008).

In questo contesto, dunque, la legge n. 2008-789 del 20.8.2008 (rénovation de la démocratie sociale et réforme du temps de travail) incide sulla legittimazione del sindacato (accertamento della rappresentatività e riscontro elettorale), sul sistema di rappresentanza dei lavoratori nei luoghi di lavoro, e sulla regolamentazione dell'orario di lavoro. L'operatività di queste norme è posta in una logica di graduale applicazione, con la piena operatività nel 2013 del nuovo sistema (Borenfreund, 2008). 
Il quadro non del tutto nitido sulla rappresentanza dei lavoratori all'interno dei luoghi di lavoro è dato da un sistema tendenzialmente duale (Tebano, 2009). Ci sono organismi elettivi (comité d'entreprise/comitato aziendale - délégués du personnel/delegati del personale) e organismi associativi (délégués syndical/ delegati sindacali - section syndical/sezione sindacale).

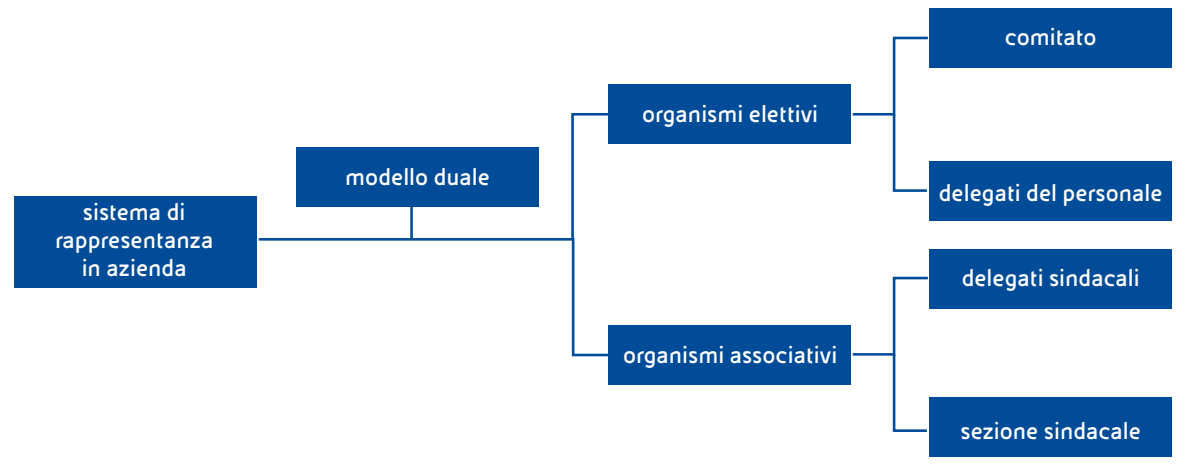

Il delegato sindacale deve ricevere almeno il $10 \%$ dei voti espressi al primo turno delle elezioni del comitato aziendale o dei delegati del personale.

I sindacati che hanno costituito una sezione sindacale in azienda con più di 50 lavoratori, i quali non dovessero rispondere ai requisiti di rappresentatività, pur non potendo designare un delegato sindacale, possono designare un rappresentante sindacale.

In aziende con meno di 50 lavoratori, ove non è possibile designare un delegato sindacale, la contrattazione collettiva viene svolta da lavoratori ai quali viene conferito un mandato ad hoc da un'organizzazione sindacale a livello nazionale.

Il contratto collettivo di branche può autorizzare il coinvolgimento nell'attività contrattuale di altri soggetti sindacali, ponendo in alternativa i rappresentati eletti dal personale e i lavoratori con mandato ad hoc. Dal 2004 i secondi svolgono una funzione di supplenza che si attiva in caso di assenza dei rappresentanti eletti.

\section{b. Principio maggioritario per la validità del contratto collettivo e preminenza del livello aziendale}

L'obiettivo della recente strategia legislativa è incidere sulla funzione negoziale a livello locale/aziendale, con una moltiplicazione di soggetti sindacali, aventi funzioni diverse in azienda, ricollegabili a schemi elettivi o a forme varie di designazione (Neron, 2009). Ciò sarebbe volto a permettere una gestione della flessibilità in via paritetica, non unilateralmente imposta dal datore di lavoro. Il meccanismo prescelto dal legislatore consiste nel collegare alla negoziazione di livello aziendale la possibilità di definire regimi di flessibilità da applicare al rapporto di lavoro. 
In questa prospettiva si sono succeduti nel tempo molteplici interventi legislativi.

A. Tra questi si può notare il sistema Aurox (leggi del 1982/1983) che introdusse forme articolate di comitati aziendali, con funzioni parallele e non coincidenti con quelle dei delegati sindacali, e promosse la possibilità di negoziare assetti più flessibili a livello aziendale. Il ricorso ad accordi "de fait" stipulati con i comitati aziendali (e non con i delegati sindacali) creò una serie di problematiche giuridiche nelle piccole e medie imprese/PMI (Bodin, 1987), alle quali si cercò di dare una risposta nel 1995 introducendo, mediante un accordo quadro sindacale (EIRR), il principio secondo cui i contratti collettivi aziendali/decentrati potevano essere stipulati dal comitato aziendale, o in alternativa dal delegato sindacale, o ancora in alternativa, ma solo in caso di PMI, da lavoratori delegati ad hoc dalle organizzazioni sindacali nazionali (una specie di abilitazione speciale alla negoziazione sindacale). Era un regime sperimentale di durata triennale che in questa ottica di apertura autorizzò anche la clausola di deroga in peius da definire a livello aziendale rispetto ai contratti collettivi nazionali.

B. Con la legge Fillon del 2004 si incardinarono definitivamente (i) il principio di derogabilità in peius, indicando la possibilità di accordi aziendali derogatori in tutti casi in cui non vi sia un divieto espresso dalla legge o dal contratto collettivo nazionale, e (ii) il principio di alternatività nella stipula di contratti aziendali tra comitato aziendale, delegato sindacale e lavoratore delegato ad hoc dall'organizzazione sindacale con successiva ratifica del personale. In quella occasione venne anche definito (iii) il principio di maggioranza. È il principio volto a evitare schemi automatici o quasi-automatici di selezione delle istituzioni sindacali che a livello aziendale possono svolgere attività di contrattazione collettiva (Jobert \& Saglio, 2005). Il campo elettivo di questo principio è stato il regime delle flessibilità dell'orario di lavoro. Nella legge Fillon del 2004 si stabilisce che la validità dei contratti collettivi di settore è subordinata alla firma di una o più organizzazioni sindacali che rappresentino la maggioranza dei lavoratori del settore stesso. Questa maggioranza è stabilita mediante consultazione (nella forma di referendum) fra i lavoratori o facendo riferimento ai risultati delle più recenti elezioni del comité d'entreprise o, in mancanza, dei delegati del personale. Si stabilisce altresì che la validità dei contratti collettivi di settore in alternativa all'ipotesi precedente è subordinata alla firma delle organizzazioni sindacali rappresentative che abbiano ottenuto almeno la metà dei suffragi espressi al primo turno delle più recenti elezioni del comité d'entreprise (questo principio si esprime anche con la "majorité des suffrages exprimés lors des dernières élections au comité d'entreprise"). Le criticità di questo sistema sono state significativamente rappresentate (Ray, 2004). Sono stati rilevati i problemi connessi al tasso di astensione, alla c.d. dittatura delle minoranze, nonché ai problemi della bassa sindacalizzazione nelle PMI (Antonmattéi, 2006).

C. La legge Aubry limitò nel periodo 1998-2002 I'uso del meccanismo di delega ad hoc per la negoziazione dei contratti aziendali/locali in materia di orario di 
lavoro. In particolare nelle PMI, qualora non fosse stato presente il comitato aziendale o il delegato sindacale, il contratto aziendale doveva essere approvato dalla maggioranza dei lavoratori e da una commissione ammnistrativa (articolazioni territoriali del ministero del lavoro). L'impatto di questa specifica legislazione sulla contrattazione aziendale è stato notevole. Nel 1999 il numero dei contratti aziendali venne a duplicarsi. Circa il 70\% dei contratti aziendali relativi all'orario di lavoro è stato definito con il meccanismo dell'approvazione della maggioranza dei lavoratori. Riferendosi al periodo 2004-2005, nel 77\% delle aziende con più di 20 lavoratori risultano esistenti forme di rappresentanza sindacale con elezione o designazione delle organizzazioni nazionali, in caso di aziende con più di 50 lavoratori il dato sale al 93\% (Jacod, 2007). Nel 50\% dei casi il contratto aziendale è stipulato con il meccanismo dell'approvazione successiva secondo il principio di maggioranza, con consultazione dei lavoratori, in forma di referendum (Ministère de I'Emplois, 2006).

La contrattazione collettiva sopravvive tra le difficoltà correlate alla rappresentatività, ai livelli di negoziazione, ai rapporti fra legge e contrattazione collettiva, all'efficacia soggettiva. In materia di rappresentatività I'interazione fra legge e contrattazione collettiva è stata regolata nel 2004 dalla legge Fillon. Il sistema centralizzato e gerarchizzato francese, che si basava sulla nozione di ordine pubblico e sul principio di favor, è stato gradualmente destrutturato. L'ordine pubblico permetteva di definire la supremazia della legge sul contratto collettivo; il principio di favor obbligava ad applicare il regime di maggior favore per il lavoratore nel caso di conflitto tra legge e contratto collettivo.

I tre grandi assi che le riforme appena menzionate hanno impostato sono i seguenti:

- il principio maggioritario;

- la destrutturazione del rapporto gerarchico tra legge e contratto collettivo e tra contratto di branche e contratto aziendale;

- l'estensione del campo della negoziazione collettiva.

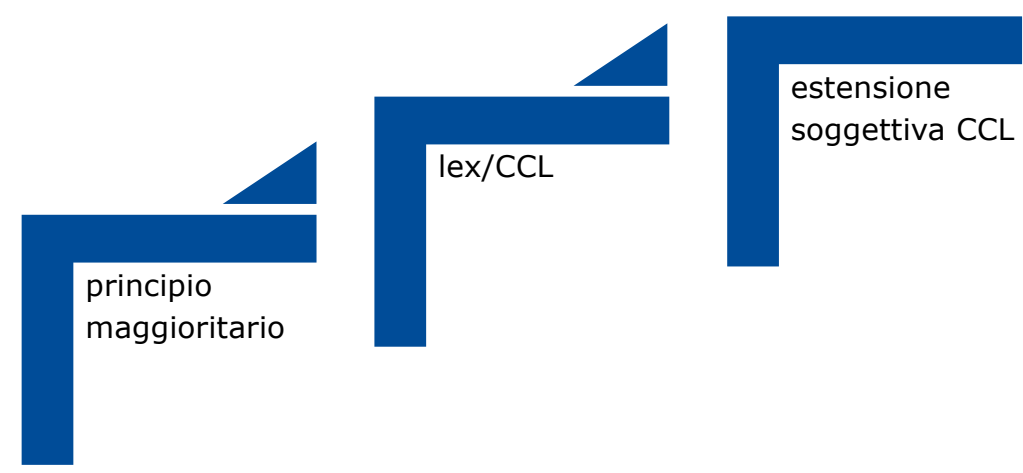


Il principio maggioritario impone che la validità del contratto collettivo sia subordinata al consenso della maggioranza dei lavoratori. Si deve chiarire il senso dei due concetti secondo la legge francese.

La nozione di maggioranza assume due significati (Supiot, 2005). Si è di fronte a una maggioranza elettorale (sono maggioritari i sindacati che hanno ottenuto la maggioranza dei voti nelle elezioni dei rappresentanti del personale nelle aziende vincolate al contratto collettivo) e a una maggioranza di organizzazioni sindacali (sono maggioritari i sindacati che rappresentano la maggioranza delle organizzazioni sindacali che sono rappresentative nel campo di applicazione del contratto collettivo).

Per i contratti intercategoriali si ritiene che vi sia maggioranza se tre su cinque organizzazioni sindacali abbiano nell'insieme almeno il 30\% dei voti alle elezioni: è una forma di rappresentatività comune sufficiente (Supiot, 2005).

Per i contratti di branche la maggioranza esiste in base a ciò che viene definito dal c.d. accordo elettorale di categoria. Questo accordo può prevedere due metodi: (i) I'organizzazione periodica di una consultazione elettorale di tutti i lavoratori delle imprese vincolate al contratto, e (ii) il riferimento ai risultati delle ultime elezioni del comitato aziendale/delegati.

Per i contratti aziendali la maggioranza è definita dai meccanismi stabiliti dal contratto di branche (v. sopra soglie minime) ${ }^{5}$.

Il consenso della maggioranza può essere esplicito (sottoscrizione del contratto collettivo - maggioranza di consentment) o implicito (non opposizione al contratto collettivo). La legge distingue tra

(i) casi in cui le organizzazioni sindacali maggioritarie possono esercitare il diritto di opposizione agli accordi firmati da sindacati non maggioritari (se non si esercita il diritto di opposizione viene a crearsi il c.d. schema della maggioranza di consensus - il silenzio della maggioranza vale accettazione ${ }^{6}$ ), nonché

(ii) casi in cui si subordina la validità del contratto collettivo all'impegno esplicito delle organizzazioni maggioritarie. Se non vi è l'impegno esplicito di queste, il contratto deve essere approvato dalla maggioranza dei lavoratori.

La sanzione di invalidità (nullità) colpisce il contratto collettivo privo di una delle maggioranze di cui sopra.

5 Il contratto aziendale privo dei requisiti di maggioranza del consenso è sottoposto a referendum in azienda a iniziativa delle organizzazioni minoritarie da cui è stato sottoscritto.

6 È un principio mutuato dal diritto internazionale pubblico. 
Ma il principio cardine del sistema francese risiede della posizione di preminenza del livello aziendale sugli altri livelli di contrattazione.

Dal 2004, infatti, il contratto collettivo di branche svolge funzioni di parziale definizione delle discipline di tutela rispetto a quello aziendale. Alcuni segnalano una forma di supplenza del contratto di branche rispetto a quello aziendale (Supiot, 2005). Mediante l'inserimento di clausole convenzionali è possibile ripristinare la tradizionale relazione di gerarchia tra livelli di contrattazione. Ciò che rileva è, dunque, la derogabilità del contratto di branche ad opera di quello aziendale. Il contratto aziendale può contenere clausole diverse e meno favorevoli rispetto a quello di branche, a meno che quest'ultimo non preveda un meccanismo di favor per il lavoratore.

c. Il principio di favor è sostituito dal principio specialia generalibus derogant. La regola che risolve il problema a monte?

La legge Fillon ha sostituito il principio di favor con quello di "specialia generalibus derogant". Il contratto di branche può essere derogato dal contratto aziendale. Il contratto di branche pare assumere un ruolo suppletivo perché il contratto aziendale prevale in modo quasi assoluto sul contratto di categoria, salvo che quest'ultimo disponga diversamente (Pélisser, Supiot, \& Jeammaud, 2008).

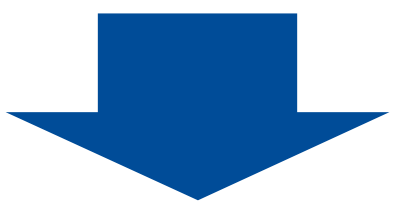

contratto aziendale

prevale

sul contratto di

categoria

(c.d. di branche)

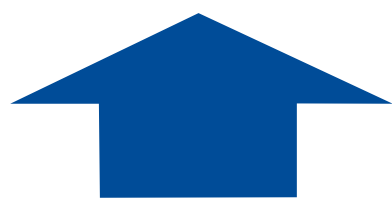


Tale prevalenza viene esclusa solo per quattro materie (zona di inderogabilità assoluta). Tale materie sono le seguenti:

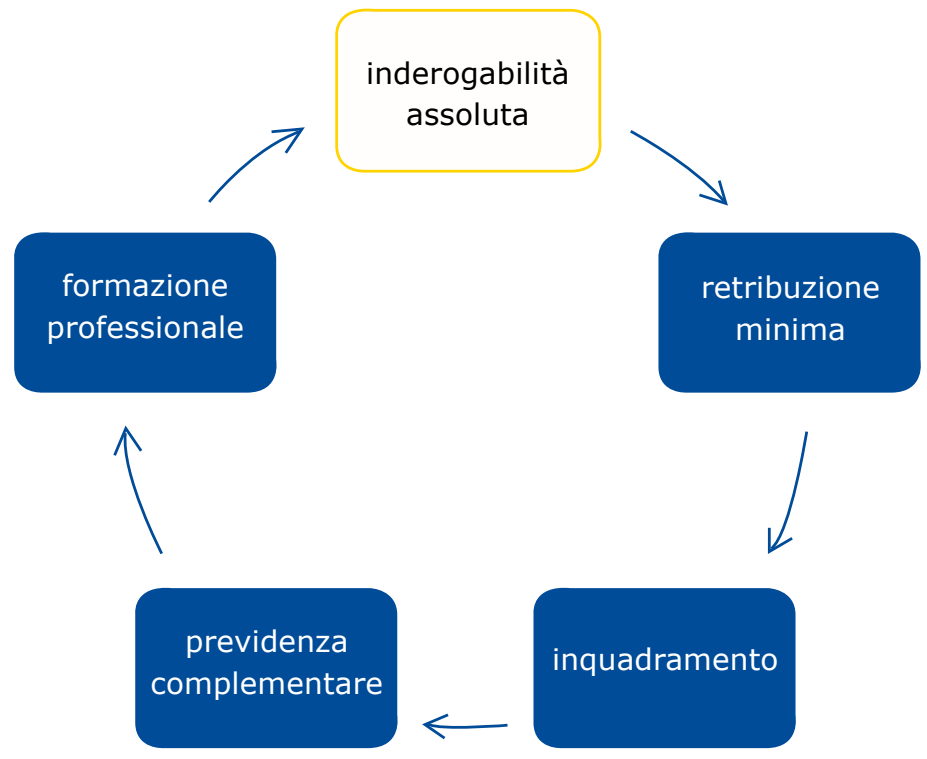

Nelle altre materie il principio di favor non governa più il rapporto gerarchico tra contratto di branche e contratto aziendale.

In questa logica il contratto aziendale può introdurre deroghe rispetto alle quali non si procederà con comparazioni sulle regole più favorevoli, più recenti o speciali. Il conflitto tra contratti collettivi di diverso livello è risolto a monte dalla legge, con l'introduzione della regola "specialia generalibus derogant". Le deroghe possono essere totali o parziali.

Il Consiglio costituzionale (Cons. Cost. 29.4.2004, Dic. 2004-494 DC) ha ritenuto che il principio di favor non possa essere considerato come un principio fondamentale riconosciuto dalla Repubblica, essendo esso un principio di diritto del lavoro la cui portata spetta al legislatore ordinario determinare.

\section{d. Clausole di blocco e clausole di autorizzazione}

Nel 2008 (legge n. 2008-789 del 20.8.2008) questa impostazione è stata ulteriormente rafforzata. Il livello aziendale di contratto collettivo non potrà essere neutralizzato dalle clausole di blocco (clausole del contratto di branche volte a definire le materie e i limiti di regolazione del contratto aziendale). In particolare nella materia dell'orario di lavoro viene ridimensionato lo spazio di operatività della branche, in 
quanto il contratto di branche viene limitato ad alcuni aspetti dell'orario di lavoro. Sul lavoro straordinario, ad esempio, viene rafforzato il contratto aziendale in ordine alla sostituzione totale o parziale della maggiorazione retributiva con riposi equivalenti, i quali non concorrono a determinare il monte ore annuo di straordinario che può essere utilizzato nell'impresa.

\section{Dal 2008 è venuto meno anche il collegamento tra contratto collettivo di} branche étendu (esteso erga omnes) e contratto aziendale. In materia di orario di lavoro si dispone che in presenza di un contratto aziendale non è più necessario far riferimento a un contratto collettivo di branche étendu (Freyssinet J., 2008).

Ciò evidentemente riduce il senso della procedura di estensione erga omnes dei contratti di categoria (branche). Resta, però, non risolto il potenziale conflitto tra le fonti (Supiot, 2005), anche per i riflessi sul mercato del lavoro e sulla modernizzazione del diritto del lavoro successivamente all'accordo del 2008 (Ballestrero, 2008).

Vi sono modalità alternative di negoziazione collettiva per le imprese prive di rappresentanti sindacali. Nelle PMI il radicamento sindacale è, infatti, diversificato. Non viene rafforzato per esse il livello di contrattazione di branche, ma al contrario viene posta una modalità alternativa di negoziazione mediante le clausole di autorizzazione fissate da un contratto di branche étendu.

Nelle aziende ove non siano presenti delegati sindacali o delegati del personale, i rappresentati eletti nel comitato aziendale o i delegati del personale vengono abilitati dall'accordo di categoria a negoziare e a concludere contratti aziendali. Nelle imprese sprovviste di qualsiasi istituzione sindacale/di rappresentanza, il contratto di branche può autorizzare lavoratori abilitati ad hoc da una organizzazione rappresentativa sul piano nazionale alla negoziazione/conclusione del contratto aziendale. Questo contratto sarà in ogni caso sottoposto a referendum per la verifica della maggioranza dei voti (pena l'invalidità).

Le clausole di autorizzazione definiscono le seguenti materie:

\section{clausole di autorizzazione}

lista delle materie relative alla negoziazione in deroga

regole sul calcolo della maggioranza dei lavoratori

regole per la concessione del mandato a negoziare

modalità di monitoraggio dei contratti conclusi in questo modo

Le clausole di autorizzazione determinano una dimensione di democrazia diretta in quanto la determinazione ultima circa il contratto dipende dal referendum tra i lavo- 
ratori (Mériaux O., 2000). Il referendum aziendale di ratifica/approvazione dell'azione svolta dal lavoratore con mandato ad hoc (abilitato alla negoziazione) introduce un sistema parallelo a quello del comitato aziendale o del delegato sindacale.

Il sistema di relazioni industriali francese si compone, pertanto, di due modelli: il primo riconduce alla democrazia rappresentativa e il secondo alla democrazia diretta (Howell, 2009).

La tecnica giuridica delle clausole di autorizzazione - le quali valgono per entrambe le ipotesi di azione sindacale (azione del lavoratore con mandato ad hoc; azione del comitato aziendale/delegato sindacale) - è stata voluta nel medesimo contesto legislativo che definì il principio della specialità/prevalenza del contratto aziendale.

Il collegamento tra clausola di autorizzazione e prevalenza del livello aziendale del contratto collettivo è volto a garantire l'efficacia del contratto collettivo aziendale (Howell \& Givan, 2011).

\section{e. Osservazioni conclusive. Sindacalismo "virtuale" e contrattazione collettiva "micro-corporativista"}

La destrutturazione delle organizzazioni sindacali francesi dipende dalla legislazione di flessibilità dei rapporti di lavoro, attuata mediante la contrattazione collettiva volta all'introduzione di deroghe a livello aziendale. Ciò ha determinato una riformulazione delle funzioni e delle identità sindacali: in Francia esiste un sindacato c.d. "ubiquo", presente tendenzialmente presso ogni azienda.

Ubiquità significa anche porre in essere forme di "sindacalismo virtuale". L'influenza del sindacato francese viene esercitata prevalentemente a livello politico (il sindacato rappresenta al governo le problematiche del lavoro; il governo fa riferimento al sindacato per misure economiche da introdurre) ${ }^{7}$.

L'ubiquità del sindacato è riposta nella predisposizione francese a definire norme di legittimazione di ogni azione sindacale e di ogni istituzione sindacale a livello aziendale, con i relativi schemi di democrazia diretta (approvazione/ratifica dei contratti collettivi aziendali).

L'ubiquità del sindacato ha ulteriori effetti sulla contrattazione decentrata. In tempo di crisi e di disoccupazione, la possibilità di ritagliare spazi consistenti per una contrattazione collettiva concessiva/ablativa tende a espandersi. Nel trade-off tra parti può esserci

È significativa la valutazione di alcuni studiosi su questo tema. In particolare è stato segnalato che "the influence of organized labor rests not on class power (in the sense of control over labor's collective capacities) nor any of the conventional measures of labor strength but rather on two functions: representing labor interests to the state (deployed by workers, who are rarely union members, to bargain with the state during moments of social crisis) and providing the state with an institution to legitimize economic policies that cause social dislocation" (Howell, 2009). 
lo scambio tra flessibilità (funzionale, di articolazione, di orario di lavoro, per delocalizzazione geografica, etc.) e occupazione.

È uno scambio che secondo alcuni ha riportato l'oggetto del contratto collettivo nell'alveo di una "negoziazione collettiva micro-corporativista" (Streeck, 1984).

Il livello aziendale è inteso come il luogo dell'operatività del sistema di relazioni industriali francese.

Ciò è il risultato delle riforme degli anni '80-'90. Gli studi più attenti alla vicenda dimostrano che i dieci anni di applicazione del sistema Auroux hanno definito un quadro di relazioni industriali ove il contratto collettivo nazionale/di settore, posto in una situazione di marginalità nella regolazione delle discipline di tutela, coesiste con molteplici e differenziati contratti aziendali (Coffineau, 1993).

In questo scenario agiscono le principali organizzazioni sindacali. Pur godendo di una serie di prerogative, esse si impegnano in alcuni casi in forme di "iper-riformismo" (Pernot, 2005), siglando gli accordi a rilievo nazionale e locale di riforma del sistema (è il caso della CFDT), o sono disimpegnate del tutto, dunque soffrono del male opposto (di "ipo-riformismo"), rifiutando di siglare o partecipare a negoziazione volte all'attuazione di riforme (è il caso della CGT).

Gli imprenditori si organizzano in movimenti (MEDEF) che sono poco rappresentativi, divisi al proprio interno, ma quasi sempre cooperativi con il governo per ottenere maggiore flessibilità nei rapporti di lavoro in cambio del richiesto decentramento del sistema di relazioni industriali (Woll, 2006). 


\section{Germania. Relazioni industriali e livelli di contrattazione. Co-determinazione e vincolo al contratto collettivo}

La peculiarità del sistema di rappresentanza tedesco è particolarmente evidente nel ruolo e nelle funzioni che il consiglio di fabbrica svolge in azienda. La regolamentazione di questo sistema risale al Betriebsverfassungsgesetz del 1952, con riforma successiva del 2001.

Il contratto collettivo è negoziato a livello settoriale (o regionale, e in alcuni casi anche nazionale) con le organizzazioni sindacali; il contratto collettivo aziendale è negoziato con il consiglio di fabbrica.

Il tasso di sindacalizzazione in Germania tende a diminuire (25\% nel 2000, 22\% nel 2005 - dati EIRO del 2009). I giorni di sciopero in un anno si attestano da sempre su quantità medio-basse (5,62\% giorni nelle annualità che corrono tra 2004 il 2007 su mille lavoratori - dati EIRO; la media europea è di circa 34 giorni). Gli incrementi salariali su base collettiva si attestano sull'1.8\% contro la media europea del 5.53\% nel periodo 2004-2007 (dati EIRO). Le maggiori organizzazioni sindacali sono la DGB (6.371.475 aderenti nel 2008), al cui interno vi sono i metalmeccanici IG METALL (2,3 milioni) e i lavoratori dei servizi (2,8 milioni), la DBB (1.280.802 associati), la CGB (278.412 associati) - dati EIRO. Le organizzazioni datoriali maggiori, le quali svolgono funzioni di coordinamento di micro e macro associazioni settoriali interne, sono la BDA e la BDI.

Esistono diverse analisi e valutazioni su questo sistema (Turner, 2009).

Alcuni ritengono la Germania un modello di coordinamento economico che si interfaccia con un network significativo di istituzioni sindacali relativamente stabili (Hall \& Soskice, 2001). Nel caso tedesco le istituzioni sindacali tendono a mutare lentamente, creando collegamenti e interazioni tra di esse.

Altri, invece, vedono l'inesorabile "disintegrazione incrementale" del sistema sindacale tedesco (Kitshelt \& Streeck, 2003).

Queste due visioni possono essere anche rilette in modo complementare (Turner, 2009). Un buon punto di partenza è l'analisi dell'azione sindacale tedesca in questi ultimi 40 anni: il sindacato ha dovuto affrontare una serie di sfide, adattando la propria organizzazione a trasformazioni sociali e economiche importanti, partecipando in via istituzionale alla sicurezza sociale pubblica e privata, gestendo la contrattazione collettiva anche aziendale (Streeck \& Thelen, 2005). Ciò che appare evidente agli studiosi della materia è una significativa erosione della contrattazione collettiva settoriale e del sistema di co-determinazione (Addison, Bryson, Teixeira, Pahnke, \& Bellmann, 2010). Leggendo queste valutazioni, si può ritenere che, se esiste un'erosione della contrattazione collettiva settoriale, vi è anche una 
forma di erosione "concatenata" (destrutturazione del contratto settoriale, con contestuale destrutturazione del contratto aziendale), con picchi di crisi dal 2001 in poi, cioè nel periodo che coincide con I'introduzione della riforma del consiglio di fabbrica.

L'analisi muove da questo punto e si arricchisce dell'indagine sul contratto collettivo settoriale e sul contratto aziendale, derivante dal diritto di co-determinazione, individuando due percorsi paralleli, o strategie anti-crisi, intrapresi dagli attori sociali tedeschi.

La prima strategia riguarda lo stepping out, inteso come dissociazione, del datore di lavoro dall'organizzazione datoriale di riferimento. Ciò è generalmente considerato un segno della crisi delle relazioni sindacali tedesche (Streeck, 2010). Tuttavia alcuni osservatori dimostrano che si tratta di una risposta alla crisi del sistema (Haipeter, 2011), che implica un rilancio dell'organizzazioni datoriali tanto da far affermare che essa costituisce un caso di "regain associational power".

La seconda strategia attiene alla deroghe o concessioni che vengono stipulate con contratto aziendale dai consigli di fabbrica. Questa strategia sarebbe utilizzata dalle organizzazioni sindacali per rendere più forte la propria presenza in azienda (Turner, 2009), per rilanciare il movimento sindacale.

Queste due strategie, I'una di risposta all'altra, confluiscono verso il medesimo obiettivo: rafforzare la presenza organizzativa-istituzionale sul territorio (dal lato datoriale, garantendo lo stepping out) e in azienda (dal lato del consiglio di fabbrica, permettendo deroghe).

Su questo rafforzamento poggia il futuro degli attori sociali in Germania, che avvertono l'esigenza di rinvigorire il potere associativo-organizzativo, reclutando nuovi aderenti (datori e prestatori di lavoro), mobilitando gli aderenti verso obiettivi comuni, e fissando norme contrattuali più adatte al contesto economico.

\section{a. Contrattazione collettiva settoriale e "stepping out" del datore di lavoro}

Come si è già visto, in Germania la contrattazione collettiva è prevalentemente settoriale. Viene negoziata a livello territoriale, nell'ambito di ciascuno stato federale (Länder). Tra il 1998 e il 2007 la contrattazione collettiva settoriale è stata applicata a un numero di lavoratori rilevante (dal 76\% al 63\% in Germania Ovest, $63 \%-54 \%$ in Germania Est - dati EIRO). Un dato interessante riguarda i contratti collettivi aziendali: nel 2008 il 46,8\% dei contratti collettivi era di tipo aziendale, con applicazione sul 7\% dei lavoratori in Germania Ovest e sul $13 \%$ dei lavoratori in Germania Est (dati EIRO).

I contratti collettivi sono vincolanti per i lavoratori aderenti alle organizzazioni sindacali e per i datori di lavoro aderenti alle associazioni imprenditoriali (la norma di riferimento Tarifvertragsgesetz del 1949, art. 3, $1^{\circ}$ co., stabilisce questo principio). Vi è un meccanismo, peraltro residuale, di estensione degli effetti del contratto collettivo 
regolato dall'art. 5 della Tarifvertragsgesetz. Il ministero del lavoro sulla base di alcune condizioni emana un provvedimento di estensione; le condizioni di estensione ministeriale sono verificate nell'ambito di una procedura di carattere amministrativo-sindacale. Nel 2008 sono stati oggetto di questo meccanismo solo il $10 \%$ dei 64.300 contratti collettivi registrati presso il ministero del lavoro (dati EIRO).

Il meccanismo di dissociazione (stepping out) dall'organizzazione datoriale (Arbeitgeberverbände) introdotto nel sistema tedesco consiste nella possibilità del datore di lavoro di appartenere all'organizzazione datoriale senza vincolo di assoggettamento al contratto collettivo settoriale (Ohne Tarifbindung Status - OT Status).

La portata di questo meccanismo risulta chiara dai dati: nell'ambito del settore metalmeccanico nel 1985 il 77\% circa di datori di lavoro era aderente a una organizzazione; nel 2006 solo il 56\% dei datori di lavoro aderiva a una delle organizzazioni datoriali (Haipeter, 2011).

L'OT Status determina la possibilità di beneficiare delle strutture che l'istituzione datoriale provvede a offrire, ma nel contempo, non vincolando all'assoggettamento contrattuale, evita la fuga dall'organizzazione e l'applicazione di regimi e discipline non applicate alla generalità dei datori di lavoro. In prospettiva alcuni hanno notato che, da una parte, le associazioni imprenditoriali usano I'OT Status per reclutare nuovi aderenti e, dall'altra, i sindacati fanno ricorso alle deroghe negoziate a livello aziendale per rafforzare la propria presenza in azienda ${ }^{8}$.

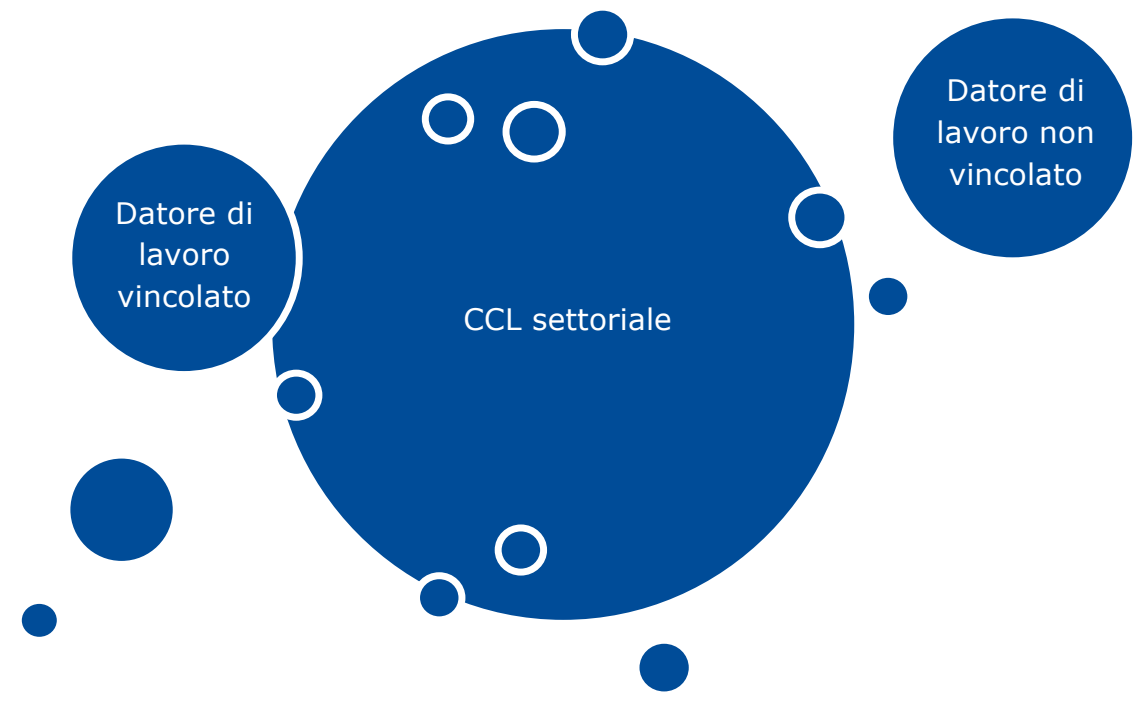

8 In particolare Haipeter afferma che "in this respect evidence can be given that employers' associations use 'unbound associations' mainly to recruit new members and that the union tries to make use of derogations to strengthen its organisational power in the plants" (Haipeter, 2011). 
Ripercorrendo le fasi di questa impostazione organizzativa si possono individuare almeno due situazioni.

La prima situazione riguarda ciò che accadde sul finire degli anni '80. Molti datori di lavoro iniziarono a dissociarsi dalle organizzazioni datoriali per timore di essere vincolati a contratti collettivi di settore non competitivi. Il sistema sindacale tedesco come il nostro segue la regola secondo cui la dissociazione datoriale dall'organizzazione firmataria non libera dalle obbligazioni derivanti dal contratto collettivo sino alla scadenza del suo termine. Per evitare la fuga dall'associazionismo datoriale si introdusse il c.d. quick notice (preavviso breve): il datore poteva dissociarsi nel tempo che corre tra la stipula del contratto collettivo e la data (non coincidente) di efficacia iniziale delle norme contrattuali. Ciò provocò la diaspora dei datori di lavoro, con il relativo decremento delle adesioni alle associazioni/organizzazioni datoriali, e nel contempo distese i rapporti tra datori e organizzazioni.

La seconda situazione attiene all'introduzione dell'OT Status negli anni '90. Il datore di lavoro decide di aderire solo per beneficiare dei servizi, dell'azione di lobby e di altre strutture. Il contratto collettivo di settore non vincolerà quel datore di lavoro.

L'OT Status è diffuso in tutti i settori produttivi, attraendo particolarmente le PMI.

I rischi di questo status sono evidenti. Riguardano il contratto collettivo settoriale e le finalità delle organizzazioni datoriali (Stephen \& Schroeder, 2007).

La diffusione dell'OT Status ha comportato il venir meno nel tempo della rilevanza dei contratti settoriali (Addison, Bryson, Teixeira, Pahnke, \& Bellmann, 2010). Anzi il sistema di relazioni industriali presenta una serie di instabilità per la divisione che è venuta a crearsi tra settori produttivi (Hassel, 2010). Vi sono alcuni settori ove il contratto collettivo mantiene una propria capacità regolativa; in altri settori questo sta velocemente perdendo ogni collegamento con le realtà decentrate/locali. Sono questi i settori che vedono sfuggire il lavoro verso il subappalto o altre forme di esternalizzazione (Addison, Bryson, Teixeira, Pahnke, \& Bellmann, 2010).

Il rischio dell'OT Status è collegato anche alle funzioni dell'associazionismo imprenditoriale. Viene meno la rappresentatività degli interessi, riducendosi notevolmente il numero degli aderenti a status pieno. Viene meno anche I'insieme delle prerogative e dei compiti di queste organizzazioni che diventano sempre più strumenti lobbistici.

All'interno di questa dinamica esiste, però, anche un tentativo di rilanciare il contratto collettivo settoriale. I datori di lavoro hanno interesse a mantenere un contratto collettivo settoriale con capacità regolativa coordinata con contratti aziendali aperti a deroghe o ad altre forme di deregolazione controllata. Questo 
è il fenomeno di "trasformazione senza distruzione" che alcuni studiosi hanno analizzato con valutazioni positive (Streeck \& Thelen, 2005).

b. Consiglio di fabbrica e diritto di co-determinazione. II potere di veto nella contrattazione aziendale di deroga. La regola del favor (Günstigkeitsprinzip)

Il consiglio di fabbrica - Betriebsrat - è istituito in ogni azienda con almeno cinque lavoratori. I componenti del consiglio di fabbrica sono eletti. Elettorato attivo e elettorato passivo coincidono. Viene fissato il principio di buona fede per la cooperazione tra consiglio di fabbrica e datore di lavoro (artt. 2 e 74 del Betriebsverfassungsgesetz) nonché l'obbligo di informazione a carico del datore di lavoro (art. 81 della medesima normativa) con una serie di prerogative del consiglio di fabbrica che si realizzano in attività di audit/ispezioni o incontri.

La norma più importante è l'art. 87 del Betriebsverfassungsgesetz, ove si stabilisce il diritto di co-determinazione che il consiglio di fabbrica può esercitare in ogni momento con riferimento alle materie seguenti:

\section{Materie}

Condotte dei lavoratori e codice disciplinare

Orario di lavoro

Riduzione orario di lavoro

Tempo e luogo del pagamento della retribuzione

Monitoraggio e vigilanza sui lavoratori

Aspettative, congedi

Coordinamento per sicurezza sul lavoro

Impostazione di forme di previdenza/assistenza privata aziendale

Gestione di appartamenti aziendali da locare

Retribuzione (metodi)

Bonus o perfomance plan

Organizzazione del lavoro

Performance di gruppi di lavoratori. Piani e gestione 
Il consiglio di fabbrica può negoziare su queste materie e su altre che siano oggetto di delega specifica da parte della contrattazione settoriale. Il consiglio di fabbrica esercita di fatto un potere di veto su ciascuna materia, decidendo di volta in volta se e come accettare le controproposte datoriali.

Qualora non si raggiunga un'intesa su un certo tema, la vicenda viene posta nelle mani di arbitri, il cui lodo è inoppugnabile. Si tratta di una commissione (Einigungsstelle) i cui componenti sono nominati dal consiglio di fabbrica e dal datore di lavoro; il presidente, se non vi è accordo tra le parti, è indicato dal tribunale del luogo.

I poteri/diritti del consiglio di fabbrica possono essere rappresentati nel modo seguente:

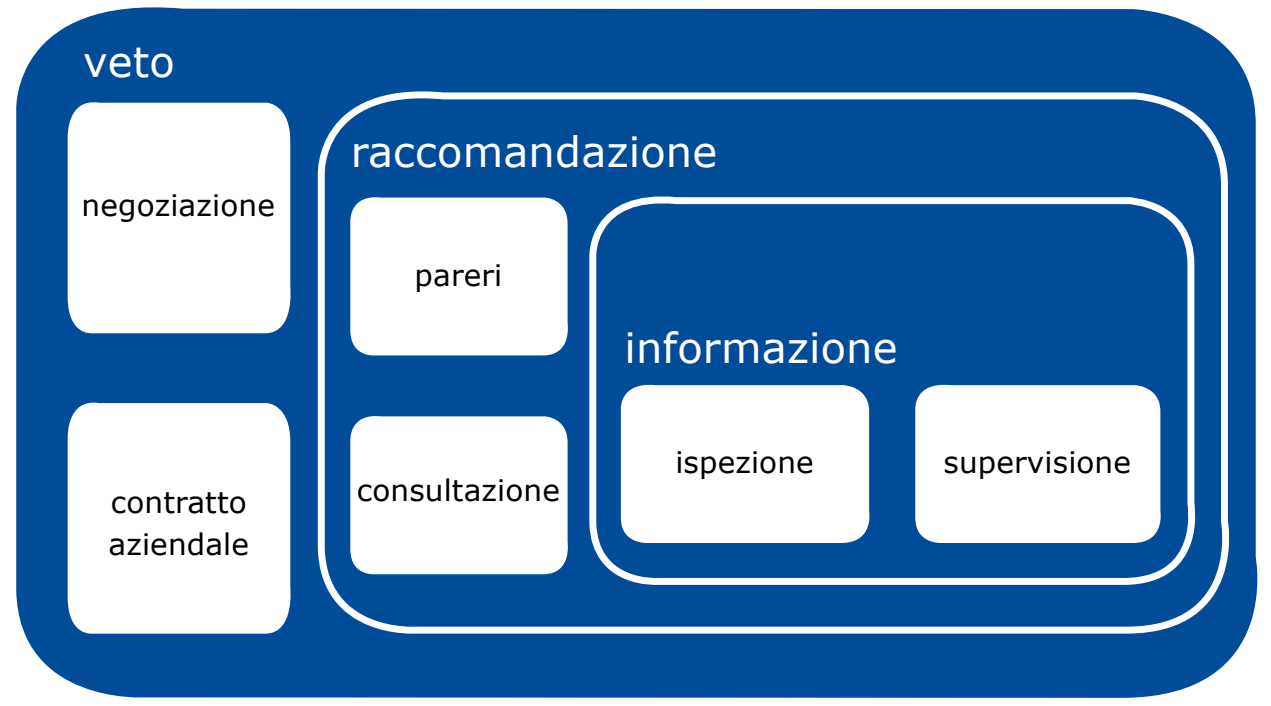

Tali poteri/diritti sono strutturati dalla legge in relazione alla tempistica, al contenuto e alle finalità. Ad esempio il diritto di ispezione riguarda un certo di tipo di documentazione e viene svolto periodicamente. Il potere/diritto di consultazione riguarda alcune materie, tra cui il licenziamento individuale. La mancata consultazione con il consiglio di fabbrica sulle ragioni oggettive/soggettive del licenziamento lo rende nullo.

Il contratto collettivo aziendale, concluso con il consiglio di fabbrica nell'ambito nelle materie ex art. 87 , è vincolante per tutti lavoratori.

L'incremento di questa contrattazione collettiva aziendale con il consiglio di fabbrica ha fatto ritenere a alcuni che vi è nel sistema tedesco una inclinazione verso "a new and clearly more segmentalist logic, involving trade-offs and compromises in which managers secure cost-saving concessions on working times and some aspects of company-level pay packages in exchange for increased job security" (Palier \& Thelen, 2010). 
Questa c.d. logica segmentale o di scambio, la quale deriva dall'impegno datoriale di ottenere concessioni dal consiglio di fabbrica, ha però il merito di garantire una continuità della produttività aziendale.

Altri hanno segnalato una disintegrazione verticale e una disorganizzazione del sistema delle relazioni industriali che viene causata da "two ways that this can undermine co-ordinated bargaining. First, vertical disintegration may allow managers to move jobs from a well-organized core to a more poorly organized periphery of firms that have no collective agreements or that are covered by firm-level agreements. Alternatively, it may result in a shift of work to new sectorial agreements, typically negotiated by different unions. Under both scenarios, new strategies to segment work across firm boundaries contribute to increased variation in wages and working conditions in a sector and make it more difficult for unions and works councils to co-ordinate collective negotiations in the sector as a whole" (Doellgast \& Greer, 2007).

Ciò che è rilevante in questa dinamica sindacale è l'inversione della regola di maggior favore (Günstigkeitsprinzip).

Le materie dell'art. 87 elencate sopra muovono dall'assunto legislativo secondo cui tutto ciò che non è oggetto dell'art. 87 resta nelle mani della contrattazione di settore/nazionale, con l'obbligo per i soggetti della contrattazione decentrata/aziendale di non derogare in peius quanto stabilito nel contratto settoriale/nazionale (zu Gunsten des Arbeitnehmers, e pertanto - Günstigkeitsprinzip). Questa regola è stata pensata per reggere il sistema delle deroghe contrattuali: viene, dunque, attuata una divisione delle materie tra livelli di contrattazione (nazionale/aziendale), una divisione delle competenze tra soggetti della contrattazione (OOSS nazionali e consigli di fabbrica), con la conseguente indicazione della regola di favor.

Nei fatti è, però, accaduto che il trade off che i consigli di fabbrica hanno concordato con il datore di lavoro a livello aziendale ha avuto spesso come oggetto la riduzione del salario a fronte della protezione dell'occupazione (Thelen, 2009). Il rischio della disoccupazione in alcuni settori o in alcune aeree geografiche ha promosso comportamenti collusivi/cooperativi tra consiglio di fabbrica e datore di lavoro.

Il giudice del lavoro chiamato a decidere sul rispetto dell'applicabilità della regola del favor non ha esitato a considerare questi contratti aziendali in linea con il principio Günstigkeitsprinzip. Si trattava di contratti che, avendo salvato l'occupazione, anche a fronte di sacrifici che incidevano sul quantum della retribuzione, rispettavano il principio del favor.

Il sistema sindacale ha trovato, pertanto, una soluzione che "without any kind of major legislative fight or rewriting of the formal law - [what will have happened is that] a rule that was originally designed to shore up centralization would be converted into a potentially very powerful vehicle for decentralization" (Thelen, 2009). 


\section{c. Il decentramento regolato. Le clausole di apertura (Öffnungsklauseln) provengono "dall'interno del sistema"}

Legge e contratti collettivi settoriali non escludono il potere di negoziare clausole di apertura - Öffnungsklauseln, le quali nel sistema tedesco sono utilizzate per fronteggiare situazioni di crisi o situazioni di altro genere. Si tratta di una delle forme di decentramento regolata del sistema sindacale tedesco più usata. Essa è alternativa a forme di deviazione dalle protezioni standard che possono essere più o meno elusive delle norme di legge e di contratto (Hassel, 1999).

Il rapporto di gerarchia tra livelli di contrattazione collettiva (settoriale e aziendale) risulta così assai debole, lasciando lo spazio al sindacato che opera in azienda e/o al consiglio di fabbrica di concordare deroghe di vario genere.

Le clausole di apertura sono una "riforma dall'interno" della contrattazione nazionale, alternativa all'uscita delle imprese dal sistema contrattuale e a una deregolazione del mercato del lavoro (Hassel, 2010). Tuttavia esse "hanno permesso al sistema tedesco di contenere l'impatto della crisi e delle deroghe, ma non hanno impedito la erosione del sistema contrattuale, visibile nel calo della sindacalizzazione, nelle tendenze autonomistiche se non centrifughe dei consigli aziendali e nella tendenza a uscire tout court dal sistema di rappresentanza contrattuale di un numero consistenti di imprese, non frenate dalle concessioni negoziabili con il sindacato" (Treu, Le relazioni industriali nell'era della globalizzazione: gli accordi in deroga in Europa e la sfida ai sistemi contrattuali, 2011). Di qui si può pensare che esiste un orientamento del sistema tedesco verso il contratto collettivo settoriale necessariamente concatenato a contratti aziendali aperti a modifiche.

È il modo per evitare la disintegrazione verticale delle relazioni industriali, e dunque la caduta della negoziazione fuori dalle aree istituzionali sindacali. In questa ottica si deve notare che dal 2000 al 2008 l'incremento di imprese non vincolate a contratto collettivo di settore e senza consiglio di fabbrica è stato del $10 \%$ circa, il decremento delle imprese contestualmente vincolate a contratto collettivo e con consiglio di fabbrica è stato del 2\% (Addison, Bryson, Teixeira, Pahnke, \& Bellmann, 2010).

Tra i primi modelli di clausole di modifica/deroga vanno annoverate le clausole di ristrutturazione introdotte a metà anni '90 mediante accordi quadro, utilizzabili in quasi tutti i settori produttivi e collegate alle crisi cicliche, e le clausole di gestione della crisi o hardship clause (Härteklauseln), riferibili prevalentemente alle imprese della Germania dell'Est. Questo tipo di clausola riguarda imprese che affrontano una serie difficoltà economiche. La situazione che permette la negoziazione delle clausole di gestione della crisi deve essere adeguatamente documentata, tanto da permettere una valutazione sul futuro 
dell'impresa. Solo nel caso in cui vi siano concrete possibilità di rilancio dell'impresa si procede con misure contrattuali concessive/ablative ${ }^{9}$.

Alle clausole di ristrutturazione, le quali erano libere da vincoli e a-proceduralizzate, si affiancarono dal 2004 in poi, grazie all'accordo Pforzheim, le clausole di apertura.

Tali clausole, inserite in procedimenti sindacali, hanno come oggetto prestazioni e controprestazioni specifiche. Da una parte la flessibilità (di orario, di articolazione, di gestione, etc.) richiesta dal datore di lavoro, dall'altra la protezione/salvezza del lavoro o incrementi retributivi, con tutte le istanze poste a tutela dei lavoratori. Tali clausole non riguardano imprese in crisi: I'impresa è tenuta solo alla giustificazione del ricorso a tali clausole e non deve dimostrare i motivi di crisi né attuale né potenziale ${ }^{10}$. Nel 2005 sono state introdotte guidelines ministeriali per permettere agli attori sociali di seguire un modello informativo-consultivo più preciso, con il coinvolgimento dei diversi livelli territoriali delle organizzazioni sindacali e la creazione di un database per la raccolta dei contratti stipulati e delle relative deroghe.

Volendo fare sintesi del trade off che sta alla base delle clausole aperte, si possono così indicare gli oggetti specifici richiesti dal sindacato al datore di lavoro (Haipeter, 2011):

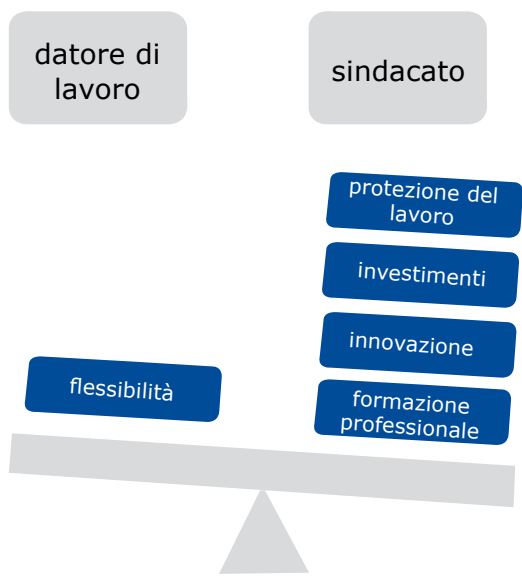

\footnotetext{
9 In questo senso, infatti, si afferma che "a firm must open its books completely to union representatives to demonstrate true need. As a rule, hardship clauses require both the employers association and the trade union with jurisdiction over the workplace in question to ratify any agreement reached by workplace management and the works council before it can go into effect. Firms that are only temporarily experiencing difficulties but are otherwise sound are the ones most likely to receive approval to use a hardship clause at one or more workplaces. In contrast, the collective bargaining parties usually do not approve contractual abrogations for firms that are performing so badly that even temporary cuts in compensation will not save them, because propping up hopeless enterprises can force other companies on the margins out of business" (Stephen S. \& Schroeder W., 2007).

10 Il contratto collettivo permette la deroga che riguarda prevalentemente "flexibility in weekly working time, or temporary reductions in wages and benefits either for new hires to promote employment or for the whole workforce to avoid layoffs. Opening clauses may also be used to permit practices such as performance-based pay and lower compensation scales for small enterprises" (Stephen S. \& Schroeder W., 2007).
} 
La flessibilità negoziata con le clausole di aperura attiene in prevalenza all'orario di lavoro, alle deroghe temporanee per crisi economica, alla riduzione del salario (anche dei minimi tabellari in caso di PMI) o al differimento del pagamento del salario.

Nel caso di orario di lavoro vengono introdotti conti individuali o definiti incrementi per lavoro straordinario (si v. Parte Speciale).

\section{d. Osservazioni conclusive. Il perché della tenuta sistemica del modello tedesco}

Alcuni studiosi hanno pronosticato fin dagli anni '90 la fine del modello tedesco (Flecker \& Schulten, 1999; Kapstein, 1996; Katz \& Darbishire, 1999; Mahnkopf \& Altvater, 1995; Martin \& Ross, 1999).

Secondo questa tesi il modello tedesco di contrattazione collettiva centralizzata, introdotto negli anni '70 per moderare le spinte inflazionistiche, e i livelli di inoccupazione in tendenziale crescita avrebbero determinano la crisi del sistema tedesco.

Le rigidità contrattuali che avevano retto tale sistema sarebbero venute meno con l'impatto della globalizzazione economica e con la necessità di introdurre forme contrattali decentrate e flessibili per permettere una competizione delle imprese tedesche nella dinamica transnazionale.

Tuttavia osservando i dati sulla contrattazione collettiva e cogliendo le innovazioni che il sistema tedesco di relazioni industriali ha saputo darsi appare più condivisibile la tesi di coloro che negano la prospettiiva di crisi del modello (Thelen, 2009).

È certamente prudente l'impostazione di coloro che hanno notato che "nothing much has changed in terms of the formal structure of negotiations, which are still conducted at the multi-industrial level and by unions that in the meantime-through mergers-have actually become more encompassing than they were before [...] there have indeed been some rather consequential changes in bargaining, even if these changes have not taken the form of a formal decentralization, let alone a complete breakdown of traditional institutions" (Thelen, 2009).

Questa prospettiva conferma che il profilo istituzionale del sistema tedesco di relazioni industriali (comprensivo della dinamica che riguarda la sindacalizzazione, la contrattazione collettiva, i diritti/poteri di concertazione/informazione, l'applicazione del contratto collettivo) riesce a resistere alle dinamiche della globalizzazione economica. La tendenza a una ridotta applicazione del contratto collettivo è prevalentemente connessa a settori più permeabili all'informalità e alla destrutturazione (servizi, commercio, etc.).

Il rischio che si può correre nel medio-lungo periodo è relativo a un certo dualismo nell'applicazione delle protezioni offerte dalla contrattazione collet- 
tiva (Thelen, 2009). Quel rischio, tuttavia, è insito in qualsiasi sistema di relazioni industriali. Esso dipende dalla diversa capacità dei soggetti istituzionali di offrire risposte alla ineludibile dinamica di concorrenza internazionale in cui le imprese si vengono a trovare.

Per questa ragione, analizzando il sistema tedesco, si deve prendere in considerazione la struttura formale della contrattazione con i segnali direttamente provenienti dalla azione sindacale, tra cui il basso livello di sindacalizzazione e la ridotta applicazione del contratto collettivo.

Ciò significa che il contesto delle relazioni industriali tedesco presenta per il momento una gamma ampia di scelte che vengono operate dai sindacati (contratto collettivo - livelli - derogabilità), o dai consigli di fabbrica (art. 87), o dalle organizzazioni datoriali (OT Status) o dal datore di lavoro (OT Status - art. 87 - regola del maggior favore). Questa ampia gamma permette le risposte di cui l'assetto industriale tedesco necessita di volta in volta nell'attuale situazione economica. 


\section{Sezione seconda}

\section{Contenuti specifici. Negoziare la flessibilità in azienda}

\section{Orario di lavoro}

Nel sistema francese il collegamento tra flessibilità e atteggiamento cooperativo (o, come già segnalato da alcuni, micro-corporativista) del sindacato è importante per comprendere il regime dell'orario di lavoro negoziato, anche in via di deroga, a livello aziendale. In un assetto come quello francese il rischio che la pressione concorrenziale sia scaricata direttamente sulle singole aziende è relativamente alto. Da questo snodo passa la recente riforma del sistema di relazioni industriali del 2008 (v. sopra Sezione B - Analisi comparativa - Parte generale) che, essendo stata programmata per facilitare simultaneamente flessibilità delle protezioni e decentramento contrattuale, promuove forme di negoziazioni aziendali volte alla ri-articolazione o riduzione dell'orario di lavoro. La quantità di contratti aziendali dipende in larga misura dalla legislazione di favore per i regimi flessibili dell'orario di lavoro (Howell \& Givan, 2011). Nella generalità dei casi si è fatto riferimento allo strumento della ratifica/approvazione successiva all'azione del lavoratore con mandato ad hoc delle organizzazioni sindacali (Howell, 2009). La flessibilità dell'orario di lavoro resta sotto il controllo esterno dell'ispettorato del lavoro.

La legislazione francese sull'orario di lavoro ha determinato una significativa spaccatura fra relazioni industriali attuata da una parte dalle grandi imprese e dall'altra dalle PMI (Palier \& Thelen, 2010). Nelle grandi imprese la capacità di negoziazione sull'orario di lavoro si è tradotta in maggiore produttività, in maggiore salario, e in una migliore combinazione vita-lavoro. Nelle PMI, invece, "working arrangements and conditions have deteriorated and external flexibility has increased. Thus, while high-skill and white-collar workers were able to translate working-time reduction into much appreciated improvements in work and life quality, lower paid and less skilled workers suffered income losses, more variable schedules, and intensified work" (Palier \& Thelen, 2010).

Dalle statistiche DARES risulta che nel periodo 2002-2010 il ricorso al lavoro straordinario nel settore dell'energia è aumentato di circa 4 punti percentuali (con riferimento all'ultimo trimestre T di ogni anno la serie è $\mathbf{8 , 0 7 \%}$ nel T4-2002, 7,89\% nel T4-2003, 8,26\% nel T4-2004, 9,09\% nel T4-2005, 9,05\% nel T4-2006, 9,57\% nel T4-2007, 10,96\% nel T4-2008, 12,09\% nel T4-2009, 12,88\% nel T4-2010). 
Il grafico che segue rappresenta la situazione:

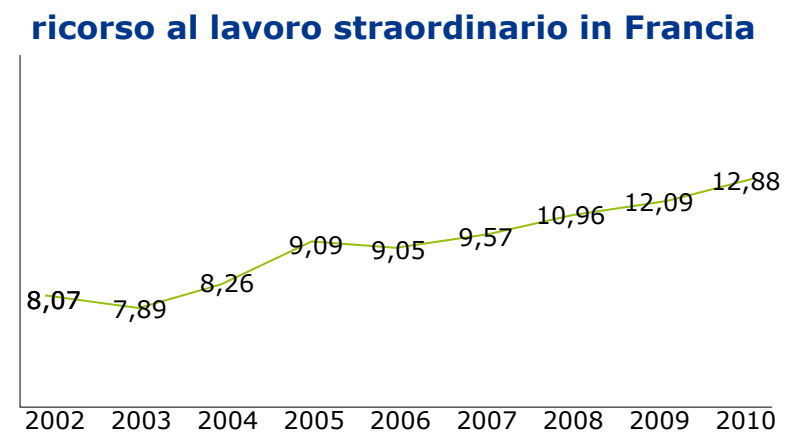

Sui dati aggregati dell'orario di lavoro in Francia si può vedere lo schema che segue:

\begin{tabular}{|c|c|c|c|c|c|c|c|c|c|}
\hline & & Ion-salar & $\begin{array}{l}\text { urée hebdon } \\
\text { s }\end{array}$ & ladaire $\mathrm{mc}$ & $\begin{array}{l}\text { enne du } \\
\text { Salarié }\end{array}$ & avail des ac & ifs en emp & semble a & \\
\hline & $\begin{array}{l}\text { Temps } \\
\text { complet }\end{array}$ & $\begin{array}{l}\text { Temps } \\
\text { partiel }\end{array}$ & Ensemble & $\begin{array}{l}\text { Temps } \\
\text { complet }\end{array}$ & $\begin{array}{l}\text { Temps } \\
\text { partiel }\end{array}$ & Ensemble & $\begin{array}{l}\text { Temps } \\
\text { complet }\end{array}$ & $\begin{array}{l}\text { Temps } \\
\text { partiel }\end{array}$ & Ensemble \\
\hline 1990 & 54,6 & 22,5 & 51,0 & 39,6 & 21,8 & 37,5 & 41,2 & 21,9 & 38,9 \\
\hline 1991 & 55,0 & 22,6 & 51,4 & 39,7 & 22,1 & 37,6 & 41,4 & 22,1 & 39,1 \\
\hline 1992 & 54,1 & 22,7 & 50,5 & 39,7 & 22,1 & 37,4 & 41,3 & 22,1 & 38,8 \\
\hline 1993 & 54,6 & 23,7 & 51,0 & 39,8 & 22,2 & 37,3 & 41,4 & 22,4 & 38,7 \\
\hline 1994 & 54,6 & 22,7 & 50,8 & 39,9 & 22,4 & 37,1 & 41,4 & 22,4 & 38,6 \\
\hline 1995 & 54,4 & 23,3 & 50,5 & 39,9 & 22,6 & 37,0 & 41,3 & 22,7 & 38,4 \\
\hline 1996 & 54,3 & 23,4 & 50,5 & 39,9 & 22,7 & 36,9 & 41,2 & 22,7 & 38,2 \\
\hline 1997 & 54,7 & 22,7 & 50,8 & 39,8 & 22,6 & 36,7 & 41,1 & 22,6 & 37,9 \\
\hline 1998 & 54,6 & 22,9 & 50,6 & 39,7 & 22,9 & 36,6 & 41,0 & 22,9 & 37,8 \\
\hline 1999 & 54,7 & 22,9 & 50,6 & 39,6 & 22,9 & 36,5 & 40,9 & 22,9 & 37,7 \\
\hline 2000 & 54,7 & 22,9 & 51,0 & 38,9 & 23,1 & 36,1 & 40,2 & 23,1 & 37,2 \\
\hline 2001 & 54,6 & 23,0 & 51,0 & 38,3 & 23,3 & 35,7 & 39,6 & 23,3 & 36,8 \\
\hline 2002 & 54,3 & 23,7 & 50,8 & 37,7 & 23,0 & 35,2 & 38,9 & 23,1 & 36,3 \\
\hline 2003 & 54,3 & 25,0 & 51,8 & 38,8 & 23,3 & 36,2 & 40,8 & 23,4 & 38,0 \\
\hline 2004 & 54,5 & 23,6 & 51,6 & 38,9 & 23,0 & 36,2 & 40,8 & 23,1 & 37,9 \\
\hline 2005 & 55,1 & 23,6 & 51,9 & 39,1 & 23,2 & 36,3 & 41,0 & 23,2 & 38,0 \\
\hline 2006 & 54,8 & 22,5 & 51,6 & 39,1 & 23,3 & 36,3 & 41,1 & 23,2 & 38,1 \\
\hline 2007 & 54,6 & 22,0 & 51,4 & 39,2 & 23,4 & 36,4 & 41,1 & 23,4 & 38,1 \\
\hline 2008 & 54,0 & 22,9 & 50,8 & 39,3 & 23,4 & 36,6 & 41,0 & 23,3 & 38,1 \\
\hline 2009 & 53,5 & 22,6 & 50,2 & 39,4 & 23,1 & 36,5 & 41,1 & 23,1 & 38,0 \\
\hline
\end{tabular}

Champ : France métropolitaine, population des ménages, personnes de 15 ans ou plus ayant un emploi.

Lecture : En 2009, la durée hebdomadaire moyenne du travail des salariés à temps complet a été de 39,4 heures.

Source : Insee, Enquêtes Emploi annuelles 1990-2002 ; Enquêtes Emploi en continu 2003-2009. 
I dati sul lavoro effettivo per anno su base individuale sono riportati di seguito:

\begin{tabular}{|l|c|c|c|c|c|c|c|c|c|}
\hline & \multicolumn{5}{|c|}{ Durée annuelle effective du travail des actifs en emploi } \\
\cline { 2 - 12 } & \multicolumn{3}{|c|}{ Non-salariés } & \multicolumn{3}{c|}{ Salariés } & \multicolumn{3}{c|}{ Ensemble actifs } \\
\hline & $\begin{array}{c}\text { Temps } \\
\text { complet }\end{array}$ & $\begin{array}{c}\text { Temps } \\
\text { partiel }\end{array}$ & Ensemble & $\begin{array}{c}\text { Temps } \\
\text { complet }\end{array}$ & $\begin{array}{c}\text { Temps } \\
\text { partiel }\end{array}$ & Ensemble & $\begin{array}{c}\text { Temps } \\
\text { complet }\end{array}$ & $\begin{array}{c}\text { Temps } \\
\text { partiel }\end{array}$ & Ensemble \\
\hline $\mathbf{2 0 0 3}$ & 2518 & 1059 & 2375 & 1620 & 956 & 1504 & $\mathbf{1 7 3 1}$ & $\mathbf{9 6 3}$ & $\mathbf{1 6 0 4}$ \\
\hline $\mathbf{2 0 0 4}$ & 2534 & 1056 & 2378 & 1631 & 973 & 1516 & $\mathbf{1 7 3 6}$ & $\mathbf{9 7 8}$ & $\mathbf{1 6 0 9}$ \\
\hline $\mathbf{2 0 0 5}$ & 2562 & 1040 & 2393 & 1661 & 984 & 1540 & $\mathbf{1 7 6 6}$ & $\mathbf{9 8 8}$ & $\mathbf{1 6 3 2}$ \\
\hline $\mathbf{2 0 0 6}$ & 2555 & 1035 & 2392 & 1660 & 991 & 1540 & $\mathbf{1 7 7 0}$ & $\mathbf{9 9 4}$ & $\mathbf{1 6 3 6}$ \\
\hline $\mathbf{2 0 0 7}$ & 2548 & 991 & 2384 & 1658 & 990 & 1537 & $\mathbf{1 7 6 4}$ & $\mathbf{9 9 0}$ & $\mathbf{1 6 3 0}$ \\
\hline $\mathbf{2 0 0 8}$ & 2495 & 1023 & 2332 & 1673 & 985 & 1551 & $\mathbf{1 7 6 6}$ & $\mathbf{9 8 7}$ & $\mathbf{1 6 3 4}$ \\
\hline $\mathbf{2 0 0 9}$ & 2440 & 1001 & 2278 & 1640 & 961 & 1517 & $\mathbf{1 7 3 4}$ & $\mathbf{9 6 4}$ & $\mathbf{1 6 0 1}$ \\
\hline
\end{tabular}

Champ : France métropolitaine, population des ménages, personnes de 15 ans ou plus ayant un emploi.

Lecture : En 2009, les salariés à temps complet ont, sur une base annuelle, travaillé 1640 heures.

Source : Insee, Enquêtes Emploi en continu 2003-2009

Questi dati consentono di svolgere alcune riflessioni sui diversi schemi flessibilità concordati in azienda. Tra questi si segnala il Compte épargne temps ("CET").

Il CET è un conto-ore che permette al lavoratore di scegliere, a fronte di ferie non godute/lavoro straordinario, tra sospensione del lavoro con retribuzione o liquidazione di un importo/indennità per equivalente. Il lavoratore è I'unico titolare di tale diritto di scelta.

Il contratto collettivo aziendale stabilisce i criteri di funzionamento del CET. In particolare, il contratto collettivo aziendale dispone in materia di (i) limiti e quantità del lavoro straordinario utile per il conto ore, (ii) modalità di gestione del CET, (iii) modalità di liquidazione dell'importo corrispondente alle ore accumulate, (iv) la durata delle sospensioni equivalenti.

Il quadro normativo è stato recentemente rinnovato ed è crescente l'attenzione delle parti sociali su tale istituto anche al fine di promuoverne l'introduzione nelle negoziazioni aziendali.

La garanzia sul montante corrispondente al conto-ore individuale è prestata da soggetti qualificati (enti bilaterali, società di mutuo soccorso, banche, assicurazioni, etc.). L'ispettorato del lavoro verifica le caratteristiche del soggetto qualificato e del contratto di garanzia.

In caso di cessazione del rapporto di lavoro, si può ottenere l'indennità per equivalente o chiedere la trasferibilità a un organismo speciale (Casse des dépots et consignations). Con un meccanismo articolato (il c.d. déblocage des droits consignés) il lavoratore potrà trasferire la posizione finanziaria derivante dal conto individuale a altri piani di rispar- 
mio aziendale (il PEE - plan d'épargne d'enterprise o il PERCO - plan d'épargne pour la retraite collectif - v. di seguito).

Se il lavoratore non chiede la liquidazione del conto-ore sino alla pensione di vecchiaia avrà diritto a benefici contributivi e fiscali ${ }^{11}$.

\section{(i). Case study: Polimeri Europa France}

Lo studio del caso specifico ha permesso di verificare che l'assetto dell'orario di lavoro aziendale è stato oggetto di intese modificative (Accord sur la réduction du temps de travail del 22.12.1999, sottoscritto da CFTC, CGC, CGT, FO - di seguito "A-1999"; Accord sur la réduction du temps de travail del 5.1.2000, sottoscritto da CGC - di seguito "A-2000"). A tali accordi si aggiunge il Reglement de l'horaire individualisé del 2.2.2000 (di seguito "R-2000").

Dal $1^{\circ}$ gennaio 2000, in forza dell'A-1999, I'orario settimanale è passato da 36,75 ore (36h45min) a 34,75 ore (34h15min). Per i dirigenti e i quadri, in forza dell'A-2000, I'orario settimanale è passato da 37,50 ore (37h30min) a 35 ore.

L'impatto della riduzione di orario in entrambi i casi è stato totalmente compensato/ assorbito dalle retribuzioni esistenti e da eventuali incrementi futuri (art. 9 dell'A-1999, art. 6 dell'A-2000).

Nell'A-1999 si conviene anche un meccanismo di consultazione obbligatoria del personale, a scrutinio segreto, per la gestione di alcuni cicli di lavoro, con i relativi turni (art. 3).

Il sistema dei turni è stato oggetto di consultazione e negoziazione sindacale nel 2009. Il sistema dei turni avendo un impatto sulle mansioni dei lavoratori occupati, sulla funzione del capoturno e della relativa squadra nonché potenzialmente sull'occupabilità di nuovi lavoratori è divenuto nel tempo un tema di significativo confronto tra le parti.

La gestione del lavoro straordinario è definita nel modo che segue:

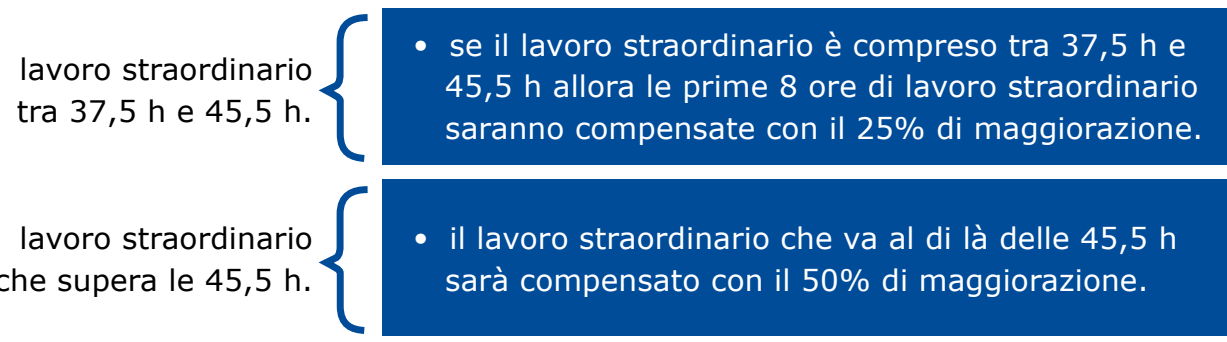

11 Il sistema di sgravi fiscali e contributivi è volto a incentivare il lavoratore a mantenere la posizione presso il CET. In particolare, analizzando le norme del codice di sicurezza sociale (L. 911-1) e del codice sulle imposte (art. 83), il regime applicato è composto da una deduzione fiscale, entro determinati limiti, e dalla esclusione dalla base imponibile ai fini contributivi, entro determinati limiti, dell'importo versato al CET. 
In termini esemplificativi si può proporre la schematizzazione che l'A-1999 riporta:

\begin{tabular}{|l|l|l|l|}
\hline $\begin{array}{l}\text { Orario effettivo } \\
\text { settimanale }\end{array}$ & $41,5 \mathrm{~h}$ & $44,5 \mathrm{~h}$ & $46,5 \mathrm{~h}$ \\
\hline Lavoro straordinario & $4 \mathrm{~h}$ & $7 \mathrm{~h}$ & $9 \mathrm{~h}$ \\
\hline Maggiorazione & $\begin{array}{l}4 \mathrm{~h} \text { (ore effettuate) }+1 \mathrm{~h} \\
\text { (maggiorazione 25\%) }\end{array}$ & $\begin{array}{l}7 \mathrm{~h} \text { (ore effettuate) }+1,75 \mathrm{~h} \\
\text { (maggiorazione 25\%) }\end{array}$ & $\begin{array}{l}9 \mathrm{~h} \text { (ore effettuate) }+2 \mathrm{~h} \\
\text { (maggiorazione 25\%) } \\
+0,5 \mathrm{~h} \text { (maggiorazione } \\
50 \% \text { su 1 h) }\end{array}$ \\
\hline
\end{tabular}

È stato introdotto, mediante il R-2000, I'orario individualizzato, il quale prevede un regime di flessibilità di ingresso in azienda nei limiti di fasce orarie predefinite (7:00$9: 30 ; 11: 45-14: 00 ; 16: 00-19: 00)$. Viene, inoltre, data la possibilità al lavoratore di scegliere periodicamente (su base annuale) tra regime fisso e regime flessibile.

Nel sistema tedesco, il potere di veto del consiglio di fabbrica permette una definizione flessibile dell'orario di lavoro non comparabile con quella analizzata nel modello francese. Si è di fronte a una flessibilità del tempo di lavoro costruita su più livelli, multidimensionale e riguardante la durata e l'allocazione delle ore di lavoro (Berg, 2008).

La prassi gestionale è variegata: dalla banca-ore alla programmazione settimanale o annuale, dalla conciliazione tempi di vita-tempi di lavoro ai modelli di rendicontazione delle ore lavorate, dallo straordinario non retribuito agli schemi alternativi di recupero.

Il ricorso al lavoro straordinario in Germania era relativamente basso all'inizio degli anni 2000 scorso (dati EIRO):

\begin{tabular}{|c|c|c|c|c|}
\hline \multicolumn{5}{|c|}{ Extent of overtime working, 2001} \\
\hline Country & $\begin{array}{l}\text { Average hours } \\
\text { of overtime per } \\
\text { employee }\end{array}$ & $\begin{array}{l}\text { Overtime as \% of } \\
\text { total volume of } \\
\text { hours worked }\end{array}$ & $\begin{array}{l}\% \text { of wage-ear- } \\
\text { ning population } \\
\text { doing overtime }\end{array}$ & Notes \\
\hline Austria & - & - & 26.5 & $\begin{array}{l}\text { Figure includes } \\
\text { part-timers and all } \\
\text { additional hours. }\end{array}$ \\
\hline Denmark & - & - & 13.8 & $\begin{array}{l}\text { Figure includes all } \\
\text { additional hours. }\end{array}$ \\
\hline Finland & - & 8.4 & - & - \\
\hline France & 55 per year & - & 48 & $\begin{array}{l}\text { Figures refer only } \\
\text { to full-time workers } \\
\text { and companies with } \\
\text { over } 20 \text { employees, } \\
\text { based on declara- } \\
\text { tions by employers. }\end{array}$ \\
\hline Germany & 61.5 per year & 3.6 & - & $\begin{array}{l}\text { Figures from Insti- } \\
\text { tute for Employ- } \\
\text { ment Research } \\
\text { (Institut für Arbei- } \\
\text { tsmarkt- und Be- } \\
\text { rufsforschung, IAB). }\end{array}$ \\
\hline Greece & 32.9 per year & - & - & $\begin{array}{l}\text { Figures from La- } \\
\text { bour Inspectorate } \\
\text { (SEPE). }\end{array}$ \\
\hline
\end{tabular}


Da una recente ricerca dell'Istituto IAB (Zapf \& Brehmer, 2010) si evince che il ricorso al lavoro straordinario in Germania è aumentato nel biennio 2008-2009 per contrastare la fase peggiore della crisi economica.

Lo IAB ha verificato che nel biennio 2008-2009 i conti-ore, sotto forma di banca ore e contii individualizzati, hanno subito una diminuzione significativa: dalle 72 ore (in media) del 2008 si è passati alle 27 ore (in media) nell'autunno del 2009.

Il settore manifatturiero è stato particolarmente interessato da questo fenomeno.

Le banche ore (o conti individuali) permettono al datore di lavoro di ridurre o incrementare il ricorso al lavoro straordinario. Superata una certa soglia di ore, i lavoratori lavorano più o meno ore di quelle accordate collettivamente, ottenendo sul conto individuale crediti/debiti di ore. Esiste un limite temporale entro il quale il conto deve ritornare in "pareggio" (12-24 mesi). I crediti di ore vengono compensati con ferie, congedi, anticipazione dell'accesso a pensione, o in mediante salario.

I lavoratori riescono a delineare un proprio modello di combinazione tempi di vita-tempi di lavoro, facendo ricorso al conto individuale. Il ricorso al lavoro flessibili (lavoro a termine, ecc.) viene a ridursi notevolmente in ragione della flessibilità di orario così congegnata, con profili di stabilizzazione dell'occupazione esistente (Schnabel, 2011). In particolare alcuni studi hanno dimostrato che i lavoratori in eccedenza durante la crisi non sono stati oggetto di licenziamento anche per questo meccanismo di flessibilità organizzativa dell'orario di lavoro (Schnabel, 2011). Tra le misure che hanno accompagnato questa flessibilità vi sono la riduzione dell'orario settimanale, la riduzione degli straordinari, la riduzione del salario (clausole di apertura).

Nel modello gestionale tedesco la flessibilità interna è privilegiata rispetto a quella esterna (v. Conclusioni).

\section{(ii). Case study: Eni Germany}

Gli accordi studiati permettono di osservare due potenziali aree di intervento: (i) la definizione dell'orario standard settimanale e (ii) il Langezeitkonto.

Orario di lavoro. Nel settore chimico l'orario normale settimanale è fissato in 39 ore, con la possibilità di raggiungere, senza superare, 45 ore.

L'orario settimanale può variare mediante un contratto aziendale stipulato con il consiglio di fabbrica. I contratti analizzati mostrano una valutazione del lavoro straordinario su certo lasso di tempo (3/6 mesi), con l'introduzione del lavoro nel week end. Tuttavia i contratti settoriali stabiliscono un limite massimo annuo di lavoro straordinario. 
La clausola aperta del contratto aziendale ha stabilito che a fronte di una riduzione dell'orario di lavoro vi sia una riduzione della retribuzione con l'impegno alla stabilità occupazionale (no layoffs clause).

È interessante anche richiamare il regime del Langezeitkonto. Con un fondo-patrimonio separato viene raccolto un montante virtuale di ore di lavoro straordinario o ferie non godute.

Quel montante può essere liquidato al lavoratore con sospensioni della prestazioni di lavoro equivalenti (congedi, ferie, ecc.), con accesso alla pensione in via anticipata, 0 in danaro. Ciascun lavoratore ha un conto individuale, con diritto alla portabilità presso altro fondo-patrimonio in caso di dimissioni/licenziamento. Esiste una protezione speciale in caso di insolvenza del datore di lavoro. La partecipazione è volontaria.

\section{Reazione alla crisi di impresa - Programmi di Short-Time Work (STW)}

Nel sistema francese i programmi di riduzione dell'orario - Short Time Work (STW) rientrano negli schemi di sostegno al reddito in caso di crisi dell'impresa (Chomage Partiel).

Il meccanismo di STW è stato definito con accordi interconfederali (1968, 2008, 2009). Viene negoziata, in ragione della crisi/ristrutturazione di impresa, una riduzione dell'orario di lavoro. Il sistema pubblico di sicurezza sociale interviene con un sostegno al reddito a integrazione totale o parziale. I lavoratori sono tenuti a seguire corsi di formazione nel periodo di non lavoro.

La prestazione di sostegno al reddito è la combinazione di due schemi. Quello pubblico, con anticipazione del datore di lavoro, è pari al 60\% dell'importo minimo per ora lavorata; quello privato è erogato sulla base della misura definita dai contratti collettivi dal datore di lavoro, il quale potrà ottenere un finanziamento statale parziale.

Le ore che possono essere oggetto di questo schema sono 800 per anno (600 sino al 2008, 1000 per alcuni settori dal 2009). Il lavoratore deve aver ricevuto un salario medio settimanale superiore 18 volte il minimo tabellare/per ore lavorate e almeno 600 ore/lavoro di copertura contributiva. Non rientrano nello schema i lavori flessibili (lavoro a termine, lavoro somministrato, ecc.).

\section{(i). Case study: Polimeri Europa France}

Nel caso Polimeri Europa France il STW è connesso a una temporanea riduzione delle attività derivante da crisi economica, o da crisi energetica, o da situazioni climatiche eccezionali, o da riorganizzazione aziendale. 
Il procedimento di consultazione e informazione si evince dalla documentazione analizzata. Dalle interviste effettuate è stato dedotto che non vi sia stato un ricorso, almeno recentemente, a questo strumento nella Polimeri Europa France. Il procedimento di consultazione/informazione è svolto tra impresa e rappresentanza sindacale (comitato aziendale) mediante una serie di riunioni. In caso di mancato accordo viene chiesto al giudice di intervenire (procedimento di urgenza). Il provvedimento giudiziale, volto a dirimere il contrasto sui presupposti del STW, è immediatamente esecutivo. In caso di accordo, invece, il comitato aziendale propone richiesta formale del STW alla Direzione dipartimentale del ministero del lavoro. Il limite delle ore inseribili nel programma di STW è di 600 per anno. Il datore di lavoro nel settore chimico anticipa il $75 \%$ del salario lordo mensile; successivamente compensato dal sistema di welfare.

Nel sistema tedesco i programmi di riduzione dell'orario - STW sono riducibili al modello più importante: il Kurzarbeit.

Il Kurzarbeit è stato ritenuto lo strumento più adatto a fronteggiare la crisi dell'occupazione nell'attuale fase economica (Burda \& Hunt, 2011). Anzi è stato affermato che la Germania ha attraversato la crisi (e continua a farlo) senza impatti eccessivi sull'occupazione in ragione del Kurzarbeit. Si coglie che "Germany's jobs miracle hasn't received much attention in this country - but it's real, it's striking (...) Germany came into the Great Recession with strong employment protection legislation. This has been supplemented with a -short-time work schemell, which provides subsidies to employers who reduce workers' hours rather than laying them off. These measures didn't prevent a nasty recession, but Germany got through the recession with remarkably few job losses" (Krugman, 2009).

In realtà studi più approfonditi dimostrano che il numero dei lavoratori coinvolti in questi programmi in Italia, Germania e Giappone in questa fase di crisi è tra il 2,5 e il 5\%. Da ciò si deduce che questi programmi abbiano avuto una incidenza sul mantenimento dell'occupazione e dell'occupazione già specializzata solo perché incastonati in assetti più ampi di reazione alla crisi, tra cui la sicurezza sociale, i programmi di formazione professionale, la contrattazione decentrata con funzione derogatoria, ecc. (Boeri \& Bruecker, 2011). È stato, infatti, notato che "if macroeconomic conditions do not improve, STW may well turn out to be much less effective in containing job losses" (Boeri \& Bruecker, 2011).

Il modello di funzionamento è relativamente semplice. Le aziende comunicano ai servizi per l'impiego federali il ricorso allo SWT. Le ragioni del ricorso allo schema sono ricollegabili alla crisi/ristrutturazione aziendale, anche ciclica (la crisi deve riguardare almeno $1 / 3$ dei dipendenti e deve incidere per almeno il $10 \%$ sul salario lordo). I lavoratori sono tenuti a seguire corsi di formazione e ricevono una prestazione di sostegno al reddito. Non vi sono limitazioni relative al tipo di contratto di lavoro assoggettabile allo schema.

L'accordo con il consiglio di fabbrica viene sottoposto al servizio per l'impiego federale, 
il quale verifica i presupposti. Il diritto di co-determinazione che il consiglio di fabbrica può esercitare incide anche sul numero di ore da ridurre.

Il programma di riduzione oraria non supera i 6 mesi, ma vi è la possibilità di prorogare in casi eccezionali il limite sino a 12-24 mesi.

La prestazione previdenziale - che può arrivare sino al $60 \%$ del salario netto precedente - è proporzionale alle ore di lavoro ridotte.

Le imprese tedesche sono incentivate a far ricorso dello STW in attesa della ripresa economica. È uno strumento costoso ma non ha ripercussioni sugli aggiustamenti strutturali per il disincentivo all'utilizzo prolungato (Bruecker, 2011).

Il quadro macro che è stato studiato presenta questi numeri (Bruecker, 2011):

\section{1,31 milioni di lavoratori in STW nel 2009}

\section{- 2,4 milioni di posti di lavoro mantenuti nel 2009}

\section{riduzione delle ore lavorate}

\section{- 55\% pre-recessione; 34\% nel 2010}

Questi studi dimostrano che "il numero dei posti di lavoro salvati equivale al numero dei posti di lavoro full-time equivalenti in STW. In altri termini, non c'è perdita secca" (Boeri \& Bruecker, 2011; Bruecker, 2011). Questi programmi, dunque, sostengono l'aggiustamento dell'occupazione. Si tratta di un aggiustamento che avviene "al margine intensivo delle ore lavorative per le imprese che subiscono shock negativi" (Bruecker, 2011). In termini esemplificativi, il programma STW permette all'azienda di mantenere per un certo periodo una occupazione stabile e re-inseribile nel sistema produttivo non appena possibile ${ }^{12}$.

12 Questa indicazione deve essere inserita in un contesto di valutazioni più ampio. In particolare alcuni hanno rilevato che "the rationale for STW is that firms are more likely to adjust the number of workers rather than the working hours in case of temporary shocks to demand" (Boeri \& Bruecker, 2011). Questo punto è interessante perché mette in evidenza il limite dei programmi STW: si tratta di una evidente inefficienza dei programmi STW (ridurre posti di lavoro più che ridurre ore di lavoro). Le esternalità derivanti dai vantaggi fiscali e contributivi fanno ritenere che l'intervento statale non sempre sia utile, anzi "these costs could be also internalized if bargaining is decentralized and work sharing agreements exist". A ciò si aggiunge che un uso prolungato dei programmi STW "may prevent the enjoyment of productivity gains resulting from workers reallocation from less to more productive jobs". Di fronte a queste criticità si deve notare che molto dipende dal modo in cui i programmi STW sono costruiti e gestiti. La domanda per programmi STW è bassa nei paesi che hanno una più consistente forma di flexicurity ("displaying less strict employment protection and generous unemployment benefits") e un livello di decentramento contrattuale più articolato (Boeri \& Bruecker, 2011). I programmi STW debbono essere rivolti a crisi macroeconomiche, molto serie, con il coinvolgimento contributivo significativamente elevato del datore di lavoro per evitare situazioni di moral hazard (è il tema che Boer \& Bruecker, 2011 sollevano sul sistema tedesco di STW, affermando quanto importante sia nel programma STW tedesco l'elevato contributo datoriale e il rigoroso metodo di selezione degli accessi a questo schema previdenziale - "at the same time, high costs for employers reduce take-up rates and may end-up increasing the tax burden on firms just at a time where they need to be encouraged to hire more. One possible way out of this problem is to let average contribution rates to increase during upturns allowing to accumulate a surplus of the fund which could then be used to finance a reduction in contribution rates during downturns. Moral hazard problems are also likely to be less important during a recession, when most firms have to reduce the labour input"). 


\section{Sistema partecipativo}

\section{(i). Partecipazione alla gestione}

Nel sistema francese il quadro della rappresentanza sindacale in azienda è stato schematizzato in questo modo:

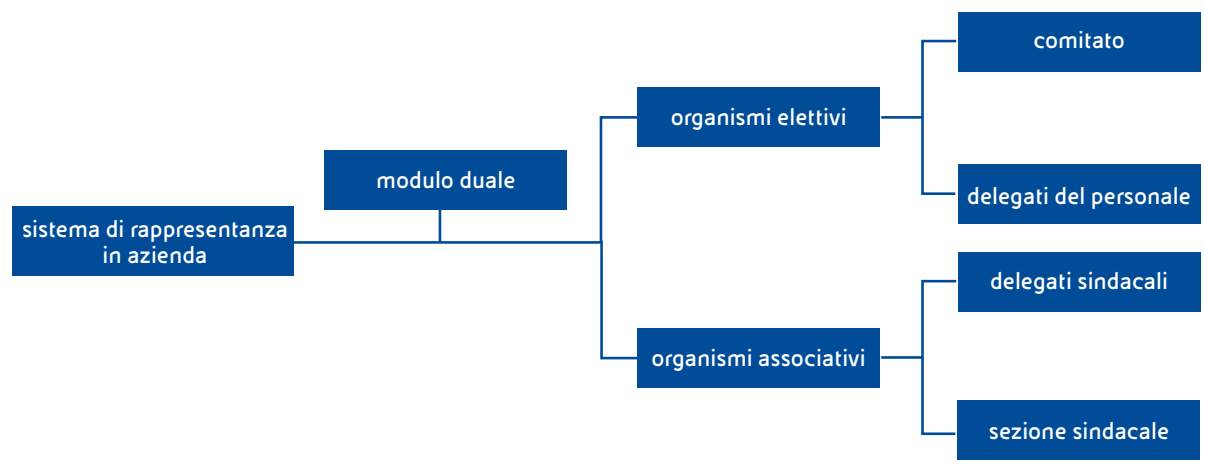

Il delegato del personale viene eletto in azienda con più di 10 lavoratori. Egli è responsabile dell'applicazione della legislazione e della contrattazione collettiva.

Il comitato aziendale viene eletto in aziende con almeno 50 lavoratori. Esercita i diritti di informazione e consultazione.

Il delegato sindacale deve ricevere almeno il $10 \%$ dei voti espressi al primo turno delle elezioni del comitato aziendale o dei delegati del personale.

I sindacati che hanno costituito una sezione sindacale in azienda con più di 50 lavoratori, i quali non dovessero rispondere ai requisiti di rappresentatività, pur non potendo designare un delegato sindacale, possono designare un rappresentante sindacale. In aziende con meno di 50 lavoratori, ove non è possibile designare un delegato sindacale, la contrattazione collettiva viene svolta da lavoratori ai quali viene conferito un mandato ad hoc da un'organizzazione sindacale a livello nazionale. 
La tabella riporta la proporzione tra delegati e numero dei lavoratori (fonte ETUI).

\begin{tabular}{|c|c|}
\hline Number of employees & Number of employee delegates \\
\hline $11-25$ & 1 \\
\hline $26-74$ & 2 \\
\hline $75-99$ & 3 \\
\hline $100-124$ & 4 \\
\hline $125-174$ & 5 \\
\hline $175-249$ & 6 \\
\hline $250-499$ & 7 \\
\hline $500-749$ & 8 \\
\hline $750-1,000$ & 9 \\
\hline
\end{tabular}

La tabella riporta la proporzione tra numero dei componenti del comitato e numero dei lavoratori (fonte ETUC).

\begin{tabular}{|c|c|}
\hline Number of employees & Number of works council delegates \\
\hline $50-74$ & 3 \\
\hline $75-99$ & 4 \\
\hline $100-399$ & 5 \\
\hline $400-749$ & 6 \\
\hline $750-999$ & 7 \\
\hline \multicolumn{2}{|c|}{$\begin{array}{l}\text { Thereafter the number of delegates increases by one for each extra } 1,000 \text { employees until } 5,000 \text {, then } \\
\text { by one extra delegate for each } 2,500 \text {. The maximum number of delegates, with } 10,000 \\
\text { or more employees, is } 15 .\end{array}$} \\
\hline
\end{tabular}

Nel sistema tedesco il modello di rappresentanza dei lavoratori in azienda può essere rappresentato nel modo che segue:

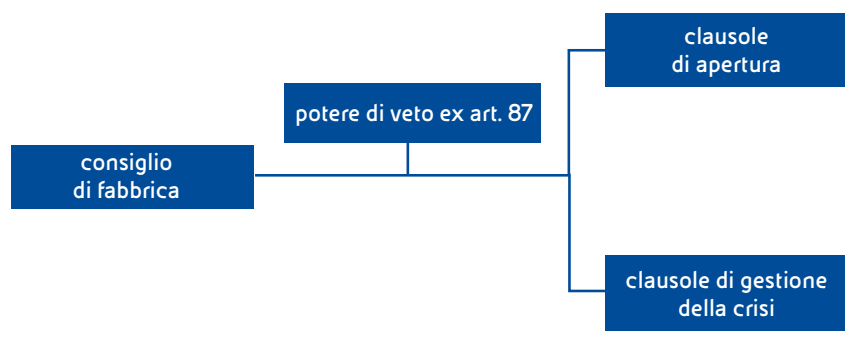

Il Betriebsrat/consiglio di fabbrica è un istituto di partecipazione sindacale alla gestione dell'impresa. I diritti di informazione e consultazione sono definiti nella legislazione sin dagli 
anni '50. Il diritto di veto posto dal consiglio di fabbrica si traduce in una co-determinazione dei profili organizzativi aziendali più rilevanti.

I componenti del consiglio di fabbrica sono protetti da ogni forma di discriminazione sindacale e dal licenziamento, il quale può essere comunicato solo previo consenso del consiglio di fabbrica. L'azienda sostiene i costi del consiglio di fabbrica. Tra questi costi rientrano quelli di gestione del consiglio e di formazione dei componenti. Il diritto alla sospensione del lavoro (congedo/aspettativa/permessi) per motivi sindacali è esercitato dai componenti del consiglio di fabbrica. Sussiste il diritto di utilizzo dei locali aziendali per le riunioni e le assemblee.

La composizione dei consigli di fabbrica, in parte determinata da elezioni e in parte da indicazione sindacale, è la seguente:

\begin{tabular}{|c|c|}
\hline Number employed & Number of works council members \\
\hline $5-20$ & 1 \\
\hline $21-50$ & 3 \\
\hline $101-100$ & 5 \\
\hline $201-400$ & 7 \\
\hline $401-700$ & 9 \\
\hline $701-1,000$ & 11 \\
\hline $1,000-1,500$ & 13 \\
\hline
\end{tabular}

Esistono circa 97.000 consigli di fabbrica in Germania. Il consiglio di fabbrica è presente nel $10 \%$ delle aziende con più di 5 lavoratori e nel $90 \%$ di aziende con più di 500 lavoratori. Il $45 \%$ di lavoratori nella Germania ovest e il 38\% nella Germania Est è in aziende con il consiglio di fabbrica (dati EIRO 2009 e IAB 2010).

\begin{tabular}{|l|l|c|c|c|c|c|c|}
\hline \multicolumn{7}{|c|}{ Aziende con consiglio di fabbrica con riferimento al numero dei lavoratori } \\
(tasso di presenza)
\end{tabular}

Note: Based on establishments in the private sector with at least 5 employees. 
I temi che sono oggetto dei procedimenti di informazione e consultazione del consiglio di fabbrica sono stati elencati nella Parte generale. Da stime dell'EIRO/IAB del 2007 risulta quanto segue:

Temi oggetto delle contrattazioni con il consiglio di fabbrica (in \%)

\begin{tabular}{|c|l|}
\hline Orario di lavoro & 58,4 \\
\hline Straordinario & 46,6 \\
\hline Benefits & 44,1 \\
\hline Sicurezza & 37,5 \\
\hline Retribuzione & 35 \\
\hline Formazione & 34,9 \\
\hline Piani aziendali & 34 \\
\hline Inquadramento & 29,8 \\
\hline Flessibilità & 28 \\
\hline
\end{tabular}

Note: Based on establishments with 20 and more employees and a works council, survey conducted in the fourth quarter of 2007.

Si è altresì accertato che il consiglio di fabbrica tende a incontrarsi in media almeno due volte al mese con il management aziendale (dati WSI del 2005). Per il Cologne Institute for Economic Research nel 1999 lo $0,1 \%$ delle liti tra consiglio di fabbrica e azienda è stato oggetto di arbitrato e lo 0,3\% oggetto di contenzioso giudiziale.

(ii). Partecipazione finanziaria/retribuzione incentivante

Nel sistema francese possiamo distinguere almeno quattro modelli di partecipazione finanziaria/retribuzione incentivante:

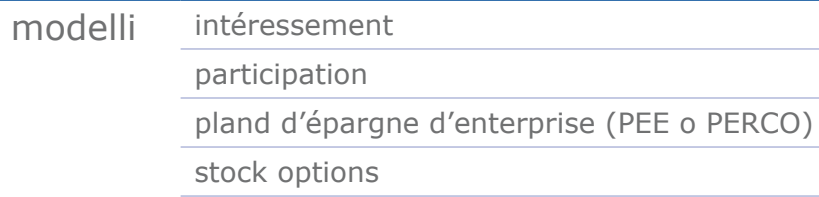

L'intéressement è una forma di partecipazione finanziaria dei lavoratori ai risultati economici dell'impresa. Essa è basata su formule matematiche che permettono di definire periodicamente il quantum da versare al lavoratore. Mediante contratto collettivo aziendale, ratificato dai lavoratori, successivamente comunicato alle articolazioni territoriali del ministero del lavoro, si stabilisce il regime dell'intéressement. Il datore di lavoro può anche applicare direttamente il regime già definito del contratto di branche. Il contratto aziendale viene rinnovato periodicamente, anche per comportamento concludente. La retribuzione così ottenuta è soggetta a sgravi fiscali e contributivi. Per questa ragione è fatto divieto di erogare importi che superino la metà del platfond annuale dei contributi sociali. Nel caso 


\section{Polimeri Europa France (v. Accord d'interessement lié aux resultats de l'enterprise}

- années 2009, 2010, 2011 del 4.6.09) questa forma di partecipazione finanziaria parrebbe volta anche premiare l'affidabilità, che è da intendersi come concetto più ampio della produttività e più attinente alla sostenibilità economico-ambientale dell'impianto industriale.

La participation è una forma di partecipazione finanziaria, attuata con contratto collettivo aziendale, da datori di lavoro con almeno 50 lavoratori alle proprie dipendenze. La riserva speciale per la participation è costituita in base agli utili netti realizzati dall'impresa. L'importo da erogare a ciascun lavoratore non può superare i $2 / 3$ del platfond annuale di contribuzione sociale. L'insieme degli importi resta bloccato per un certo periodo (nel caso Polimeri Europa France per 5 anni) e viene investito secondo le norme di legge mediante investitori istituzionali. Gli importi erogati, salvo non siano anticipati per ragioni speciali (tra cui malattia, matrimonio, ecc.), sono integralmente esentati dalla base imponibile fiscale e contributiva.

Il PEE (plan d'éepargne d'enterprise) permette al lavoratore di costituire, anche mediante contribuzione a carico dell'azienda, un portfolio di valori mobiliari. I contributi versati al piano sono bloccati per ameno 5 anni. Verso il PEE possono confluire, su richiesta del lavoratore, importi derivanti dall'interessanza e dalla partecipazione.

II PERCO (plan d'épargne pour le retrait collectif) è una forma di previdenza complementare, con adesione libera del lavoratore e contribuzione dell'azienda.

Questi quattro schemi di partecipazione sono impostati, attivati e regolati mediante contrattazione collettiva (branche e/o aziendale).

Il regime contributivo di favore applicato ai quattro schemi di partecipazione è il seguente (le informazioni sono tratte dal sito del ministero del lavoro - www.travailemploi-sante.gouv.fr) ${ }^{13}$ :

\section{Esonero dalla base imponibile ai fini contributivi in caso di (i) PARTICIPATION, (ii) INTERESSEMENT, (iii) PEE e PEI, (iv) PERCO}

(i) esonero/forfait del $6 \%$ dal 1.1 .11

(ii) esonero/forfait del $6 \%$ dal 1.1 .11

(iii) esonero/forfait del $6 \%$ dal 1.1 .11

(iv) esonero/forfait del $6 \%$ dal 1.1 .11

e contribuzione specifia dell' $8,2 \%$ per

frazioni di importo eccedenti 2.300 Euro (i) esonero parziale

(ii) esonero parziale

(iii) esonero parziale

(iv) esonero parziale

13 Anche il regime fiscale è finalizzato a determinare una serie di vantaggi, tra cui l'esonero dalla base imponibile o la deduzione di quanto versato. 
Con riferimento al sistema tedesco, recenti studi hanno dimostrato che esistono differenze importanti nella definizione delle quote di retribuzione incentivante tra lavoratori in imprese con consiglio di fabbrica e lavoratori in imprese senza consiglio di fabbrica in Germania.

\section{I lavoratori in imprese con consiglio di fabbrica sono garantiti con "higher wages, higher skills, higher tenure, and lower wage dispersion" (Addison,} Teixeira \& Zwick, 2010).

Nel marzo 2011 la BAVC (associazione imprenditoriale chimici) e la IG BCE (sindacato chimici) ha stipulato un contratto collettivo settoriale con un aumento salariale del $4,1 \%$ in 14 mesi, con clausole di flessibilità salariale, obblighi di formazione professionale e misure di supporto alle PMI del settore. Il contratto collettivo vincola 550.000 lavoratori e 1.900 imprese. L'incremento salariale può essere posposto mediante accordo aziendale con il consiglio di fabbrica.

\section{Conflitto e clausole di tregua}

Dall'analisi dei giorni di sciopero in un anno in Germania, Francia e Italia si può comprendere quanto segue (dati EIRO):

\section{Germania \\ 5,62 giorni}

Italia

47,3 giorni

\section{Francia}

122,91 giorni

Riflettendo su queste cifre, il caso francese è certamente un laboratorio molto interessante. Nel caso Polimeri Europa France si è avuto modo di analizzare accordi con clausole di tregua (tra questi v. I'Accordo del 3.6.2003, sottoscritto da CFDT, CFTC, CGT - di seguito "A-2003").

Il Tribunale di Dunkerque aveva ordinato di rimuovere i picchetti, dopo circa tre mesi di conflitto e rivendicazioni. Anche con I'ausilio di un mediatore, proveniente dal dipartimento locale del ministero del lavoro, le parti hanno sottoscritto un contratto collettivo aziendale contenente i seguenti due gruppi di clausole:

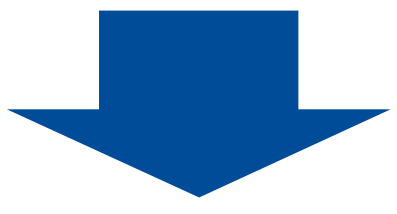

clausola di tregua

retribuzione

fissa/incentivante

(incrementi e aumenti)

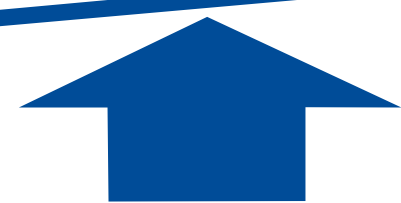


L'art. 6 dell'A-2003 stabilisce il regime di tregua (Mesures de fin de conflit). In sostanza, la fine del conflitto e la ripresa del lavoro condizionano l'applicazione delle clausole migliorative della retribuzione contenute nel contratto collettivo aziendale sottoscritto.

Non esiste un accordo o una procedura endoaziandale sulle prestazioni minime garantite in caso di sciopero. Per prassi si individuano le figure professionali (chi e quanti) debbono garantire la tenuta dell'impianto industriale.

\section{Lotta all'assenteismo}

Il problema dell'assenteismo, inteso come pratica elusiva o abusiva delle sospensioni del rapporto di lavoro, dovute a malattia o altre ipotesi determinate da legge o contratto collettivo, appare del tutto marginale nei due sistemi studiati.

Esistono prassi aziendali che, mediante il coinvolgimento attivo delle rappresentanze sindacali o del personale, determinano interlocuzioni privilegiate su assenze, congedi, ferie, malattie. Mediante questi rapporti, in caso di elusione o abuso delle posizioni collegate a malattie, congedi, ecc., si riesce a dissuadere dal comportamento non corretto.

Il periodo di carenza (waiting period) in Germania, in caso di malattia, non sussiste. Vi sono 78 settimane di prestazione previdenziale a favore del lavoratore in malattia.

Il periodo di carenza in Francia, in caso di malattia, è pari a 3 giorni. La CPAM (istituto di previdenza) può erogare l'indennità di malattia sino a 3 anni. 


\section{Conclusioni}

a cura di Tiziano Treu

Le pagine precedenti hanno analizzato le diverse risposte dei due sistemi di relazioni industriali alle sfide poste dalle trasformazioni economico-sociali e le variabili rilevanti: quelle del contesto istituzionale, le politiche pubbliche e le norme legislative, la struttura contrattuale, i caratteri e le strategie degli attori sociali. Entrambi i paesi hanno dimostrato una significativa capacità di adattamento, che hanno fatto leva sulle risorse del sistema e con risultati diversi per i due attori sociali ${ }^{14}$.

I caratteri del modello tedesco hanno permesso al sistema contrattuale di mantenere una relativa stabilità e capacità di regolazione dei rapporti di lavoro nell'impresa, nonostante le pressioni competitive abbiano ridotto la copertura della contrattazione nazionale e provocato ripiegamenti e concessioni negoziali.

Le reazioni delle relazioni industriali francesi a queste pressioni hanno risentito della debolezza e divisione dei sindacati, oltre che della fragilità della struttura contrattuale, di interventi diffusi del potere pubblico e di una legislazione non sempre pro labor.

Nello specifico ci sembrano particolarmente significative le risposte dei due sistemi rispetto a tre grandi questioni con cui si sono confrontati negli ultimi anni le relazioni industriali di tutti i paesi europei e che sono rilevanti per l'evoluzione anche delle nostre relazioni industriali, soprattutto aziendali.

Il decentramento contrattuale, le sue modalità e i mutati rapporti fra contrattazione nazionale e contratti aziendali.

La regolazione e la gestione delle flessibilità nei vari aspetti dei rapporti di lavoro in azienda: in particolare orari, organizzazione del lavoro, mobilità professionale.

Gli orientamenti fondamentali delle relazioni di lavoro, in particolare riguardo alle logiche della contrattazione collettiva rispetto al conflitto e alle forme e prassi partecipative ${ }^{15}$.

Una delle tendenze preminenti, in larga parte comune alle moderne relazioni industriali, è quella verso il decentramento, che ha investito in misura maggiore e minore tutti i sistemi europei, compresi quelli a struttura contrattuale tradizionalmente più centralizzati. Tale tendenza è apparsa già negli anni ' 80 , con le spinte alla negoziazione relativa alla riduzione degli orari di lavoro e agli orari flessibili; si è estesa poi ad altri contenuti del rapporto fino agli aspetti retributivi. I motivi addotti a fondamento di questa tendenza non sono contin-

14 Gli studi comparati danno crescente importanza alla capacità di adattamento delle relazioni industriali ma differiscono nelle valutazioni delle modalità e dell'impatto conseguente. Alla visione tradizionalmente prevalente nelle teorie istituzionaliste, secondo cui il cambiamento delle istituzioni sarebbe nel complesso limitato e incrementale e manterrebbe quindi le tradizionali differenze fra le varianti nazionali (delle relazioni industriali), si contrappongono, ma con sfumature diverse, altre analisi che enfatizzano la discontinuità, sottolineando che il cambiamento incrementale tende a diventare trasformativo (Howell \& Givan, 2011).

15 Le analisi comparate presentano valutazioni diverse circa il grado di convergenza o divergenza delle soluzioni offerte dai diversi paesi a questi problemi, secondo Howell- Givan, nonostante la diversità delle forme e dei meccanismi di cambiamento istituzionale, il grado di convergenza dei principali paesi europei su questi temi sarebbe maggiore di quanto sia comunemente ritenuto. Più articolata la posizione di Visser (Visser, 2004). 
genti, ma riguardano le determinanti strutturali del sistema, in particolare la diversificazione dei sistemi produttivi, dei mercati del lavoro e della composizione della manodopera indotta dalle innovazioni tecnologiche e organizzative, che rendono meno praticabili forme regolatorie standardizzate per interi settori. L' accresciuta competizione internazionale ha enfatizzato la stessa tendenza, perché ha ridotto la funzione storica dei contratti nazionali di togliere le condizioni di lavoro dalla concorrenza fra le diverse imprese nazionali.

La globalizzazione e la crisi hanno modificato anche la tendenza storica per cui le fasi basse del ciclo favoriscono la centralizzazione contrattuale. Tali tendenze sono state sostenute in passato per l'esigenza, condivisa dagli imprenditori, di controllare centralmente le dinamiche salariali, in un contesto inflazionistico. A fronte delle pressioni competitive questa preoccupazione degli imprenditori cede il passo all'esigenza di ridurre l'incidenza degli istituti, non solo salariali ma soprattutto organizzativi e normativi, che ostacolano le flessibilità e le innovazioni produttive necessarie a rispondere alle mutevoli richieste dei mercati internazionali e ai fattori di qualità e affidabilità soprattutto in periodi di difficoltà di crescita (Cella \& Treu, 2009).

È significativo il mutamento di indirizzo emerso anche in sede europea, ove si è sottolineata la necessità di collegare le dinamiche retributive non più solo o tanto all'andamento dell'inflazione e all'obiettivo di tutelare il potere d'acquisto, quanto all'andamento della produttività: il che enfatizza ulteriormente l'esigenza di valorizzare gli strumenti di flessibilità e competitività aziendale, in via contrattuale e di gestione manageriale, con particolare attenzione non solo alla competitività di prezzo ma alle questioni di qualità e affidabilità; sono tutti fattori company specific che richiedono relazioni industriali sensibili alle esigenze aziendali.

In realtà i sistemi a più livelli come quelli qui esaminati ${ }^{16}$ e quello italiano, risentono di spinte contrastanti. Da una parte la maggioranza degli imprenditori, specie quelli più piccoli e meno esposti alla concorrenza, mostra di apprezzare ancora la funzione stabilizzatrice del CCNL. Nello stesso tempo molte imprese, in particolare le più competitive, richiedono maggiore flessibilità e più spazi per regolarla direttamente a livello aziendale con il sindacato ${ }^{17}$.

Proprio per rispondere a queste pressioni si sono introdotte le clausole di deroga, via via diffusesi in quasi tutti i sistemi contrattuali europei. Questa è la risposta più rilevante, anche se non I'unica, che i sistemi europei strutturati in più livelli contrattuali hanno pre- 
disposto per conciliare le spinte al decentramento e alla diversificazione delle condizioni di lavoro con il mantenimento di un quadro di regole generali. Tali clausole sono alquanto differenziate sia per i contenuti sia per le condizioni di applicabilità: il che riflette la diversa incidenza delle pressioni competitive sulle singole imprese, più ancora che sui diversi settori, in corrispondenza con le specifiche condizioni produttive.

\section{Decentramento contrattuale. Better not cheaper}

Abbiamo visto come le modalità del decentramento, la sua regolazione e lo spazio della contrattazione aziendale rispetto al contratto nazionale siano differenziate nei due sistemi francese e tedesco. Inoltre all'interno del singolo sistema nazionale e categoriale ne viene fatto un uso diverso a seconda delle pressioni competitive sulle singole imprese.

In Francia la spinta al decentramento ha trovato appoggio e regolazione in sede legislativa già all'inizio degli anni '80 (legge Aroux) in concomitanza con le generali tendenze alla liberalizzazione dei mercati del lavoro e dell'economia. Il riconoscimento legislativo della legittimazione negoziale a istituzioni aziendali diverse dai sindacati ha contribuito ad aumentare l'autonomia del livello aziendale e a diffondere la contrattazione, ma non senza controindicazioni, in quanto ha sancito se non favorito la debolezza del sindacato (Howell \& Givan, 2011). In Francia, come si è visto, è la legge che ha definito il perimetro delle materie negoziabili in sede decentrata; essa ha influenzato gli orientamenti contrattuali, già allora sotto la spinta prevalente del datore di lavoro, dando diverso peso agli interessi delle parti e definendo le possibili aree di scambio, a seconda degli orientamenti governativi peraltro largamente convergenti sull'urgenza di dare risposte all'esigenza di flessibilità (Howell \& Givan, 2011).

In Germania la presenza di un sistema consolidato di contrattazione nazionale, sostenuto da una presenza sindacale diffusa anche attraverso i consigli di fabbrica e da una prassi tradizionale di "social partnership", ha permesso di governare dal centro le spinte al decentramento in via negoziale, attraverso clausole specifiche che hanno definito i possibili contenuti della contrattazione aziendale e i suoi rapporti con il contratto nazionale; come si vedrà gli andamenti sono peraltro diversi nel tempo e l'impatto sul sistema è ancora in parte indeterminato.

Ma un dato è comune: il decentramento più o meno accentuato del sistema contrattuale serve a liberare la dinamica della contrattazione aziendale affinché possa ricercare soluzioni innovative alla gestione dei rapporti di lavoro nell'impresa. Tali spazi d'azione negli ultimi anni sono stati utilizzati largamente dalle parti per affrontare momenti di difficoltà aziendale: ristrutturazioni e riposizionamenti fino a vere e proprie crisi produttive.

Sovente si sono tradotti in accordi di concessione, cioè peggiorativi delle condizioni economiche e di lavoro. Ma non sono questi necessariamente i contenuti degli accordi in deroga. In prospettiva anzi la sfida vera per simili intese è di facilitare scambi 
virtuosi, fuori dagli schemi tradizionali ma apportatori di esiti positivi per entrambe le parti: better not cheaper secondo la terminologia USA (Turner, 2009).

Esiti simili sono stati riscontrati nella ricerca, in particolare in aziende tedesche $e$ francesi facenti parte del Gruppo Eni, che hanno registrato andamenti produttivi ed economici mediamente positivi; e quindi hanno per lo più potuto evitare il ricorso ad accordi peggiorativi.

Analogamente è significativo al riguardo il recente accordo Eni Italia del 26 maggio 2011. Pur riconoscendo l'incertezza e la debolezza dell'economia, anche per il settore petrolchimico, in premessa l'impresa ritiene di impegnarsi in processi di razionalizzazione, di miglioramento del conto economico e di efficientamento nonché a intensificare le attività di ricerca e innovazione con i necessari investimenti.

Come si vede il Gruppo adotta un approccio proattivo e questo indica in relazioni industriali innovative e partecipative uno strumento per rispondere alle esigenze di efficienza aziendale.

Una tendenza rilevata non solo in questa ricerca, segnala che l'area di elezione della contrattazione aziendale, e un oggetto importante delle clausole di apertura, è costituita dalla gestione delle flessibilità riguardanti vari aspetti dell'organizzazione e dell'impiego del lavoro, a cominciare dagli orari di lavoro.

L'intervento sugli orari è diversificato, perché risponde sia all'esigenza di promuoverne la flessibilità sia alla necessità di aumentarne la durata (tramite per lo più il ricorso agli straordinari) in controtendenza rispetto a quanto avvenuto nei decenni passati. In Germania la tendenza è di tornare alle 40 ore dopo la riduzione a 35 degli anni ' 80 . Un contenuto frequente di questi accordi riguarda la definizione di periodi di orario ridotto, intesi a ridurre l'impatto occupazionale delle crisi con forme di compensazioni salariale a carico sia dei sistemi previdenziali, sul tipo della nostra Cig, sia delle parti datoriali. In questo come in altri casi, le clausole di apertura, anche se negoziate in sede bilaterale dalle parti contraenti, sono accompagnate da interventi mediatori e di sostegno del potere pubblico (quindi hanno carattere sostanzialmente trilaterale) e talora da programmi di riqualificazione professionale dei lavoratori interessati.

L'importanza di questi aspetti è tale che si è ritenuto che proprio la flessibilità interna, espressa nell'uso modulato degli orari di lavoro e in interventi mobilità e qualificazione professionale, costituisce un tratto caratterizzante del modello tedesco.

In realtà anche nel sistema francese la gestione flessibile degli orari è largamente prevista nella contrattazione aziendale fin dagli anni '80 (Howell, 2009). L'apertura su orari flessibili, in una varietà di forme (v. sopra) ha costituito una contropartita "offerta" agli 
imprenditori in cambio della riduzione dell'orario di lavoro. Per tale motivo è stata favorita dalla legge con riduzioni contributive: ma con la condizione che la flessibilità di orario vada negoziata a livello aziendale con rappresentanti dei lavoratori.

Questa prassi contrattuale decentrata nel sistema francese, come in quello italiano, si combina con una attenzione molto focalizzata a livello generale sugli aspetti della flessibilità, esterna o numerica: in particolare uso dei contratti non standard, in particolare a termine, modalità e costi del licenziamento.

Il tema, anche in quel paese, è oggetto di aspre controversie negli anni recenti, specie a fronte delle iniziative dei governi di centro destra. Si può riscontrare in questo fatto una sorta di divisione di ruoli. Nella dimensione nazionale l'enfasi e la contesa riguardano le regole della flessibilità numerica, mentre la contrattazione aziendale si è ampiamente dedicata ai vari aspetti della flessibilità interna, sia pure con le debolezze delle rappresentanze dei lavoratori in azienda, proprie del sistema francese (che lo distingue da quello tedesco).

È significativo che i recenti accordi interconfederali francesi, come quello del 2008, sulla modernizzazione del mercato e del rapporto di lavoro, si concentrano prevalentemente sulle dimensioni esterne della flessibilità, anche se non mancano misure relative alla formazione dei lavoratori ed alla GPEC (gestione previsionale delle crisi) rivolti ad aumentare la capacità di adattamento dei lavoratori alle variazioni delle condizioni di lavoro e dell'andamento dell'impresa. Sono invece ignorati temi quali appunto l'orario e l'organizzazione del lavoro. Tale omissione viene ricondotta al carattere potenzialmente conflittuale di questi temi, tale che le parti non avrebbero potuto controllarlo e d'altra parte alla volontà dei poteri pubblici di occuparsi direttamente della durata della prestazione di lavoro: così è stato ad es. per il sostegno legislativo al lavoro straordinario, in controtendenza con la tendenza alla riduzione dei tempi di lavoro caratteristico della stagione degli anni '90. La diversità di enfasi dei due livelli contrattuali è stata confermata anche nel nostro campo di analisi ove si sono registrati esempi significativi di accordi aziendali sulle flessibilità e modulazione dei tempi di lavoro ${ }^{18}$.

Il rapporto fra flessibilità interna ed esterna e il peso reciproco delle due e le modalità con cui sono gestite sono un elemento significativo della qualità delle relazioni industriali nell'impresa e assumono sostanzialmente una rilevanza generale di sistema. Un ampio ricorso alla flessibilità interna come avviene nel modello tedesco, contribuisce a valorizzare la qualità e la fedeltà del capitale umano nell'impresa e gli investimenti nella sua qualificazione e formazione continua, favorendo in generale la specializzazione delle imprese. Nel caso tedesco la sua diffusione nelle imprese ha contribuito a farle puntare su produzioni ad alto valore aggiunto.

18 Lo confermano, sia pure con minore nettezza che nel caso tedesco, i dati aggregati riguardanti il tempo di lavoro: il ricorso al part time, lo straordinario, la banca ore, il lavoro notturno e a turni. Si v. Sezione Seconda sopra. 
Nel sistema tedesco la regolazione e la gestione aziendale delle varie forme di flessibilità interna - come di altre materie attinenti ai rapporti di lavoro - è sottoposta per legge (il paragrafo 87 del BGB) a un controllo da parte della rappresentanza aziendale (il Betriebsrat) che si sostanzia in un potere di codecisione (e di veto). Questa condizione non è senza rilievo nei rapporti fra le parti, ma non è ritenuta ostativa alla adozione delle flessibilità necessarie da parte delle imprese.

Una simile valutazione è comune agli operatori di entrambe le parti e viene attribuita al profondo radicamento e all'uso responsabile del metodo partecipativo in quel paese, che lo indirizza alla soluzione condivisa dei problemi, senza intenti restrittivi o ostruzionistici.

Nel sistema francese i controlli su (molte di) queste materie sono affidati all'autorità pubblica, per lo più ispettori e direzioni del lavoro, secondo l'orientamento pubblicistico caratteristico di quel paese anche nella regolazione dei rapporti di lavoro.

Neppure qui peraltro i giudizi dei nostri interlocutori francesi hanno ritenuto che questo intervento esterno abbia impedito utili esperienze di flessibilità negoziata, di rilievo diverso in dipendenza degli orientamenti delle parti. Inoltre la gestione partecipata e a livello decentrato di questa forma di flessibilità costituisce un'ulteriore componente di quel modello partecipativo e ne rafforza l'efficacia ai fini della coesione e stabilità della comunità di impresa e della fedeltà dei lavoratori (Ciccarone \& Saltari, 2011).

Al contrario, il ricorso alla flessibilità esterna, specie nelle forme dell'uso diffuso di contratti brevi e atipici, come è avvenuto nelle recenti esperienze italiane, può contribuire a ridurre al margine i costi del lavoro; e in certi periodi a permettere la crescita occupazionale. Di converso può andare a scapito degli investimenti in formazione e qualificazione dei dipendenti e della produttività aziendale. Inoltre, il ricorso alle varie forme di contratto non standard, e la regolazione di queste, sono da anni oggetto di tensioni e di polemiche per gli effetti negativi sulla precarietà del lavoro e sulla qualità della vita, specie dei giovani.

Il confronto con queste diverse opzioni è una delle responsabilità maggiori della contrattazione aziendale. Lo è tanto più in quanto anche in Italia si è allargato lo spazio di libertà per questo livello contrattuale, a seguito degli accordi interconfederali del 2009 e del 2011. Le esperienze aziendali in materia presentano gradi diversi di innovazione. Non mancano quelle che hanno innovato anche in questa materia, puntando su una gestione e modulazione negoziata dei sistemi di orario e della flessibilità interna, come una strategia partecipata e consensuale, intesa a contemperare la necessità aziendale di rispondere alle variabili domande del mercato con il mantenimento di una ragionevole stabilità e sicurezza della manodopera. 


\section{Accordo Eni e contesto italiano}

È questa la strada indicata dall'accordo di Eni: l'intesa attribuisce alla gestione della flessibilità degli orari di lavoro una importanza primaria per la efficienza e la produttività aziendale. Altrettanto significativa è l'indicazione che l'orario flessibile deve essere strettamente connesso con i mutamenti del mercato e compatibile con le esigenze operative dell'impresa; ma che d'altra parte deve tenere conto della necessità di conciliazione fra tempo di lavoro e tempo di famiglia, con l'impegno ad approfondire "ulteriori iniziative legate al work life balance".

Nello specifico si prevede che tali orari possano prevedere un incremento della prestazione lavorativa del $4 \%$ in relazione a particolari situazioni legate alla variabilità del mercato, segnatamente per il personale turnista. Tale percentuale è tale da permettere margini di flessibilità in grado di rispondere alle esigenze di mercato a preferenze del ricorso a contratti brevi, come dimostrano anche altre esperienze aziendali recenti.

La gestione flessibile degli orari diventa parte del generale impianto partecipativo del protocollo; che si manifesta in altre clausole, relative alla gestione dell'assenteismo, alla formazione, alle variazioni degli assetti produttivi in caso di non pieno utilizzo della capacità degli impianti.

Il percorso partecipativo è regolato puntualmente a conferma della delicatezza del tema per ambedue le parti. L'obiettivo dichiarato è di strutturare un processo di condivisione più snello e veloce che preveda tempi certi e semplificati dei percorsi negoziali: tali da garantire che la fitta interlocuzione con il sindacato non pregiudichi la necessaria celerità delle decisioni aziendali.

È da segnalare che nella gran parte di queste esperienze, compresa quella di Eni, la variabilità degli orari è concordata nell'ambito delle regole del contratto nazionale e delle flessibilità ammesse, quindi senza la necessità di ricorrere a deroghe. Questo è un elemento di facilitazione delle intese fin qui raggiunte, date le controversie che hanno finora circondato in Italia I'ammissibilità delle deroghe.

L'intesa interconfederale siglata il 28 luglio ha dato alla materia una soluzione condivisa, sia pure di quadro. L'accordo dovrebbe facilitare forme innovative di orari flessibili con minori occasioni di tensione fra le parti.

Anche qui le indicazioni dei due ordinamenti francesi e tedesco sono significative, in quanto la materia delle flessibilità interne è tipicamente affidata alla valutazione delle parti aziendali e non incontra di norma limiti specifici nella contrattazione nazionale.

Nel caso dell'orario di lavoro restano fermi i limiti della legislazione, nazionale e 
comunitaria, che peraltro non sembrano avere ostacolato le parti nella conclusione di accordi rispondenti alle loro esigenze. Per altro verso la legislazione di quei paesi ha facilitato il ricorso a variazioni di orario legate a situazioni di crisi, del tipo ampiamente utilizzato in Italia con le varie normative sulla CIG. Nel caso tedesco la recente normativa sul Kurzarbeit è stata utilizzata, anche qui con metodo negoziale partecipato, al fine di assorbire lo shock della crisi senza traumatiche decisioni di licenziamenti collettivi, mantenendo nelle aziende le professionalità acquisite che si sono rivelate utili nel momento della ripresa.

Va notato peraltro che il ricorso al Kurzarbeit è stato rigorosamente contenuto nel tempo, a differenza di quanto avvenuto in Italia, e ha potuto essere superato nel tempo previsto dei 24 (48) mesi, a fronte della ripresa del sistema produttivo.

La contrattazione aziendale ha acquisito crescente importanza anche in materia retributiva. Nei paesi in esame, come in Italia, si è consolidata tradizionalmente una divisione di compiti fra i livelli contrattuali, in base alla quale la contrattazione nazionale mantiene la funzione di definire i salari di base, mentre alla contrattazione decentrata spetta di stabilire elementi retributivi variabili di carattere incentivante, in particolare legati a indicatori di produttività.

Nel periodo della crisi non sono mancate ipotesi in cui la contrattazione aziendale derogatoria di quei paesi ha riguardato anche i temi retributivi, con significative varianti: riduzione o soppressione di elementi accessori del salario, differimento di aumenti previsti dai contratti nazionali, vere e proprie riduzioni salariali, per lo più riferite ai lavoratori neo assunti e, per altro verso, aumento dei differenziali salariali, (in controtendenza con i precedenti).

La materia retributiva è invece esclusa dalle possibilità di accordi in deroga dal nostro contratto nazionale dei metalmeccanici (novembre 2010), non firmato dalla CGIL. Sembra invece ricompresa nell'ampia formula utilizzata dall'accordo interconfederale del 28 luglio 2011, ove la possibilità di tali accordi è riferita "a tutti gli istituti del contratto nazionale riguardanti la regolazione del rapporto di lavoro".

In Italia qualche ipotesi di intesa aziendale in deroga sul tema retributivo è riportata dalle ricerche: peraltro limitata per lo più al rinvio di aumenti retributivi stabiliti in sede nazionale. Le forme retributive incentivanti a premi si sono diffuse ampiamente nella contrattazione aziendale italiana, già dopo l'accordo del 1993; e la tendenza si è consolidata a seguito degli accordi confederali più recenti del 2009 e 2011 che attribuiscono alla contrattazione decentrata il compito di regolare la materia. La dinamica di queste forme di retribuzione incentivanti è determinata sulla base di indicatori diversi, spesso con modalità alquanto sofisticate, specie nelle aziende e i gruppi con relazioni industriali più sviluppate come il Gruppo Eni. 
Le tendenze prevalenti in Italia indicano peraltro che l'impegno in tal senso non si traduce in una grande incidenza dei premi retributivi né in una loro significativa variabilità in relazione agli andamenti degli indicatori previsti (v. Treu, 2010). La percentuale retributiva così distribuita per la generalità dei lavoratori non supera in media il 4-5\% e tende a diventare in larga parte fissa.

Tendenze simili si riscontrano anche in altri paesi. Va però rilevato che sia in Francia e sia in Germania la flessibilità delle retribuzioni si è manifestata non solo con il ricorso ai premi a incentivi ma anche a istituti di tipo più direttamente partecipativo, quali le varie forme di partecipazioni agli utili e all'azionariato delle società. Le origini e i contenuti di tali istituti sono diversi nei due paesi, ma sono ritenuti funzionali alla qualità partecipativa delle relazioni aziendali. Le ricerche attestano che la loro rilevanza a tale fine non può essere giudicata in astratto, ma dipende dai contenuti specifici: dalla loro incidenza quantitativa sul reddito dei lavoratori, dalle vicende aziendali cui sono correlati e dal nesso che hanno con il sistema del governo delle imprese. Questo è evidente in Germania ove fin dall'origine la partecipazione finanziaria dei lavoratori è stata concepita come parte del sistema partecipativo vigente nelle imprese di quel paese che, come si è visto, si esprime a livello di base, con ipotesi di codecisione dei consigli di azienda poi procede fino alla partecipazione di rappresentazione dei lavoratori nei consigli di gestione o di vigilanza delle società. Non sono pochi i casi di aziende tedesche di grande dimensione in cui la partecipazione azionaria dei lavoratori non si è limitata ad essere uno strumento di distribuzione del reddito correlato con l'andamento aziendale ma ha contribuito a determinare o a rafforzare la loro incidenza sul governo delle imprese (Volkswagen).

Questo carattere è prefigurato anche per l'Italia da alcuni dei disegni di legge sulla partecipazione in discussione al Parlamento. In tale materia l'accordo Eni non dà indicazioni ulteriori rispetto alle prassi esistenti e diffuse di contrattazione delle retribuzioni a premio. Ma la generale ispirazione partecipativa dell'intesa è suscettibile di avere sviluppi anche in tale direzione. In particolare può essere utilizzata per verificare possibili sviluppi. La Commissione sulla partecipazione ha proprio il compito di individuare possibili nuovi modelli di partecipazione in coerenza con le evoluzioni nazionali in materia, tenendo conto di esperienze anche di altri paesi europei. È una indicazione importante affidata alla futura gestione ed evoluzione dell'accordo.

Nella tradizione europea lo strumento principale delle relazioni industriali e della finanza regolativo delle condizioni di lavoro è rappresentato dalla contrattazione collettiva.

Essa continua tuttora a essere la forma più diffusa di azione collettiva, ancorché variamente contrastata dall'affermarsi dei processi di individualizzazione del lavoro. Nelle sue manifestazioni storiche essa ha non solo ampliato i suoi contenuti ma ha assunto metodi e finalità diverse, specie in quanto le parti contrattuali hanno preso a utilizzare strumenti diversi rispetto alle forme rivendicative tradizionali (e alle iniziative unilaterali proprie delle fasi originarie). Tanto che nelle analisi è consueto adottare un concetto ampio di contrattazione, estesa ai processi di consultazione e concertazione e persino alle negoziazioni fra parti sociali e poteri pubblici. 
Qui interessa sottolineare che è andata sfumando anche la distinzione della contrattazione collettiva con un altro tipo di azione collettiva diffuso in varie esperienze europee, le c.d. forme di partecipazione o di democrazia industriale. Le forme istituzionali "organiche" di partecipazione, quali si sono sviluppate da decenni nei paesi centro europei, Germania in primis, sono state storicamente differenziate dalla contrattazione, fino ad escluderla in senso formale: così alle intese del Betriebsrat tedesche non è stata per lungo tempo riconosciuta la qualità di contratti collettivi.

Ma quando nella contrattazione collettiva si riduce il peso degli obiettivi conflittuali o competitivi, e tendono a emergere obiettivi di "convivenza" fra le parti, specie su temi critici come quelli relativi alla competitività aziendale e alle esigenze di ristrutturazione e risanamento, allora i contorni fra contrattazione collaborativa e forme di partecipazione diventano meno nette.

Questa evoluzione è riscontrabile anche negli ordinamenti orientati in senso decisamente contrattuale rivendicativo (e conflittuale) come sono quello francese e italiano. Tale convergenza si è qui espressa segnatamente nell'uso dei diritti di informazione e consultazione, come strumento di "comprensione" fra le parti e di avvicinamento delle loro posizioni, utile anche ai fini contrattuali: diritti che hanno come terreno di elezione propri $i$ temi sopra esaminati, della flessibilità, dell'innovazione organizzativa, della gestione delle crisi, fino alle forme di salario variabile legato agli andamenti di produttività e redditività.

È significativo che le pratiche di contrattazione collettiva collaborativa abbiano avuto sviluppo, ancorché spesso contrastato, soprattutto a livello aziendale, in concomitanza con i processi di decentramento.

Il sistema tedesco è la patria di elezione e di più ampia strumentazione del metodo partecipativo nelle forme non solo dei diritti di partecipazione e consultazione, ma anche di partecipazione "organica", consistente nella presenza di rappresentanti dei lavoratori negli organi di gestione e di vigilanza delle società.

È questa che viene comunemente indicata come la caratteristica essenziale del modello partecipativo tedesco. Ma incentrare l'attenzione solo su essa è riduttivo, perché un tratto rilevante delle relazioni industriali tedesche, quello più influente nelle dinamiche concrete quotidiane, è che l'orientamento partecipativo si manifesta nella gestione complessiva dei rapporti collettivi nell'impresa, a cominciare dalla contrattazione aziendale. Essa ispira il contenuto degli accordi, sia nei momenti economicamente positivi, favorendo una condivisione dei risultati sul piano retributivo, sia nei momenti difficili, permettendo una gestione non conflittuale delle ristrutturazioni e delle crisi aziendali, anche attraverso accordi "di concessione" implicanti sacrifici alle condizioni di lavoro e agli stessi livelli retributivi.

Le affermazioni di tutti gli operatori tedeschi incontrati nell'indagine, sia sindacali sia datoriali, hanno confermato che la fiducia nel metodo partecipativo è stata decisiva nell'affrontare la crisi economica del 2008-2010, con scelte anche difficili ma senza conflitto e proiettate nel futuro. 
La partecipazione è diventata parte integrante della cultura delle relazioni industriali di quel paese, e la normativa di legge I'ha nel tempo consolidata. Normativa, contrattazione e prassi hanno contribuito a creare, ben prima della recente crisi, un clima che ha portato ad affrontare anche i problemi più critici in spirito collaborativo e con la fiducia nelle possibilità di scambio vantaggiosi per entrambi.

Nell'ordinamento francese non si sono sviluppate forme partecipative istituzionali come quelle affermatesi in Germania e in altri paesi centro europei. Per questo aspetto l'impostazione delle relazioni industriali francesi presenta tratti più vicini al sistema italiano, prevalentemente segnato da attori sindacali fra loro in competizione, da divisioni e tensioni, anche ideologiche fra sindacati, e da una prassi contrattuale prevalentemente rivendicativa. Anche in Francia peraltro tale impostazione tradizionale è stata progressivamente messa in discussione sia con l'apertura di spazi al decentramento contrattuale e alla flessibilità, sia con lo sviluppo di relazioni industriali meno conflittuali e più collaborative. Prassi innovative in questo senso sono emerse anzitutto in alcune aziende semi-pubbliche e sono presenti nell'esperienza Eni.

Nel sistema francese assume un rilievo particolare il ricorso a forme di partecipazione finanziaria dei lavoratori le cui prime esperienze risalgono nel tempo, con prevalenti origini legislative, non prive di tratti paternalistici.

Negli anni più recenti tali forme partecipative si sono evolute e differenziate, come si è visto, per iniziativa sia legislativa sia contrattuale, con una enfasi sugli aspetti economico-finanziari che ha portato a una diffusione sia delle retribuzioni incentivanti, comuni alle prassi contrattuali di ogni paese europeo, sia di forme di partecipazione agli utili e azionaria, favorite sul piano fiscale e sostenute da indicazioni di policy pubblica. Al di là del diverso approccio fra i sistemi tedesco e francese, entrambi segnalano una evoluzione in senso partecipativo delle relazioni industriali, ancora una volta con l'epicentro in azienda. Si tratta di una tendenza comune a molti paesi europei, che si è di recente manifestata anche in Italia, pur con le resistenze e le particolarità ben note. È significativo come nel nostro paese tale tendenza sia stata anticipata nelle esperienze di grandi aziende e gruppi industriali al di fuori e oltre le direttive nazionali, che si sono in prevalenza espresse nella previsione di diritti e procedure informative (la prima parte dei contratti).

Il recente accordo del Gruppo Eni è, proprio per questo aspetto, un esempio significativo del ri-orientamento delle relazioni industriali italiane. Non a caso il suo asse strategico principale, al di là dei contenuti innovativi sopra ricordati si incentra sulle procedure partecipative. Tale centralità, rilevata anche dai commentatori, si fonda sull'affermazione, posta in testa all'accordo, che lo sviluppo e l'incremento del processo partecipativo sono da considerarsi elementi fondamentali del modello di relazioni industriali aziendale, perché consentono una migliore crescita professionale dei laureati e nel contempo rendono più efficace l'attuazione dell'innovazione partecipativa. 
Per altro verso l'accordo precisa che negli attuali sistemi organizzativi la cooperazione è indispensabile per ottenere anche le opportune forme di flessibilità in grado di garantire la competitività dell'azienda.

In questa enunciazione si individua I'essenza principale dei sistemi partecipativi attivati in Europa ed enfatizzati nel modello tedesco. Essa sta ad indicare che tali sistemi sono finalizzati a sistema di relazioni industriali stabili, di lungo periodo fra le parti e proficue per entrambe ${ }^{18}$, cioè a somma positiva basati su una combinazione virtuosa fra coinvolgimento continuo e preventivo dei lavoratori, innovazione dei sistemi organizzativi e flessibilità nell'impiego dei fattori produttivi.

Tale combinazione è ritenuta essenziale per garantire una competitività dell'azienda di alto profilo, cioè basata non sulla compressione delle condizioni e dei costi del lavoro, ma sulla qualità delle scelte manageriali e delle relazioni con i dipendenti e per altro verso sugli investimenti in innovazione. Infatti le indicazioni sul metodo partecipativo si legano coerentemente nell'accordo agli impegni specifici dell'azienda necessari per la crescita competitiva di alto profilo dell'azienda: quelli per il piano degli investimenti e per le attività di ricerca e sviluppo, per la ricerca di nuovi modelli organizzativi finalizzati all'efficienza produttiva dei propri siti, fino all'attività formativa mirata allo sviluppo della professionalità in coerenza con l'evoluzione del modello organizzativo e di business di Eni.

Da questa impostazione strategica discendono le indicazioni dell'accordo sugli strumenti e sulle procedure partecipative: a cominciare dall'uso diffuso e preventivo sia delle informazioni e dei momenti di consultazione, entrambi utili a una contrattazione informata e cooperativa.

Questi strumenti già in passato utilizzati nella prassi del gruppo, sono ulteriormente valorizzati e resi sistematici non solo in ordine alle scelte generali dell'azienda e alle loro implicazioni (progetti di ricerca, piani di investimento) ma a tutti i temi considerati nell'accordo: dalle questioni locali e relative alle singole unità produttive, compresi i dettagli sugli investimenti (pag.7); alle varie forme di gestione degli orari (pag.13); alle modalità e condizioni di eventuali decisioni riguardanti la fermata temporanea degli impianti e ai conseguenti assetti produttivi (pag. 19); ai piani e ai percorsi formativi (pag. 21).

L'importanza di una simile specificazione degli strumenti partecipativi fino al livello micro organizzativo, è attestato dall'esperienza comparata che collega il successo del metodo partecipativo al di là delle sue forme istituzionali alla capacità di seguire i vari aspetti della vita quotidiana dell'azienda e dei lavoratori.

L'accordo Eni ha cura di precisare la tempistica delle procedure informative, con particolare attenzione alle ipotesi di modifica degli orari di lavoro (pag. 12). Tali indicazioni sono importanti per segnalare che il metodo e le procedure partecipative non devono pregiudicare la capacità decisionale dell'azienda e devono includere la certezza e la ragionevole celerità dei tempi di decisione.

18 Sono questi i motivi per cui si rileva che le trasformazioni del sistema produttivo costituiscono un contesto più favorevole alla partecipazione di quanto non fosse la produzione fordista. 
Questo è un tema emerso anche nelle esperienze straniere esaminate ove si è riscontrata la preoccupazione comune di contemperare le necessità di discussione e coinvolgimento dei lavoratori con la effettività e tempestività delle decisioni aziendali.

\section{Assenteismo}

L'ottica partecipativa che ispira l'accordo si manifesta non solo nella gestione dei vari aspetti della flessibilità e dell'innovazione organizzativa ma anche nel controllo dei fenomeni di assenteismo e del contrasto delle sue forme anomale.

Anche per questo aspetto sono significative le esperienze di altri paesi. Come si è visto del sistema tedesco, il fenomeno dell'assenteismo anomalo è pressoché sconosciuto.

A giudizio conforme delle parti tale situazione non deriva da specifici strumenti sanzionatori di comportamenti anomali, ma dipende dal buon funzionamento delle relazioni industriali in genere e della prassi partecipativa in specie. La condivisione di queste prassi costituisce un fatto di prevenzione e di controllo su questo come su altri comportamenti anomali, che sono sentiti come lesivi dell'interesse comune al buon andamento delle relazioni di lavoro e del sistema produttivo. Un approccio analogo si riscontra nell'accordo Eni ove le parti stipulanti affermano che iniziative volte a valorizzare la effettiva partecipazione dei lavoratori ai risultati siano ambiti in cui ricercare le soluzioni per il contenimento dell'assenteismo per malattia e che tali soluzioni debbano essere oggetto di confronto con le rappresentanze sindacali da coinvolgere sia per garantirne l'applicazione specifica nelle singole unità, sia per verificare la risultanze dell'assenteismo medio.

È altresì specificato che la strumentazione applicativa di tale principio si basa sull'uso combinato di incentivi/disincentivi: per cui nelle unità ove tale tasso di assenteismo è superiore al 3,7\% si procederà a riproporzionare l'importo del premio di partecipazione ai singoli lavoratori in base alle ore effettivamente lavorate e in misura correlata alla gravità dello scostamento dal benchmark. Per altro verso gli importi non erogati saranno suddivisi fra gli altri lavoratori dell'unità produttiva che avranno mantenuto il tasso di assenteismo individuale per malattia al di sotto del 3,7\%; e infine percorsi particolarmente virtuosi daranno luogo a miglioramenti del piano di partecipazione anche qui in misura correlata ai tassi raggiunti.

Tale formula, compreso I'uso degli strumenti incentivanti/disincentivanti è coerente con l'impostazione partecipativa dell'accordo e con le migliori pratiche europee. Anche queste nella gestione dei premi tengono conto, in misura varia, dei tassi di assenteismo (medi e individuali). In questo l'accordo Eni indica una soluzione, al pari di quelle straniere, mirata al controllo e possibilmente al superamento dell'assenteismo: una soluzione più efficace e meno conflittuale di quella che tante polemiche ha sollevato dagli accordi FIAT, basata su un meccanismo punitivo indifferenziato. 


\section{Conflitto}

Il ruolo del conflitto nelle relazioni industriali si è variamente configurato nelle esperienze storiche dei singoli sistemi nazionali ed è diversamente rappresentato nella teoria.

Nei sistemi e secondo le teorie pluralistiche l'efficienza di un ordinamento di relazioni industriali si misura soprattutto dalla sua capacità di riduzione del conflitto e di attenuazione della portata, entro uno spazio temporale dato. I sistemi di relazioni industriali entrano in crisi quando questa efficienza decresce attenuandosi le capacità di riduzione e di controllo del conflitto (Cella \& Treu, 2009; Cella, 2004).

Da questo punto di vista i sistemi che qui consideriamo, presentano caratteri storici alquanto diversi, anzi collocati agli estremi opposti di un continuum. Quello italiano e quello francese sono tradizionalmente caratterizzati da un alto grado di conflittualità, influenzati da impostazioni ideologiche degli attori sindacali profondamente radicate e da un basso grado di utilizzazione e controllo dello sciopero. Le relazioni industriali tedesche si sono collocate da sempre all'estremo opposto fra i sistemi a conflittualità più bassa e istituzionalmente più regolata.

Tali caratteri si sono rivelati persistenti nel tempo anche se ormai da vari decenni tutti gli indicatori segnalano una tendenza alla riduzione del conflitto industriale che ha riguardato la generalità dei sistemi, compresi quelli fortemente influenzati da tradizioni di sindacalizzazione rivendicativa e ideologica, come Francia e Italia.

I motivi di tale evoluzione sono complessi e non è il caso di approfondirli qui, ma possono ritenersi concomitanti e coerenti con l'altra tendenza esaminata riguardante la diffusione di pratiche contrattuali cooperative e di vere e proprie forme di partecipazione dei lavoratori, ancora una volta a partire dall'impresa.

Il nesso fra contrattazione collaborativa e partecipazione e controllo del conflitto è strettissimo nel sistema tedesco. Anzi si può dire che il controllo del conflitto è l'altra faccia del modello partecipativo di quel paese.

A tale controllo contribuiscono varie misure, sancite per legge e confermate da prassi pluridecennali delle parti. Anzitutto la titolarità a proclamare lo sciopero è riferita alle organizzazioni sindacali rappresentative, a differenza della configurazione prevalente in Italia e in Francia che considera lo sciopero un diritto dei singoli lavoratori.

Il fondamento della regola tedesca è che la titolarità dello sciopero deve corrispondere a quella del potere di contrattazione, essendo il conflitto funzionale al contratto (in quell'ordinamento lo sciopero politico è illecito). Il controllo sindacale sulla proclamazione degli scioperi è rafforzato dalla previsione che la loro attuazione deve essere autorizzata da un referendum fra i lavoratori interessati: per l'approvazione è richiesta la maggioranza del $75 \%$ e per la revoca è sufficiente il voto della metà degli interessati. 
La scelta di tali quorum corrisponde all'idea dello sciopero come extrema ratio. Infine il conflitto è ritenuto incompatibile con gli impegni contrattuali, dal che si desume che nella stipulazione del contratto deve ritenersi implicito l'obbligo di non ricorrere all'azione diretta per tutta la sua durata e per le materie considerate, (c.d. obbligo implicito di pace). D'altra parte è comune nella pratica contrattuale che le parti confermino e integrino tale obbligo con clausole di tregua specifiche.

Abbiamo verificato, sia in Francia sia in Germania, come l'esercizio dello sciopero nelle lavorazioni a ciclo continuo debba rispettare limiti specifici in grado di evitare danni agli impianti e perdite di produzione. Tale regola risulta generalmente rispettata in entrambi i paesi.

Come si vede la regolazione dello sciopero nel sistema tedesco risponde a una impostazione generale diversa da quella italiana e da quella francese, ispirata a una concezione dello sciopero come diritto individuale non negoziabile e non limitato alle materie contrattate.

L'intera esperienza italiana del dopoguerra conferma la resistenza a porre limitazioni convenzionali allo scopo, anche riferite all'ambito contrattuale, come ha mostrato da ultimo la polemica sulle clausole di tregua inserite nel contratto FIAT.

Di qui l'importanza dell'accordo interconfederale del 28 luglio 2011 che contiene un esplicito avallo delle possibilità e opportunità di clausole negoziate di tregua, vincolanti peraltro per le sole organizzazioni stipulanti.

Ed è altrettanto significativo che la tregua sul corso del contratto e un'adesione agli impegni in esso contenuti vien di fatto rispettato, anche senza sanzioni esplicite, in molte realtà aziendali, specie quelle caratterizzate da relazioni industriali partecipative e da prassi contrattuali virtuose.

L'accordo Eni non affronta I'argomento, ma la sua impostazione generale e l'obiettivo dichiarato di sviluppare prassi partecipative e innovative, anche oltre gli ambiti esplicitamente definiti, potrebbe suggerire alle parti, tramite la commissione sulla partecipazione, di sperimentare periodi di tregua sindacale, riferite a singoli argomenti, ad es. in concomitanza con l'esperimento di procedure di confronto e di conciliazione previste nell'accordo, di approfondire il tema.

Il rilievo strategico affidato dalle parti dall'accordo Eni al metodo partecipativo le ha indotte a istituzionalizzare la relativa strumentazione non solo con incontri annuali fra l'azienda e i sindacati, ma con la previsione di un sistema di comitati bilaterali, uno sulle relazioni industriali, uno sugli scenari economici e una commissione paritetica sulla partecipazione. Questi istituti bilaterali di origine negoziale costituiscono la forma più evoluta di procedura partecipativa in un sistema come il nostro sprovvisto di norme legislative in materia di partecipazione secondo i modelli centro europei. 
L'esperienza passata italiana (peraltro limitata), favorisce indicazioni diseguali sul funzionamento e gli esiti di simili comitati bilaterali: a seconda delle loro caratteristiche specifiche, non ultimo della qualità dei loro componenti, e del contesto in cui hanno operato, in particolare del legame fra la loro attività e le dinamiche delle relazioni fra le parti. I comitati, in quanto strumenti di partecipazione, non hanno compiti negoziali, come è indicato dall'accordo Eni, esplicitamente per il comitato per gli scenari economici.

Questa distinzione è precisata nella generalità degli esperimenti partecipativi, non solo italiani, e implica una necessaria di ruoli e di metodi rispetto all'attività rivendicativa e negoziale.

Ma la distinzione non significa separazione in quanto lo sviluppo degli istituti partecipativi serve a migliorare la qualità delle relazioni industriali, a cominciare dalla contrattazione aziendale.

Da questo punto di vista assume una particolare importanza la commissione paritetica sulla partecipazione, che è istituto originale previsto nell'accordo Eni, integrato da possibili esperti esterni e istituito con l'obiettivo di sviluppare nuovi modelli di partecipazione in coerenza con le evoluzioni normative in materia, tenendo conto anche di esperienze collaudate in altri paesi europei. L'originalità sta nel fatto di costituire uno strumento strategico che deve seguire non solo all'esperienza del giorno per giorno ma guardare al futuro con il proposito di far avanzare con proposte specifiche pratiche e modelli partecipativi, anche qui entro tempi ragionevolmente brevi, (12 mesi).

Il cantiere è così aperto e potrà avvalersi del confronto con le buone pratiche europee, non per riprodurle meccanicamente nel nostro paese, ma per trarne ispirazione al fine di rafforzarne e far evolvere i contenuti.

Il contributo potrà essere utile sia qualora il nostro legislatore decida di riconoscere forme partecipative nuove sulla falsariga di quelle europee, secondo progetti bypartisan già in discussione in parlamento, sia in mancanza e in attesa di riforme legislative. Nella prima eventualità la commissione della partecipazione può contribuire a valorizzare le prassi e la cultura del Gruppo Eni per dare sostegno alle istituzioni e procedure partecipative previste dalla legge. Si tratta di un contributo essenziale come si è visto nel sistema tedesco dove le formule legali della partecipazione vivono e sono alimentate da esperienze sviluppate nelle grandi aziende. Il contributo della commissione può essere rilevante e più diretto qualora non si perfezioni nessuna nuova disciplina legislativa. In tal caso le proposte della commissione dovranno tener conto delle vicende applicative dell'accordo e quindi definirsi in itinere. 


\section{Tendenze convergenti e indicazioni generali da sviluppare}

Le indicazioni comparate qui esposte e il confronto con l'accordo Eni confermano la presenza e l'importanza delle tendenze convergenti sui tre ambiti tematici indicati all'inizio: decentramento contrattuale e funzioni innovative della contrattazione aziendale; gestione negoziale delle flessibilità all'interno dell'impresa, in particolare degli orari; regole e pratiche partecipative per uno svolgimento delle relazioni industriali equilibrato e utile alle parti.

Nell'accordo Eni queste tendenze trovano riscontro nei contenuti specifici sopra illustrati e nella strumentazione innovativa, in particolare nella commissione sulla partecipazione, che costituisce la chiave di volta dell'intesa e lo strumento in grado di promuoverne ulteriori sviluppi.

La praticabilità di queste innovazioni e le possibili evoluzioni andranno verificati sin dai prossimi mesi, con un attento monitoraggio sull'attuazione dei vari contenuti degli accordi e sull'effettivo impatto del metodo partecipativo in ordine al clima delle relazioni industriali.

Alcune indicazioni generali sulle aree da sviluppare ci sembrano già possibili.

(i) Anzitutto si potrebbe verificare, tramite la commissione, la possibilità di estendere la partecipazione ad ambiti nuovi, coerenti con l'impianto dell'accordo e importanti per la dinamica delle relazioni fra le parti: in particolare alla gestione del mercato interno del gruppo mirata all'ottimizzazione dell'impiego delle risorse umane, con forme di mobilità programmate, di arricchimento professionale, e di modalità innovative di carriera personali, fino a forme di solidarietà fra anziani, da avviare a un pensionamento graduale e assunzione di giovani, con contratti di formazione usate in altri paesi e che si stanno sperimentando anche da noi (v. accordo ABI del 28 giugno 2008).

(ii) Va inoltre verificata la possibilità di sperimentare forme di partecipazione finanziaria dei lavoratori, sia per incrementare il reddito dei dipendenti sia per aprire la strada a una loro presenza minoritaria negli organi di governo delle società. Una simile scelta sarebbe favorita dall'approvazione delle proposte legislative sopra citate, ma può essere attivata anche per decisione aziendale, con le necessarie previsioni regolamentari e/o statutarie.

(iii) Una terza area di allargamento del modello Eni potrebbe riguardare lo sviluppo di benefits e di forme di welfare aziendali che valorizzino e potenzino gli istituti già presenti. Le esperienze di welfare aziendale, che stanno moltiplicandosi nel nostro paese, possono essere non solo uno strumento efficace per il benessere e per la qualità della vita dei lavoratori ma anche un veicolo di coinvolgimento dei dipendenti, dei pensionati e delle loro famiglie nella vita aziendale.

(iv) Un'ulteriore area di sperimentazione partecipata - già ricordata - può riguardare la gestione delle controversie di lavoro con il potenziamento di procedure non solo conciliative ma anche arbitrali. Il ricorso all'arbitrato dovrebbe riguardare l'applica- 
zione e la gestione delle clausole contrattuali, con esclusione delle materie regolate da norme imperative di legge, per evitare il rischio che le scelte arbitrali possano incidere su diritti indisponibili dei lavoratori. Una pratica diffusa di procedure conciliative e arbitrali potrebbe non solo ridurre e prevenire il contenzioso legale, con evidente risparmio di costi e di tempo per entrambe le parti, ma anche estendere alla fase gestionale dei contratti una cultura condivisa delle relazioni industriali. Si tratta di una forma di democrazia industriale diffusa nell'esperienza europea.

(v) Un'esperienza positiva e durevole di relazioni partecipative secondo l'accordo potrebbe aprire la strada a concordare con i sindacati forme di autoregolazione del conflitto, fino a veri e propri impegni di tregua per materie e oggetti definiti.

(vi) Infine, sulla base di un esito positivo della gestione dell'accordo Eni, la commissione potrebbe proporre di rafforzare le procedure di partecipazione e i poteri relativi attribuendo a commissioni o comitati partecipativi il potere di formulare obbligatoriamente pareri e proposte su temi specifici di comune interesse, o anche di richiedere su questi il necessario consenso di entrambe le parti. Tale sperimentazione potrebbe ulteriormente alimentare quella cultura partecipativa, caratteristica specie del modello tedesco, fino al punto da permettere sulla base di affidamenti reciproci fiduciari sperimentazioni di forme partecipative "forti" come quelle dei consigli di azienda tedeschi che richiedono un accordo (preventivo) del comitato bilaterale, prima di procedere a certe decisioni aziendali, ad es. in materia di gestione e modifica degli orari, di mobilità e di innovazioni organizzative. Questa scelta, proprio per la sua delicatezza va verificata sulla base della pratica effettiva dell'accordo. Se si estende la cultura e la prassi partecipativa, la presenza di tali poteri non comporta ostruzionismo alla capacità decisionale dell'azienda (come si è visto nel caso tedesco).

(vii) La sperimentazione di forme avanzate di partecipazione come questa e quella sopra ricordata sul rafforzamento dei poteri dei comitati bilaterali, sarebbe uno sviluppo coerente dell'accordo e potrebbe dare una spinta importante all'avanzamento delle prassi e delle istituzioni partecipative anche in altre grandi imprese e nel sistema italiano in generale. 


\section{Intervista a Italo Carlo Gaglianò sul tema}

a cura di Domenico Noviello e Davide Calabrò

\section{Noviello/Calabrò}

Italo, visto che lavori a Monaco di Baviera, vorremo parlare con te delle relazioni industriali in Italia e in Germania. Quali sono le tue impressioni, cosa vedi di diverso, se c'è qualcosa di diverso, tra il sistema italiano e quello tedesco.

\section{Gaglianò}

Parlare delle relazioni industriali in Italia e Germania è appassionante e non solo perché, in fondo, si parla delle proprie esperienze, di un viaggio, di un sovrapporsi di emozioni e scoperte nel tempo che è trascorso.

\section{Noviello}

Dai un senso concreto alle parole, non perderti nei ricordi di trattative sindacali, fatte anche insieme.

\section{Gaglianò}

Ok. Mi viene subito in mente:

"...lei rappresenta il capitale e noi il mondo del lavoro...".

"... io rappresento un partner sociale dell'impresa...".

Non serve invertire l'ordine delle due Nazioni per capire dove mi trovavo quando mi furono dette queste frasi. Sono rimaste nella mia mente. Un ricordo indelebile, anche per uno che ha fatto molte trattative sindacali. La grande differenza, tra le relazioni industriali in Italia e in Germania, sta tutta in queste due frasi.

\section{Calabrò}

Mondo del lavoro, partner sociale in fondo sono due espressioni che rappresentano la stessa realtà, che lettura bisogna dare alle due frasi?

\section{Gaglianò}

La prima, non può essere letta che in termini di contrapposizione. Un'idea, una visione che richiama una suddivisione, tra due realtà, sconfitta dalla storia. Porta a una logica d'interessi non comuni, ad un'antitesi. Spinge la tutela del proprio interesse a discapito dell'altro, quando l'altro è qualche cosa con cui bisogna, necessariamente, interagire, convivere, collaborare.

\section{Calabrò}

Nella seconda non c'è contrapposizione?

\section{Gaglianò}

C'è maggiore equilibrio, non ci sono interessi contrastanti, divergenti. Forse è un abuso I'uso della parola "partner".

\section{Noviello}

Questo che definisci maggiore equilibrio, nasce solo dalla relazione tra i due soggetti sociali? 


\section{Gaglianò}

In parte. Il sistema delle relazioni industriali in Germania è conseguente a un volere politico tradottosi in una legislazione che riconosce, impone, un ruolo al "Partner Sociale".

\section{Calabrò}

Sin dove si spinge la legislazione? Come da noi dove, per alcune tematiche, ci sono dei passaggi formali da fare con le Organizzazioni Sindacali, o va oltre?

\section{Gaglianò}

Va oltre, sino a prevedere la presenza del sindacato negli organi direttivi dell'impresa, ma anche a dire che lo sciopero politico non è permesso, che si può scioperare solo dopo che è scaduto il contratto.

Qualche mese fa, un Direttore del Personale di una società petrolifera alla domanda:

"Avete accordi che regolamentano I'assetto impianti in caso di sciopero?" ha risposto "...l'ultimo sciopero è stato nel 1973..."

La legislazione "impone" non solo il confronto ma qualche cosa di più. L'assenso del sindacato è necessario, a titolo di esempio, per:

- assunzioni;

- mobilità interna

- straordinari

Senza il consenso, preventivo, l'azienda non può attuare il suo disegno, non può applicare le sue metodologie di gestione del personale.

\section{Noviello}

Come si fa ad agire in un contesto di questo tipo?

\section{Gaglianò}

Operare in questo quadro senza avere in mente "il bene comune" sarebbe molto difficile. Qualcuno potrebbe dire: $\mathrm{Ma}$ il sindacato ha troppo potere. Potrebbe, con la sua autorità, imporre, condizionare fortemente, le strategie dell'impresa.

Fortunatamente non avviene, ci troviamo di fronte un soggetto autorevole non autoritario.

Deve essere chiaro, comunque, che il sindacato non è prono ad ogni volere dell'azienda. $\mathrm{Ci}$ sono contrasti, divergenze che a volte vengono dipanate da un terzo, magistratura o arbitro, e la soluzione individuata diventa d'esempio per altre realtà produttive.

\section{Noviello}

Quali sono i vantaggi di operare, come hai detto tu, in tale realtà?

\section{Gaglianò}

Con questo quadro di regole definite e chiare, di rispetto degli interlocutori, di reciproca comprensione, è stata affrontata I'ultima la crisi in Germania. Non sono stati licenziati centinaia di migliaia di lavoratori, non è stato disperso un capitale di conoscenza, utilissimo, ai primi segnali di ripresa, a dare risposte alle richieste del mercato. Non sono 
stati dati al fuoco i beni dell'azienda, o lanciati bulloni a leader sindacali o rappresentanti datoriali.

Probabilmente la presenza di un sindacato non politicizzato ha facilitato e facilità, i rapporti. Ha permesso anche di raggiungere un buon equilibrio tra l'esigenza crescente di avere una normativa, il contratto collettivo con o senza clausola aperta*, o il contratto aziendale, che:

- risponda velocemente ai cambiamenti richiesti, all'impresa, dal mercato;

- dia, nello stesso tempo, garanzie ai dipendenti, soprattutto in termini di aggiornamento e sviluppo del know how.

Questa è la situazione oggi, nel futuro potrebbe non essere più cosi. Per esempio, soprattutto nel settore dei servizi pubblici e privati, hanno preso piede forme di rappresentanza a livello di mestiere, quali i piloti, i conducenti dei treni, i medici, ecc., e sono viste con forte interesse da parte di altre categorie.

\section{Noviello}

Come sai In Italia si sta dibattendo molto sull'età pensionabile, sull'inesorabile innalzamento. Con quali strumenti le parti sociali hanno affrontato gli inevitabili contraccolpi sulle persone e sull'organizzazione aziendale?

\section{Gaglianò}

Quale strumento hanno condiviso? Bisogna prima premettere che la legislazione tedesca, dal 2006, ha innalzato progressivamente l'età pensionabile, portandola a 67 anni per tutte le persone nate dopo il 1963. C'è comunque, ad oggi, la possibilità di lasciare il lavoro a 63 anni con una penalizzazione sulla rendita pensionistica.

Utilizzando una legge che dà la possibilità di creare un conto ore speciale, sono stati sottoscritti accordi con una logica finalizzata, anche, a creare le condizioni per un'uscita anticipata dal mondo del lavoro, senza costi sociali.

I dipendenti possono destinare, a questo conto speciale, diversi elementi sia monetari sia temporali (ferie, bonus, $13^{\circ}$ mensilità, straordinari, una percentuale fissa dello stipendio, ecc.) Non possono essere inseriti straordinari per lavoro notturno, o per lavoro in giorni festivi, a causa di una diversa tassazione. Gli elementi temporali vengono tramutati in valore economico secondo la retribuzione del momento.

Il datore di lavoro versa i soldi dei dipendenti partecipanti, a un "investment fond" con conti individuali. Il rendimento del fondo, positivo o negativo, influisce sul conto individuale dell'impiegato. Nel momento dell'esercizio l'ammontare accantonato verrà tramutato in tempo, in rapporto alla retribuzione percepita al momento.

Per esempio:

- accantonati, nel corso della vita lavorativa, (dal 2000 al 2040) 100.000 euro (compreso il rendimento);

- retribuzione annua lorda 100.000 euro al 2040;

* Con I'espressione clausola aperta si intende la possibilità di derogare, con l'accordo delle parti, al contratto nazionale. 
- il dipendente potrà lasciare I'azienda un anno prima o il numero dei mesi che deciderà.

L'adesione a questo istituto è a libera scelta del dipendente.

Attualmente l'ammontare è soggetto a tassazione e contributi sociali solo nel momento dell'esercizio. In caso di dimissioni l'impiegato potrà alimentare il suo "conto", se il nuovo datore di lavoro lo autorizza. Altrimenti gli sarà liquidata la somma complessiva dopo aver trattenuto i contributi sociali e le tasse del momento.

Diverse aziende hanno sottoscritto accordi sindacali sul tema. Per esempio, un'azienda petrolifera promuove l'uso di tale istituto aggiungendo il $10 \%$ dell'ammontare accantonato. Aggiunge un altro $10 / 12 \%$ nel caso chieda al lavoratore di anticipare o posticipare I'uscita.

È un'opportunità per il dipendente e per l'impresa avere uno strumento che, senza costi sociali, dia la possibilità di gestire un'uscita anticipata dall'azienda. Anche se il dipendente dovesse essere sostituito, lo sarà con un costo inferiore e con energie fisiche e psichiche completamente diverse, e, visto l'inevitabile innalzamento dell'età pensionabile, ricorrere a forme che consentano di coniugare interessi dell'impresa e dei dipendenti è sicuramente un vantaggio per entrambi.

Questo istituto serve, soprattutto, a facilitare I'uscita anticipata per la pensione, ma può essere usato anche per altre situazioni, p.e. maternità, pausa sociale, ecc.

\section{Calabrò}

Globalizzazione, crisi economica, che lezione si può trarre dal sistema di relazioni industriali tedesco?

\section{Gaglianò}

Cosa ci ha insegnato il sistema di relazioni industriali in Germania, in generale e nell'affrontare la crisi ancora in corso? Come non si può affrontare la globalizzazione con logiche meramente difensivistiche (non credo si possa pensare a mettere i "gabellieri" all'ingresso di ogni paese, cosi come avveniva qualche secolo fa), cosi come non la si può affrontare con divisioni tra i soggetti (attori) sociali. Quindi, qualsiasi sia la situazione da affrontare, crisi, globalizzazione, ecc., c'è la necessità di (ri)trovare il bene comune. È questo il driver trainante, coniugare le diverse esigenze per garantire il futuro. 


\section{Le possibili aree di sperimentazione partecipata in Eni: l'arbitrato}

a cura di Domenico Noviello e Marcella Scillieri

\section{Sommario:}

1. Eni e le possibili aree di sperimentazione partecipata. La continuità rispetto al passato.

2. L'arbitrato: uno strumento nelle mani di azienda e sindacato.

3. I possibili spazi di applicazione dell'istituto nell'ambito dei diritti disponibili.

4. Giudici e arbitri. Sentenza e Lodo. Diritto o equità.

5. I tempi del giudizio e quelli dell'arbitrato.

6. I costi dell'arbitrato.

7. Uno Sguardo Oltralpe a Francia e Germania.

8. Tabella riepilogativa e considerazioni conclusive.

\section{Eni e le possibili aree di sperimentazione partecipata. La continuità rispetto al passato}

Le aziende italiane hanno assistito ad una profonda modifica del mercato del lavoro.

In particolare, il diritto del lavoro ha attraversato, specialmente nell'ultimo decennio, una fase di ripensamento e di rinnovamento rispetto all'impostazione postcorporativa e alle norme statutarie.

In questo scenario, Eni si è mostrata aperta ad esaminare anche aree di "sperimentazione partecipata", ossia aree che estendono alla fase gestionale dei contratti una cultura condivisa delle relazioni industriali.

In linea con il passato, dove Eni è stata pioniera di istituti come, ad esempio, il Consiglio Aziendale Europeo oltre che di forme di consultazione e informazione dei lavoratori e di strumenti di partecipazione dei lavoratori all'impresa, con lo stesso spirito oggi si avvicina all'ultima riforma del 2010 introdotta dal cosiddetto "collegato lavoro".

In particolare, cogliendo gli spunti delle norme sulla giustizia del lavoro e nell'ottica di deflazionare il troppo lungo contenzioso, Eni intende ora esaminare spazi e potenzialità degli strumenti previsti dalla recente riforma e la loro idoneità a garantire soluzioni tempestive delle controversie in materia del lavoro.

Quanto sopra nell'ottica di favorire l'effettività delle tutele e della certezza del diritto, a vantaggio sia di lavoratori che d'impresa.

E tra gli strumenti, nuovi o "rimodernati" nella riforma, compaiono oltre che le procedu- 
re di certificazione dei contratti di lavoro, anche la devoluzione ad arbitri delle controversie che dovessero insorgere in relazione al rapporto di lavoro.

\section{L'arbitrato: uno strumento nelle mani di azienda e sindacato}

Come noto, il collegato lavoro prevede tre modalità differenti di accesso all'arbitrato.

Una prima modalità è quella che si svolge in qualunque fase del tentativo di conciliazione $o$ al suo termine, davanti alle commissioni di conciliazione istituite presso le DPL e ai collegi arbitrali che saranno eventualmente istituiti presso le sedi di certificazione dei contratti di lavoro.

Una seconda modalità di arbitrato è quella che si svolge presso le sedi eventualmente individuate dalla contrattazione collettiva.

Infine, una terza modalità si svolge presso un collegio ad hoc composto, su istanza delle parti, da un rappresentante di ciascuna di esse e da un terzo membro, in funzione di presidente.

Le parti sociali hanno quindi ampi spazi nella riforma del nuovo arbitrato.

In primo luogo perché ad esse è affidata la possibilità di pattuire clausole compromissorie (ossia clausole che stabiliscano che eventuali controversie che dovessero insorgere per il futuro saranno decise da arbitri) attraverso accordi interconfederali o in contratti collettivi stipulati dalle organizzazioni dei datori di lavoro e dei lavoratori comparativamente più rappresentative sul piano nazionale.

In secondo luogo perché esse potranno, nei contratti collettivi nazionali di categoria, istituire un fondo per rimborsare il lavoratore delle spese per la parte a loro carico del compenso del Presidente del collegio e per il compenso del proprio arbitro.

Pertanto, I'arbitrato è stato immaginato nell'attuale sistema, come strumento libero e responsabile, di buone relazioni industriali.

\section{I possibili spazi di applicazione dell'istituto nell'ambito dei diritti disponibili}

In questo scenario, un giurista d'impresa deve porsi una serie di domande. Innanzitutto deve verificare quale potrebbe essere il campo di applicazione dell'istituto nel proprio contesto aziendale.

Conseguentemente dovrà verificare la sua convenienza in termini di tempi, di competenza degli arbitri e di certezza della decisione e, senza dubbio, di costi sostenuti dal lavoratore e dall'impresa. 
Sulla prima indagine, la stessa norma prevede l'impossibilità di ricorrere all'arbitrato su tematiche particolarmente sensibili quali quella del licenziamento. Pertanto, resterebbe libera la strada delle controversie in tema di inquadramenti superiori, demansionamento, differenze retributive, trasferimenti, ecc.

Orbene, nella realtà Eni, dove il contenzioso si attesta su livelli che possono definirsi "fisiologici", il nuovo arbitrato potrebbe prendere piede su questioni attinenti I'inquadramento del personale non dirigente, che a oggi per Eni SpA hanno un valore che si aggira intorno ai 3.600.000 Euro.

Ad esempio potrebbero essere devolute ad arbitri le controversie aventi ad oggetto il cosiddetto C.R.E.A. (acronimo di Complessità, Responsabilità, Esperienza ed Autonomia) che costituisce, nel CCNL energia e petrolio, I'apprezzamento dei singoli apporti professionali del lavoratore all'interno delle singole categorie.

\section{Giudici e arbitri. Sentenza e Lodo. Diritto o equità}

La seconda indagine dovrebbe riguardare, innanzitutto, le motivazioni della storica diffidenza nei confronti di forme di giustizia privata.

Il primo dubbio che può insinuarsi in chi intende adire una controversia in materia di lavoro è quello che riguarda il mantenimento di standard di competenza, esperienza ed imparzialità del collegio rispetto al giudice ordinario.

Come noto il collegio può essere istituito presso la Direzione Provinciale del lavoro, presso le sedi di certificazione o presso sedi indicate nei contratti collettivi.

In alternativa alle sedi di cui sopra, il collegio istituito ad hoc si compone di tre membri, un arbitro par ciascuna parte e un Presidente.

Per il rappresentante di ciascuna delle parti non è richiesto il possesso di specifici requisiti ma, presumibilmente, solo l'esistenza di un rapporto di fiducia con la parte.

Il terzo membro del collegio, in funzione di Presidente, viene invece scelto, ove possibile, con l'accordo delle parti, tra soggetti altamente qualificati in quanto in possesso di una particolare competenza ed esperienza nella materia.

Ed invero la funzione di Presidente può essere ricoperta soltanto da professori universitari in materie giuridiche e dei soli avvocati ammessi al patrocinio davanti alla Corte di Cassazione.

Il secondo dubbio che potrebbe insinuarsi in chi deve scegliere tra giustizia ordinaria e giustizia "privata" è quello che riguarda uno dei profili più controversi dell'arbitrato, ossia la richiesta di decidere secondo equità.

Ed invero l'equità, concetto di indubbio fascino, spesso accostato a quello della giustizia e del diritto, ma che ad oggi non ha acquisito contorni definiti e non è agevole poter dire cosa, in concreto, significhi e come, nei fatti, debba essere applicato. 


\section{I tempi del giudizio e quelli dell'arbitrato}

La terza indagine dovrebbe riguardare una valutazione comparativa tra i tempi del giudizio e quelli dell'arbitrato ossia i tempi necessari ad ottenere una sentenza o un lodo nelle controversie di inquadramento superiore.

Da una stima di massima (che dipende chiaramente dal foro in cui è instaurata la controversia) si può sostenere che la durata del primo grado di giudizio sia di sei mesi nel Foro di Milano e di tre anni nel Foro di Roma.

Da parte sua, i tempi dell'arbitrato sono compiutamente scadenzati nel testo di legge, anche se in modo non necessariamente perentorio (notifica del ricorso; 30 giorni per la nomina dell'arbitro; 30 giorni per il deposito delle memorie difensive; 10 giorni per le memorie di replica; 10 giorni per le controrepliche; 30 giorni per l'udienza e rinvii a non più di 10 giorni; 20 giorni per decisione).

Complessivamente, quindi, i tempi dell'arbitrato dovrebbero aggirarsi, in media, intorno ai 6-8 mesi.

\section{I costi e i vantaggi dell'arbitrato}

È indubbio, peraltro, che il ricorso al nuovo arbitrato sarà tanto maggiore e allettante per le parti tanto più contenute resteranno le spese che esse dovranno sostenere.

In quest'ottica il risparmio di tempo può influire anche sul risparmio in termini di costi. L'azienda, infatti, in caso di soccombenza, è tenuta a corrispondere sulle somme dovute gli interessi e la rivalutazione monetaria. Entrambe le parti, peraltro, potrebbero ottenere benefici sulle parcelle dei legali di parte che sono, nel giudizio ordinario, "appesantite" proprio dall'ingente numero di udienze e di rinvii spesso inutili.

Quanto alle spese dell'arbitrato, la legge non dispone nulla in tema di spese laddove si svolga innanzi alle Commissioni istituite presso le Direzioni provinciali del lavoro o presso le sedi di certificazione.

Ove, invece, si svolga innanzi ai tre arbitri del collegio istituito ad hoc, le parti dovranno farsi carico oltre che delle spese per gli onorari dei legali, anche dei compensi degli arbitri da esse designati (pari all'1\% ciascuno del valore della controversia) e del Presidente.

In particolare, il compenso per il Presidente deve essere versato dalle parti nei cinque giorni antecedenti l'udienza mediante assegni circolari a lui intestati della misura, per ciascuna parte, dell' $1 \%$ del valore della controversia dichiarato nel ricorso. A questo anticipo si aggiungono poi, per ognuna di loro, le spese legali - per la predisposizione 
degli atti e per l'eventuale attività del rappresentante della ricorrente e dell'avvocato della convenuta - oltre che le spese per il compenso dell'arbitro di parte, indicate nella misura dell'1\% del valore della controversia.

Le suddette spese sono liquidate nel lodo, secondo le regole generali del giudizio ordinario.

Da una prima analisi, per le cause di lavoro è previsto un contributo unificato ridotto (ad eccezione di quelle promosse da titolari di redditi bassi, che sono completamente esenti dal contributo); nell'attuale scenario, pertanto, le spese di un arbitrato potrebbero essere superiori, per lavoratore e azienda, a quelle di giudizio.

Per tale motivo le parti, attraverso la contrattazione collettiva nazionale di categoria, potranno istituire un fondo a favore del lavoratore per il rimborso delle spese per il compenso del Presidente e del suo arbitro.

Tuttavia, il vero risparmio che l'arbitrato può garantire consiste nell'avere un unico grado rispetto ai tre del giudizio ordinario. In particolare, il lodo arbitrale può essere impugnato solo per specifiche e stringenti causali (violazione della convenzione arbitrale, errore). Viceversa, la sentenza di primo grado può essere appellata e successivamente impugnata con ricorso per Cassazione, con notevole aggravio di costi.

\section{Uno Sguardo Oltralpe a Francia e Germania}

Il contributo del Prof. Treu ha evidenziato come l'esperienza degli altri Paesi europei sia importante per avere una quadro completo dei vari istituti.

Tanto più questa esigenza diventa una necessità per realtà aziendali come Eni, che è presente in 79 Paesi.

Da una prima indagine sembra che la realtà francese lasci pochi margini ad ipotesi di arbitrato.

In realtà, da un esame più approfondito, è emerso proprio che il Tribunale di primo grado è composto da quattro giudici che non hanno, per studi e per esperienza professionale, il ruolo che hanno in Italia.

Trattasi, infatti, di giudici "non professionisti" in quanto facenti parte di un elenco di soggetti che hanno esperienza nell'ambito di associazioni sindacali dei datori e dei prestatori di lavoro.

In quanto tali, vantano una sensibilità diversa da quella di un vero giudice, e molto più prossima a quella di un arbitro. Ciononostante dovranno decidere secondo diritto e non secondo equità. 
L'impugnativa del primo grado di giudizio avviene presso corti composte da giudici togati veri e propri.

Quanto invece all'esperienza tedesca, in ogni società con più di cinque risorse viene costituita una rappresentanza dei lavoratori con potere di decisione e veto, il cosiddetto Work Council o Betriebsrat.

Esso interviene per tematiche di carattere collettivo, quali ad esempio l'inquadramento del personale, I'orario di lavoro, la disciplina dello straordinario, il divieto di fumo, ecc.

Se su queste tematiche di carattere collettivo (e non individuale) non si trova un accordo, è possibile rivolgersi ad un collegio arbitrale. Il collegio è composto da un numero pari di rappresentanti di azienda e sindacato (ad es. 2 o 4) e da un Presidente, spesso un giudice in pensione.

Tuttavia, l'istituto dell'arbitrato così impostato, non è decollato. Le ragioni del mancato ricorso all'istituto risiedono in due ordini di motivi: i costi più elevati rispetto al giudizio ordinario e la breve durata delle cause di lavoro (da una stima di massima il giudizio di primo grado dura in media 3-4 mesi e per esaurire tutti i gradi di giudizio sono necessari solo 5 anni). 


\section{Tabella riepilogativa e considerazioni conclusive}

Schematicamente, pertanto, per controversie di valore pari ad $€ 30.000$, potrebbe rappresentarsi il seguente scenario:

\begin{tabular}{|c|c|c|c|c|}
\hline $\begin{array}{c}\text { Controversia in } \\
\text { tema di } \\
\text { inquadramento } \\
\text { superiore di valore } \\
\text { pari ad } € 30.000\end{array}$ & Tempi & $\begin{array}{c}\text { Costi di giudizio/ } \\
\text { Arbitrato }\end{array}$ & $\begin{array}{c}\text { Spese legali: } \\
\text { Diritti ed onorari* }\end{array}$ & $\begin{array}{c}\text { Gradi, motivi } \\
\text { e costi di } \\
\text { impugnazione }\end{array}$ \\
\hline Giudizio di $1^{\circ}$ & $1,5 / 2$ anni & $\begin{array}{l}\text { Spese di giustizia } \\
€ 225 \text { (per il solo } \\
\text { ricorrente che sia } \\
\text { titolare di redditi } \\
\text { superiori a } \\
€ 31.884,48 \text { ) }\end{array}$ & $\begin{array}{l}\text { Da Tariffario } \\
\text { Forense per } \\
\text { il Giudizio } \\
\text { (elevato per } \\
\text { formalità, } \\
\text { udienze e rinvii) } \\
\text { Diritti: } € 1.200 \\
\text { Onorari: } € 4.500 \\
+ \text { iva e cpa }\end{array}$ & $\begin{array}{l}\text { Appello } \\
\text { Diritti: } € 1.600 \\
\text { Onorari: } € 3.900 \\
+ \text { iva e cpa e } \\
\text { Cassazione } \\
\text { Diritti: } € 1.500 \\
\text { Onorari: } € 6.500 \\
+ \text { iva e cpa }\end{array}$ \\
\hline Arbitrato ad hoc & $6 / 8$ mesi & $\begin{array}{l}€ 300 \text { per il } \\
\text { Presidente } \\
+€ 300 \text { per } \\
\text { arbitro }\end{array}$ & $\begin{array}{l}\text { Da Tariffario } \\
\text { Forense per } \\
\text { stragiudiziale } \\
\text { (procedura più } \\
\text { snella con meno } \\
\text { rinvii) } \\
\text { Onorari: } € 3.000 \\
+ \text { iva e cpa }\end{array}$ & $\begin{array}{l}\text { Tribunale ma } \\
\text { solo per specifici } \\
\text { e limitatissimi } \\
\text { motivi }\end{array}$ \\
\hline $\begin{array}{l}\text { Arbitrato } \\
\text { in DPL o in } \\
\text { Comm. di } \\
\text { certificazione }\end{array}$ & $\begin{array}{l}\text { La legge non } \\
\text { dispone nulla }\end{array}$ & $\begin{array}{l}\text { La legge non } \\
\text { dispone nulla }\end{array}$ & $\begin{array}{l}\text { La legge non } \\
\text { dispone nulla } \\
\text { (ma generalmente } \\
\text { analoga rispetto al } \\
\text { giudizio ordinario) }\end{array}$ & $\begin{array}{l}\text { Tribunale ma } \\
\text { solo per specifici } \\
\text { e limitatissimi } \\
\text { motivi }\end{array}$ \\
\hline
\end{tabular}

* Si tratta di stime di massima.

In questo scenario, in linea con quanto previsto per l'art. 8 della recente manovra in materia di contrattazione, anche il concreto utilizzo delle possibilità del nuovo arbitrato è rimesso alla volontà e all'iniziativa dei rappresentati di aziende e sindacati.

Non resta, a questo punto, che vedere quanto le parti sociali intenderanno "investire" su percorsi liberi e responsabili che, seppur difficoltosi, sono dovuti a nuove condizioni del mercato del lavoro e a vecchi problemi dell'ordinamento giudiziario.

Roma, 30 novembre 2011

Avv. Domenico Noviello

Dott.ssa Marcella Scillieri 


\title{
Competitività e partecipazione: il modello di relazioni industriali Eni nell'accordo del 26 maggio 2011
}

\author{
a cura di Davide Calabrò
}

Nel corso di questi ultimi anni, insieme al forte rallentamento dell'economia mondiale, abbiamo assistito a un dibattito, anche aspro, sui possibili mutamenti del sistema di relazioni industriali nel nostro Paese e come questo sistema possa agevolare i cambiamenti nell'ambito dei processi operativi, organizzativi e gestionali delle imprese.

La competizione globale impone ormai a tutti i livelli profondi cambiamenti e, quindi, anche un diverso approccio con le Organizzazioni Sindacali, fuori dal vecchio schema fordista della fabbrica del novecento ma attento a costruire un quadro di rapporti di lavoro e sindacali in grado di favorire l'aumento della competitività delle imprese, la rapida realizzazione delle innovazioni tecnologiche, ripensando vecchi schemi che regolano i rapporti di lavoro in un corretto equilibrio tra le esigenze delle imprese e dei lavoratori.

I dibattiti che si sono sviluppati intorno a temi cruciali del mondo del lavoro, che vanno dalla ricerca di nuove forme di flessibilità anche in uscita, alla regolamentazione della rappresentanza in azienda, al rapporto fra contratto nazionale e aziendale, fino alla possibile "importazione" di modelli stranieri come la forma di partecipazione tedesca o il sistema di flexsecurity danese, testimoniano l'importanza di individuare nuove strade nelle relazioni industriali.

Anche all'interno di Eni abbiamo riflettuto su come il modello di relazioni industriali potesse essere migliorato, consentendo all'azienda di realizzare, in un clima sindacale favorevole, flessibilità e maggiore efficienza produttiva nell'organizzazione del lavoro. Nelle nostre valutazioni non abbiamo tralasciato poi il tradizionale ruolo di riferimento che Eni svolge nel panorama delle relazioni industriali e quindi l'apporto che poteva dare al dibattito sulle forme di partecipazione dei lavoratori all'impresa.

In sostanza, partendo da un'analisi di quanto di positivo avevamo in casa in termini di protocollo di relazioni industriali, contrattazione collettiva nazionale e aziendale e senza innamorarci troppo di formule o modelli preconfezionati, ci siamo interrogati su quali potessero essere le soluzioni più efficaci affinché Eni potesse crescere in competitività e produttività. La crisi economica e finanziaria internazionale, infatti, ha avuto ripercussioni importanti anche su alcuni business in cui Eni opera, in particolare nella Divisione Refining \& Marketing e nel settore della petrolchimica, dove la stagnazione dei consumi ha notevolmente inciso sui margini e sui volumi dei prodotti lavorati.

Tali riflessioni, svolte non solo all'interno della Direzione Risorse Umane ma anche nel corso degli incontri con le Organizzazioni Sindacali a tutti i livelli, ci hanno portato a pensare ad un insieme armonico di soluzioni che prevedessero l'adozione di modelli organizzativi in grado di migliorare l'efficienza e la competitività e cogliere le potenzialità di un mercato sempre più flessibile e imprevedibile. 
Queste considerazioni sono state alla base della negoziazione che ha portato alla sottoscrizione il 26 maggio 2011 dell'Accordo per lo sviluppo e la competitività e per un nuovo modello di relazioni industriali.

Temi centrali dell'accordo sono: programma di investimenti e iniziative nel campo della ricerca e dell'innovazione; maggiore competitività, efficienza e produttività nell'organizzazione del lavoro; incremento della flessibilità per rispondere alle esigenze imposte dai mercati; strumenti adeguati per la programmazione di fermate temporanee degli impianti; orari flessibili e omogenei per le sedi direzionali nel rispetto del work life balance; rafforzamento della partecipazione attraverso un ampliamento delle informazioni e delle conoscenze delle strategie aziendali da parte delle Organizzazioni Sindacali per pervenire a decisioni rapide.

Con il solido piano di investimenti nell'arco quadriennale nei settori della raffinazione e della petrolchimica e nel campo della ricerca ed innovazione, si è confermato l'obiettivo della crescita come fattore determinante per un'efficace competizione.

La flessibilità degli assetti produttivi e degli orari di lavoro è stata individuata come leva importante per fronteggiare le oscillazioni dell'economia globale e le difficoltà del mercato, garantendo il recupero di produttività e riducendo al minimo - grazie a momenti di confronto e di informazione preventivi - il conflitto con il Sindacato.

L'accordo prevede, inoltre, la possibilità di incrementare la prestazione lavorativa del personale turnista; viceversa, nel caso in cui dovessero verificarsi situazioni tali da non consentire il pieno utilizzo della capacità produttiva degli impianti, congiuntamente alle Organizzazioni Sindacali, sarà possibile definire soluzioni per attenuare i disagi economici dei lavoratori coinvolti.

Ulteriore elemento per il recupero di produttività è il contenimento dell'assenteismo per malattia attraverso meccanismi di redistribuzione del Premio di Partecipazione connessi ai risultati raggiunti nel corso dell'anno.

Con le Organizzazioni Sindacali abbiamo condiviso poi un sistema di regole di partecipazione chiare, semplici e di immediata praticabilità che, in un clima di reciproca affidabilità, possano sviluppare un dialogo costruttivo sia sul merito degli argomenti trattati che sull'individuazione delle priorità.

Gli intendimenti delle Parti hanno trovato la loro concretizzazione nell'inserimento di lavoratori all'interno del Comitato di Relazioni Industriali, nella costituzione di un "Comitato per gli scenari economici" e di una "Commissione paritetica sulla partecipazione". Quest'ultima avrà il compito di individuare nuovi modelli di partecipazione, tenendo conto anche di esperienze collaudate in altri paese dell'Unione Europea. 
A pochi mesi dalla firma dell'accordo, pur perdurando la situazione di incertezza economica, è stato possibile tracciare un primo bilancio positivo dell'applicazione delle soluzioni individuate nell'intesa. Il consolidamento del processo di riconversione industriale di Porto Torres, I'efficace gestione degli assetti produttivi nello stabilimento petrolchimico di Priolo e nella raffineria di Venezia, la tendenziale diminuzione del tasso di assenteismo per malattia sono senza dubbio i primi risultati tangibili di un percorso complesso ma fortemente partecipativo, in linea con la tradizione delle relazioni industriali di Eni.

Ing. Davide Calabrò 


\section{Bibliografia}

Addison, J., Bryson, A., Teixeira, P., Pahnke, A., \& Bellmann, L. (2010). The State of Collective Bargaining and Work Representation in Germany: the Erosion Continues. IZA Discussion Paper, 5030, 1-18.

Addison, J., Teixeira, P., \& Zwick, T. (2010). German Works Councils and the Anatomy of Wages. Industrial and Labor Relations Review, 63(2), 247-270.

Amossé, T. (2006). Le Dialoge Social En Entreprise. Premiére Synthéses Informations, $39(1), 1-8$.

Antonmattéi, H. (2006). Négociation collective et CPE: le jour d'àpres. DS, 650.

Ballestrero, M. (2008). Flexicurité à la francaise: I'accoro di gennaio 2008 sul mercato del lavoro. Diritto lavori mercati, 2, 235-257.

Berg, P. (2008). Working Time Flexibility in the German Employment Relations System: Implications for Germany and Lessons for the United States. Industrielle Beziehungen, 15(2), 133-150.

Bodin, R. (1987). Les Lois Auroux dans les PME. Paris: la Documentation.

Boeri , T., \& Bruecker, H. (2011). Short Time Work Benefits Revisited: Some Lesson from the Great Recession. Milano: IAB - Università Bocconi.

Borenfreund, G. (2008). Le nouveau régime de la représentativité syndacale. RDT, 712.

Bruecker, H. (2011). Short-time work benefits: cosa possiamo imparare dal modello tedesco? IAB.

Burda, M., \& Hunt, J. (2011). What explains the German Labor Market Miracle in the Great Recession?", Brooking Papers on Economic Activity. Brooking Papers on Economic Activity Discussion Papers.

Cella, G. P. (2004). Il sindacato. Bologna: Il Mulino.

Cella, G. P., \& Treu, T. (2009). Relazioni industriali e contrattazione collettiva. Bologna: Il Mulino.

Ciccarone, G., \& Saltari, E. (2011). Si fa presto a dire Germania. Il Mulino, 1, 37.

Coffineau, M. (1993). Les Lois Auroux, Dix Ans Aprés. Paris: La Documentaton.

Doellgast, V., \& Greer, I. (2007). Vertical Disintegration and the Disorganization of German Industrial Relations. British Journal of Industrial Relations, 45(1), 55-76. 
Enrico, C. (2006). La rappresentanza degli attori sindacali: riflessioni sul caso francese. Diritto delle relazioni industriali, 4, 993-998.

Ferner, A., \& Hyman, R. (1992). Industrial Relations in the New Europe. Oxford: Blackwell.

Flecker, J., \& Schulten, T. (1999). The end of institutional stability: what future for the "German model"? Economic and Industrial Democracy, 20, 81 - 115.

Freyssinet J. (2008). L'accordo dell'11 gennaio 2008 sulla modernizzazione del mercato del lavoro: un futuro incerto. Diritto lavori mercati, 2, 259-296.

Grévy, M., Peskine, E., \& Nadal, S. (2008). Regards sur la position commune du 9 avril 2008. A propos du divenir (incertain?) des syndacats dans l'enterprise. RDT, 431.

Haipeter, T. (2011). "Unbound" Employers' Associations and Derogations: Erosion and Renewal of Collective Bargaining in the German Metalworking Industry. Industrial Relations Journal, 42(2), 174-194.

Hall, P., \& Soskice, D. (2001). Varieties of Capitalism: the Institutional Foundations of Comparative Advantage. New York: Oxford University Press.

Hassel, A. (1999). The Erosion of the German System of Industrial Relations. British Journal of Industrial Relations, 37, 483-505.

Hassel, A. (2010). Twenty Years after German Unification: the Restructuring of the German Welfare and Employment Regime. German Politics \& Society, 28(2), 102-115.

Howell, C. (2009). The Transformation of French Industrial Relations: Labor Representation and the State in a Post-dirigiste Era. Politics and Society, 37(2), 229-256.

Howell, C., \& Givan, R. (2011). Rethinking Institutions and Institutionall Change in European Industrial Relations. British Journal of Industrial Relations, 49(2), 231-255.

Jacod, O. (2007). Les Institutions Représentative du Personel. Première Synthèses Informations, 5(1), 1-7.

Jobert, A., \& Saglio, J. (2005). La Mise en Oevuvre des Dispositions de la Loi du Mai 2004 Permettant aux Enterprises de Déroger aux Accords de Branche. Paris: Ministère de L'Emploi du Travail.

Kapstein, E. (1996). Workers and the world economy. Foreign Affairs, 75(3), 16-38. Katz, H., \& Darbishire, O. (1999). Converging Divergences. Ithaca: Cornell Press. 
Kitshelt, H., \& Streeck, W. (2003). From Stability to Stagnation: Germany at the Beginining of the Twenty-First Century. West European Politics, 26(4), 1-34.

Krugman, P. (2009, 12 11). New York Times.

Le Queux, S., \& Sainsaulieu, I. (2010). Social Movement and Unionism in France:

A Case for Revitalization? Labor Studies Journal, 35(4), 503-519.

Mahnkopf, B., \& Altvater, E. (1995). Transmission belts of transnational relations? Unions and collective bargaining in the context of European integration. European Journal of Industrial Relations, 1(1), $101-117$.

Martin, A., \& Ross, G. (1999). The Brave NewWorld of European Labour: Comparing Trade Unions Responses to the New European Economy. Oxford: Berghahn.

Mériaux O. (2000). Eléments d'un Régime Post-Fordiste de la Négociation Collective en France. Relations Industrielles/Industrial Relations, 55(4), 1 ss.

Neron, S. (2009). La rénovation de la démocratie sociale: perspectives et prospectives. $R D T, 426$.

Palier, B., \& Thelen, K. (2010). Institutionalizing Dualism: Complementarities and Change in France and Germany. Politics Society, 38(1), 119-148.

Pélisser, J., Supiot, A., \& Jeammaud, A. (2008). Droit du travail. Paris: Dalloz.

Pernot, J. (2005). Syndacats: Lendemains de Crise? Paris: Gallimard.

Ray, E. (2004). Les curieux accords dits « majoritaires » de la loi du 4 mai 2004. DS, 590.

Schnabel, C. (2011). Il cambiamento dei profili della contrattazione collettiva in Germania. Friedrich-Alexander University.

Stephen, S., \& Schroeder, W. (2007). Why Are German Employers Associations

Declining?: Arguments and Evidence. Comparative Political Studies, 40, 1443-1459.

Streeck, W. (1984). Neo Corporatist Industrial Relations and the Economic Crisis in West Germany. In Goldthorpe J. H., Order and Conflict in Contemporary Capitalism. Oxford: Clarendon.

Streeck, W. (2010). Re-forming Capitalism. Institutional Change in the German Political Economy. Oxford: Oxford University Press. 
Streeck, W., \& Thelen, K. (2005). Beyond Continuity: Institutional Change in Advanced Political Economics. Oxford: Oxford University Press.

Supiot, A. (2005). La riforma del contratto collettivo in Francia. Riflessioni sulle trasformazioni del diritto. Giornale di diritto del lavoro e di relazioni industriali, 2(106), 155-175.

Tebano, L. (2009). La recente riforma della democrazia sindacale in Francia tra vecchie e nuove tendenze. Rivista italiana di diritto del lavoro (4), 403-419.

Thelen, K. (2009). Institutional Change in Advanced Political Economies. British Journal of Industrial Relations, 47(3), 471-498.

Treu, T. (2010). Le forme retributive incentivanti, in Rivista italiana di diritto del lavoro. Rivista italiana di diritto del lavoro (4), 637-692.

Treu, T. (2011). Le relazioni industriali nell'era della globalizzazione: gli accordi in deroga in Europa e la sfida ai sistemi contrattuali. Dattiloscritto.

Turner, L. (2009). Institutions and Activism: Crisis and Opportunity for a German Labor Movement in Decline. Industrial and Labor Relations Review, 62(3), 294-313.

Visser, J. (2004). Recent trends and persistent variations in Europe's industrial relations.

Woll, C. (2006). National Business Associations Under Stress: Lesson from the French Case. West European Politics, 29(3), 1 ss.

Zapf, I., \& Brehmer, W. (2010). Flexibilitat in der Wirtschaftkrise. Arbeitszeitkonten haben sich bewahrt. Nuremburg: IAB. 


\section{Documentazione analizzata}

1. Accordo ENI su Sviluppo e Competitività del 26.5.2011

2. Accord Polimeri Europa sur la réduction du temps de travail del 22.12.1999

3. Accord Polimeri Europa sur la réduction du temps de travail del 5.1.2000

4. Reglement Polimeri Europa de I'horaire individualisé del 2.2.2000

5. Accord Polimeri Europa del 3.6.2003

6. Accord Polmeri Europa d'Intéressement - anni 2009/2010/2011

7. Accord Polimeri Europa de Participation PE France - 2006/2007/2008/2009/2010

8. Accordo SAIPEM S.A. orario di lavoro e flessibilità del 3.4.2009

9. Accordo OMV Deutschland GmbH

10. Betriebsvereinbarung Nr. 62 Langzeitkonten 31.3.2008 


\section{Gruppi di lavoro, seminari e colloqui di informazione}

- Gruppo di lavoro del 20.4.2011 - Roma

- Gruppo di lavoro del 28.4.11 - Roma

- Gruppo di lavoro e colloqui via conference call del 4.5.2011 - Roma/Milano/Dunkerque

- Gruppo di lavoro del 6.6.2011 - Roma

- Gruppo di lavoro e colloqui del 16.6.2011 - Monaco (Germania)

- Seminario di presentazione dei primi esiti della ricerca del 21.7.2011 - Eni/Roma

- Gruppo di lavoro e colloqui del 12.9.2011 - Dunkerque (Francia)

- Colloqui di informazione via telefono del 10.10.2011 - Milano/Roma

I gruppi di lavoro sono stati realizzati sulla base di una griglia predefinita di domande e di temi da analizzare. I colloqui sono stati finalizzati all'approfondimento di alcuni aspetti pratici rilevati dalla documentazione che è stata fornita per lo svolgimento della ricerca.

Dirigenti del Gruppo Eni e rappresentanti delle organizzazioni sindacali tedesche e francesi hanno partecipato ai colloqui e/o ai gruppi di lavoro. 




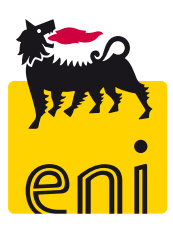

eni spa

Unità Legislazione

e Contenzioso del lavoro

Unità Pianificazione e Controllo,

Risorse Umane e Relazioni Industriali

Piazzale Enrico Mattei, 1 - 00144 Roma

\section{Crowe Horwath}

Studio Associato Servizi Professionali Integrati

Dipartimento Diritto del Lavoro

Prof. Tiziano Treu - Prof. Angelo Pandolfo 